\title{
RESÍDUOS DE ACEFATO, DE SEU METABÓLITO METAMIDOFÓS E DE CLOROTALONIL EM CULTURA PROTEGIDA DE TOMATE (Lycopersicon esculentum Mill) E DE CAMPO
}

\section{LUIZ ROBERTO PIMENTEL TREVIZAN}

Tese apresentada à Escola Superior de Agricultura "Luiz de Queiroz", Universidade de São Paulo, para obtenção do título de Doutor em Ciências, Área de Concentração: Entomologia.

\author{
PIRACICABA \\ Estado de São Paulo - Brasil
}

Novembro - 2002 
RESíduOS DE ACEFATO, DE SEU METABÓLITO METAMIDOFÓS E DE CLOROTALONIL EM CULTURA PROTEGIDA DE TOMATE (Lycopersicon esculentum Mill) E DE CAMPO.

\title{
LUIZ ROBERTO PIMENTEL TREVIZAN
}

Engenheiro Agrônomo

Orientador: Prof. Dr. GILBERTO CASADEI DE BAPTISTA

Tese apresentada à Escola Superior de Agricultura "Luiz de Queiroz", Universidade de São Paulo, para obtenção ao título de Doutor em Ciências, Área de concentração: Entomologia.

\author{
PIRACICABA \\ Estado de São Paulo - Brasil \\ Novembro -2002
}




\title{
Dados Internacionais de Catalogação na Publicação (CIP)
} DIVISÃo DE BIBLIOTECA E DOCUMENTAÇÃO - ESALQ/USP

\author{
Trevizan, Luiz Roberto Pimentel \\ Resíduos de acefato, de seu meta bólito metamidofóse de clorotalonil em \\ cultura protegida de tomate (Lycopersic on esculentum Mill) e de campo / \\ Luiz Roberto Pimentel Trevizan. - - Piracicaba, 2002. \\ $87 \mathrm{p}$.
}

Tese (doutora do) - Escola Superior de Agric ultura Luiz de Queiroz, 2002. Bibliografia.

1. Estufa 2. Resíduo de pestic idas em plantas 3. Tomate I. Título

CDD 635.642 
Ofereço e Dedico a meus Familiares e Amigos 


\section{AGRADECIMENTOS}

Ao Prof. Dr. Gilberto Casadei de Baptista pela orientação e apoio na realização deste trabalho, e sobretudo pelo exemplo de dignidade e caráter.

Ao Prof.Dr. Octávio Nakano pela confiança e oportunidades durante minha formação profissional.

Ao Conselho Nacional de Desenvolvimento Científico e Técnológico (CNPq) pela concessão da bolsa de estudos.

À Fundação de Amparo àPesquisa do Estado de São Paulo (FAPESP) pela concessão do Auxílio à Pesquisa (Proc. FAPESP $\mathrm{N}^{O}$ 00/03356-0) necessário àrealização do projeto.

À Hokko do Brasil Indústria Química e Agropecuária Ltda e ao Eng ${ }^{\circ}$ Agr ${ }^{\circ}$ Carlos Roberto Valdejão, proprietário do Sítio Pinheirinho, pelo apoio ao disponibilizarem suas instalações, para a condução dos experimentos.

Aos Professores e colegas do Programa de Pós-Graduação em Entomologia, da ESALQ/USP, pelos ensinamentos e amizade. 
À bibliotecária Sra. Eliana Maria Garcia pela auxílio na correção das referências bibliográficas e demais funcionários da Biblioteca Central da ESALQ/USP pela colaboração.

Aos amigos do Laboratório de Resíduos de Pesticidas, do Departamento de Entomologia, Fitopatologia e Zoologia Agrícola, da ESALQ/USP André, Coró, Vespa, Mosqueteiro, Xapolim, Quiabo, Ricardo, Carlão, Aline, Matheus, Juvenal, Adriana e Rosines, pela ajuda inestimável na realização das análises.

À Milena e à Carolina pelo trabalho de digitação do texto.

A todas as pessoas que de alguma forma contribuíram para a realização deste trabalho. 


\section{SUMÁRIO}

Página

LISTA DE TABELAS ............................................................................ viii

LISTA DE FIGURAS ........................................................................

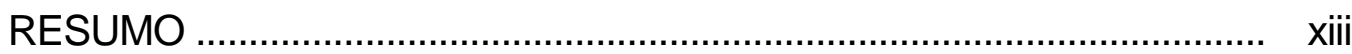

SUMMARY ............................................................................

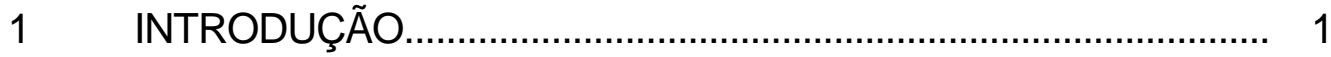

2 REVISÃO DE LITERATURA....................................................... 4

2.1 Resíduos de pesticidas em culturas protegidas .............................. 4

2.2 Acefato/metamidofós e clorotalonil.............................................. 10

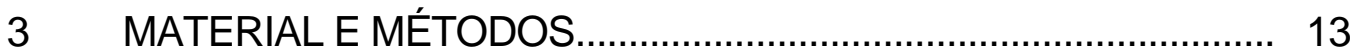

3.1 Limites de quantificação, porcentagens de recuperação e descrição do método de análises de resíduos de acefato, metamidofós e clorotalonil em fruto, folha e solo.

3.1.1 Método para análises de resíduos de acefato, metamidofós e clorotalonil em fruto, folha e..................................................... 14

3.1.1.1 Fruto e folha......................................................................... 14

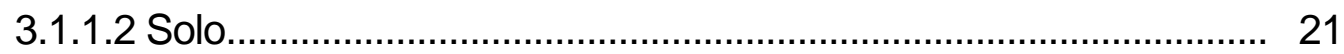

3.2 Experimento 1 - Estufa.......................................................... 22

3.3 Experimento 2-Campo............................................................ 25

4 RESULTADOS E DISCUSSÃO.................................................. 27

4.1 Limites de quantificação e porcentagens de recuperação do método de análises de resíduos de acefato, metamidofós e clorotalonil em fruto, folha e solo......................... 27 
$4.2 \quad$ Experimento 1 - Estufa..................................................... 33

$4.3 \quad$ Experimento 2 - campo...................................................... 53

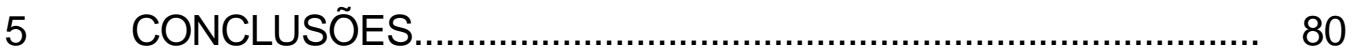

REFERÊNCIAS BIBLIOGRÁFICAS ................................................ 83 


\section{LISTA DE TABELAS}

Página

1 Condições climáticas ocorrentes no Sítio Pinheirinho durante a realização do Experimento 1 (estufa), Piracicaba-SP

2 Condições climáticas ocorrentes na Estação Experimental da Hokko do Brasil Indústria Química e Agropecuária Ltda., durante a realização do Experimento 2 (campo), Pereiras-SP

3 Porcentagens (\%) de recuperação de resíduos de acefato, metamidofós e clorotalonil em amostras fortificadas de tomate

4 Porcentagens (\%) de recuperação de resíduos de acefato, metamidofós e clorotalonil em amostras fortificadas de folhas de tomateiro

5 Porcentagens (\%) de recuperação de resíduos de acefato, metamidofós e clorotalonil em amostras fortificadas de solo

6 Resíduos de acefato em tomate (frutos). Experimento 1(estufa), Piracicaba-SP (maio-junho/2002)

7 Resíduos de metamidofós em tomate (frutos). Experimento 1 (estufa), Piracicaba-SP (maio-junho/2002)

8 Resíduos de clorotalonil em tomate (frutos). Experimento 1 (estufa), Piracicaba-SP (maio-junho/2002) ...

9 Resíduos de acefato em folhas de tomateiro. Experimento1 (estufa), Piracicaba-SP (maio-junho/2002)

10 Resíduos de metamidofós em folhas de tomateiro. Experimento 1 (estufa) Piracicaba-SP (maio-junho/2002) 
11 Resíduos de clorotalonil em folhas de tomateiro. Experimento 1 (estufa), Piracicaba-SP (maio-junho/2002)

12 Resíduos de acefato em solo cultivado com tomate. Experimento

1 (estufa) ,Piracicaba-SP (maio-junho/2002).

13 Resíduos de metamidofós em solo cultivado com tomate.

Experimento 1 (estufa), Piracicaba-SP (maio-junho/2002).

14 Resíduos de clorotalonil em solo cultivado com tomate Experimento 1 (estufa), Piracicaba-SP(maio-junho/2002)

15 Resíduos de acefato em tomate (frutos). Experimento 2 (campo), Pereiras-SP (julho-agosto/2002)

16 Resíduos de metamidofós em tomate (frutos). Experimento 2 (campo), Pereiras-SP (julho-agosto/2002)

17 Resíduos de clorotalonil em tomate (frutos). Experimento 2 (campo), Pereiras-SP (julho-agosto/2002)

18 Resíduos de acefato em folhas de tomateiro. Experimento 2 (campo), Pereiras-SP (julho-agosto/2002)

19 Resíduos de metamidofós em folhas de tomateiro. Experimento

2 (campo), Pereiras-SP (julho-agosto/2002)

20 Resíduos de clorotalonil em folhas de tomateiro. Experimento 2 (campo), Pereiras-SP (julho-agosto/2002)

21 Resíduos de acefato em solo cultivado com tomate. Experimento 2 (campo), Pereiras-SP (julho-agosto/2002).

22 Resíduos de metamidofós em solo cultivado com tomate

Experimento 2 (campo), Pereiras-SP (julho-agosto/2002)

23 Resíduos de clorotalonil em solo cultivado com tomate.Experimento 2 (campo), Pereiras-SP (julho-agosto/2002). 


\section{LISTA DE FIGURAS}

Página

1 Cromatograma de extrato de fruto de tomate/fortificação acefato e metamidofós

2 Cromatograma de extrato de fruto de tomate/fortificação clorotalonil

3 Cromatograma de extrato de folhas de tomate/fortificação acefato e metamidofós

4 Cromatograma de extrato de folhas de tomate/fortificação clorotalonil.

5 Cromatograma de extrato de solo/fortificação acefato e metamidofós

6 Cromatograma de extrato de solo/fortificação clorotalonil

7 Cromatograma de amostra testemunha/acefato e metamidofós, tomate estufa

8 Cromatograma de amostra tratamento $75 \mathrm{~g}$ i.a.. $100 \mathrm{~L}^{-1}$ (4 aplicações), acefato e metamidofós, tomate estufa

9 Cromatograma de amostra testemunha/clorotalonil, tomate estufa.

10 Cromatograma de amostra tratamento $200 \mathrm{~g}$ i.a.. $100 \mathrm{~L}^{-1}$ (4 aplicações), clorotalonil, tomate estufa

11 Cromatograma de amostra testemunha/acefato e metamidofós, folha estufa 
12 Cromatograma de amostra tratamento 75 g i.a.. $100 \mathrm{~L}^{-1}$

(4 aplicações), acefato e metamidofós, folha estufa.

13 Cromatograma de amostra testemunha/clorotalonil, folha

Estufa.

14 Cromatograma de amostra tratamento $200 \mathrm{~g}$ i.a.. $100 \mathrm{~L}^{-1}$ (4 aplicações), clorotalonil, folha estufa

15 Cromatograma de amostra testemunha/acefato e metamidofós, solo estufa

16 Cromatograma de amostra tratamento $75 \mathrm{~g}$ i.a.. $100 \mathrm{~L}^{-1}$ (4 aplicações), acefato e metamidofós, solo estufa

17 Cromatograma de amostra testemunha/clorotalonil, solo estufa

18 Cromatograma de amostra tratamento $200 \mathrm{~g}$ i.a.. $100 \mathrm{~L}^{-1}$ (4 aplicações), clorotalonil, solo estufa

19 Cromatograma de amostra testemunha/acefato e metamidofós, tomate campo

20 Cromatograma de amostra tratamento $75 \mathrm{~g}$ i.a.. $100 \mathrm{~L}^{-1}$

(4 aplicações), acefato e metamidofós, tomate campo

21 Cromatograma de amostra testemunha/clorotalonil, tomate campo 64

22 Cromatograma de amostra tratamento $200 \mathrm{~g}$ i.a.. $100 \mathrm{~L}^{-1}$ (4 aplicações), clorotalonil, tomate campo

23 Cromatograma de amostra testemunha/acefato e metamidofós, folha campo

24 Cromatograma de amostra tratamento $75 \mathrm{~g}$ i.a.. $100 \mathrm{~L}^{-1}$ (4 aplicações), acefato e metamidofós, folha campo

25 Cromatograma de amostra testemunha/clorotalonil, folha campo 66

26 Cromatograma de amostra tratamento $200 \mathrm{~g}$ i.a.. $100 \mathrm{~L}^{-1}$ (4 aplicações) clorotalonil, folha campo 
27 Cromatograma de amostra testemunha/acefato e metamidofós solo campo ......................................................... 67

28 Cromatograma de amostra tratamento 75 g i.a.. $100 \mathrm{~L}^{-1}$ (4 aplicações)acefato e metamidofós, solo campo

29 Cromatograma de amostra testemunha/clorotalonil solo campo.

30 Cromatograma de amostra tratamento $200 \mathrm{~g}$ i.a.. $100 \mathrm{~L}^{-1}$ (4 aplicações) clorotalonil, solo campo.

31 Resíduos de acefato em fruto em cultura de estufa e de campo.

32 Resíduos de clorotalonil em fruto em cultura de estufa e de campo.

33 Resíduos de acefato em folha em cultura de estufa e de campo.

34 Resíduos de metamidofós em folha em cultura de estufa e de campo.

35 Resíduos de clorotalonil em folha em cultura de estufa e de campo 75

36 Resíduos de acefato em solo de estufa e de campo cultivado com tomate 77

37 Resíduos de clorotalonil em solo de estufa e de campo cultivado com tomate 


\title{
RESídUOS DE ACEFATO, DE SEU METABÓLITO METAMIDOFÓS E DE CLOROTALONIL EM CULTURA PROTEGIDA DE TOMATE (Lycopersicon esculentum) E DE CAMPO.
}

\author{
Autor: LUIZ ROBERTO PIMENTEL TREVIZAN \\ Orientador: Prof. Dr. GILBERTO CASADEI DE BAPTISTA
}

\section{RESUMO}

O desenvolvimento da agricultura, a modernização dos meios da produção agrícola, buscando atender um mercado exigente em produtos de alta qualidade tem aumentado grandemente os cultivos conduzidos em condições de estufa. Tais culturas, demandam o uso de pesticidas para controle de problemas fitossanitários, cujos resíduos, principalmente em hortaliças e frutas, são motivo de preocupação com a saúde de consumidores e de operários que necessitam trabalhar nessas instalações. Os objetivos deste estudo foram determinar resíduos dos inseticidas acefato, de seu metabólito metamidofós e do fungicida clorotalonil em um sistema de cultura de tomate de estufa, em comparação com cultura de campo, de modo a abranger: estudo do metabolismo de acefato a metamidofós; alteração da contaminação dos 
resíduos de acefato, metamidofós e de clorotalonil em alguns compartimentos do sistema protegido (fruto, folha e solo); e comparação entre os níveis residuais encontrados nos frutos de cultura de estufa com os limites máximos de resíduos (LMRs) e os intervalos de segurança estabelecidos pela legislação brasileira. Foram conduzidos um experimento de estufa (Piracicaba-SP) e outro de campo (Pereiras-SP), no período de maio-agosto/2002 (outono-inverno), em tudo, muito semelhantes um ao outro. Os tratamentos aplicados foram: a: testemunha; b: uma aplicação de $100 \mathrm{~g}$ de Orthene 750 BR (75 g i.a. acefato) + $400 \mathrm{~mL}$ de Dacostar 500 (200 g i.a. clorotalonil).100 L $\mathrm{L}^{-1}$ de água; c: uma aplicação com o dobro das dosagens dos pesticidas do tratamento b; d: quatro aplicações na dosagem do tratamento b. As amostras fram tomadas nos dias -1, zero, 1, 3, 7, 14 e 21 dias após a última ou única aplicação. O método analítico constou da extração dos resíduos com acetato de etila, limpeza dos extratos por técnica de cromatografia de permeação em gel (GPC), com eluição procedida com uma mistura acetato de etila/ciclohexano. A determinação quantitativa foi feita por técnica de cromatografia em fase gasosa, usando-se detector fotométrico de chama (PFPD) para os resíduos de acefato e de metamidofós e detector de captura de elétrons $\left(\mu-\mathrm{ECD}, \mathrm{Ni}^{63}\right.$ ) para os de clorotalonil. Os limites de quantificação do método (LOQs) para os três pesticidas, em fruto e solo foi de $0,05 \mathrm{mg} \cdot \mathrm{kg}^{-1}$ (ppm); em folhas foi de 0,5 mg. $\mathrm{kg}^{-1}$ (ppm). Foram realizadas 1.512 análises dos três analitos, sendo 252 amostras de cada um dos experimentos. Os resultados indicaram que os resíduos de acefato, metamidofós e de clorotalonil, nos frutos de estufa e de campo, sempre estiveram abaixo dos respectivos LMRs em todo o período de colheita das amostras, inclusive no intervalo de segurança. Mostraram também, que o metabolismo de acefato a metamidofós foi muito baixo nos frutos, particularmente importante nas folhas, mas não bem caracterizado no solo. Ainda, foi observado que os resíduos de acefato e de clorotalonil foram invariavelmente maiores na estufa do que no campo, especialmente em folhas e no solo, sendo, também, estáveis e persistentes, em geral até a amostragem 
de 7 dias. Particularmente os resíduos de clorotalonil foram os mais persistentes, sendo encontrados nas amostras de 28 dias em níveis significantes, especialmente no solo. 


\title{
RESIDUES OF ACEPHATE, OF ITS METABOLITE METHAMIDOPHOS AND OF CHLOROTHALONIL IN GREENHOUSE AND FIELD TOMATO CROPS (Lycopersicon esculentum Mill).
}

\author{
Author: LUIZ ROBERTO PIMENTEL TREVIZAN \\ Adviser: Prof. Dr. GILBERTO CASADEI DE BAPTISTA
}

\section{SUMMARY}

The development of agriculture, the modernization of means of agricultural production, the attempt to supply a demanding market for high quality produce has largely increased the crops carried out in greenhouse environment. Such crops demand the use of pesticides for the control the pest problems, which residues, mainly in fruit and vegetables, are reasons for worries about the health of consumers and workers that need to work in these installations. The objective of this study was to determine residues of the insecticide acephate, of its metabolite methamidophos and the fungicide chlorotalonil in a system of greenhouse tomato crop, in comparison to field crop, as to embrace: study of the metabolism of acephate to methamidophos; alteration of the contamination of residues of acephate, methamidophos and chlorotalonil in some compartments of the protected system (fruit, leaf and soil); and comparison between the residual levels found in the fruit of greenhouse 
crop with the maximum residue levels (MRL's) and the safety intervals stablished by the Brazilian legislation. It was carried out a greenhouse experiment (Piracicaba-SP) and another in field conditions (Pereiras-SP), in the period of May-August/2002 (Autumn-Winter), on a whole very similar to each other. The treatments applied were: a: check; b: an application of $100 \mathrm{~g}$ of Orthene 750 BR (75 g a.i. acephate) + $400 \mathrm{~mL}$ of Dacostar 500 (200 g a.i. chlorotalonil). $100 \mathrm{~L}^{-1}$ of water; $\mathrm{c}$ : an application with the double dosage of the pesticides applied as treatment $b$; $d$ : four applications with the dosage of the pesticides applied as treatment $b$. The samples were taken on the days -1 , zero, $1,3,7,14,21$ days after the last or only application. The analytical method included the residue extraction with ethyl acetate, clean-up of the extracts by gel permeation chromatography technique (GPC), with elution proceeded with a mixture of ethyl acetate/cyclohexane. The quantitative determination was done by gas chromatography technique, using flame photometric detector (PFPD) for the residues of acephate and of methamidophos, and electron capture detector $\left(\mu-E C D, N^{63}\right)$ for the chlorotalonil. The limits of quantitation (LOQ's) for the three pesticides, in fruit and soil was $0.05 \mathrm{mg} \cdot \mathrm{kg}^{-1}$ (ppm); and in leaves $0.5 \mathrm{mg} \cdot \mathrm{kg}^{-1}$ (ppm). There were performed 1512 analyses of the three analytis, being 252 samples from each one of the experiments. The results indicated that the residues of acephate, methamidophos and chlorotalonil, in greenhouse and field fruits, have always been below of their respective MRL's in the whole sample collecting period, including the safety intervals. It has shown as well, that the metabolism of acephate to metamidophos was much below in fruit, specially important in leaves, but not well characterized in the soil. It was still observed that the residues of acephate and chlorotalonil were invariable bigger in the greenhouse than in the field, specially in leaves as well as in soil, being also stable and persistent, in general, specially up to 7 day samples. Particularly, the residues of chlorotalonil were the most persistent, being found in the samples of 28 days in significant levels, specially in the soil. 


\section{INTRODUÇÃO}

O desenvolvimento da agricultura, a ampliação das fronteiras agrícolas, a modernização dos meios da produção agropecuária e, principalmente, a demanda dos mercados de produtos em quantidade e em qualidade, tem exigido o uso de agrotóxicos (ou pesticidas, produtos fitossanitários ou defensivos agrícolas) para a garantia de sua produtividade.

No esforço de minimizar os danos causados pelos inimigos das lavouras, tem-se adotado vários métodos que, isoladamente ou associados, na forma de controle integrado (manejo integrado), conseguem reduzir a baixos níveis os prejuízos causados por pragas, doenças e plantas daninhas.

A sofisticação da produção agrícola, buscando atender um mercado exigente em produtos de alta qualidade, e durante todo o período do ano, tem aumentado grandemente nos últimos anos os cultivos chamados protegidos, isto é, aqueles conduzidos em condições de estufa.

Com efeito, no Estado de São Paulo, especialmente nas regiões de Atibaia, Campinas e Sorocaba e em outras áreas próximas à cidade de São Paulo, tem-se verificado intensa atividade crescente neste sistema, que envolve particularmente a produção de tomate, pepino, outras hortaliças, frutas, etc. 
Entre os organismos nocivos aos cultivos protegidos de tomate, dadas as condições especiais e peculiares decorrentes, algumas pragas e doenças que não são particularmente consideradas no campo, tornam-se principais nesse sistema de produção. Dentre as pragas, assumem grande importância a mosca branca, Bemisia tabaci (Genn., 1889) (Hemiptera-Homoptera, Aleyrodidae) e o ácaro rajado, Tetranychus urticae (Koch, 1836) (Acari, Tetranychidae).

Em face do problema causado por insetos e ácaros, além de fungos e outros agentes fitopatogênicos nos ambientes protegidos, tem-se usado principalmente substâncias químicas para controlá-los e para a preservação das colheitas; por outro lado, pode ocorrer a persistência desses agrotóxicos nos substratos ratados na forma de resíduos tóxicos, cujo consumo representa risco potencial àsaúde dos consumidores.

O controle oficial de resíduos de pesticidas em alimentos é geralmente baseado nos limites máximos de resíduos (LMRs) ou tolerâncias e intervalos de segurança (períodos de carência), estabelecidos caso a caso. Vários estudos sobre a ocorrência de resíduos em hortaliças em culturas de campo já são conhecidos entre nós. Entretanto, quase nada se sabe a respeito da ocorrência deles em culturas protegidas, nem na de resíduos deslocáveis, isto é, aqueles presentes nos diversos compartimentos do sistema que podem ser facilmente transferidos para o corpo dos trabalhadores que realizam os tratos culturais nesses locais, quase que todo caracterizado como ambiente fechado. Assim, torna-se necessária conhecer os níveis de contaminação de resíduos de pesticidas nos compartimentos de culturas protegidas, não só naqueles produtos destinados ao consumo, mas também nos que podem conter contaminação que eventualmente, possa ser transferida para trabalhadores profissionalmente expostos (saúde ocupacional), bem como para outros segmentos e sub-compartimentos. 
Estudos sobre efeitos das condições de proteção na produção agrícola, em relação a resíduos nos alimentos, fazem parte da exigência para registro de pesticidas em muitos países. O JMPR, Comitê da FAO/OMS, considera tais efeitos como parte de suas revisões de dados de resíduos de pesticidas.

Os objetivos deste estudo foram determinar resíduos de acefato, um dos inseticidas mais usados em condições de estufa por sua eficiência e baixo custo, de seu metabólito metamidofós e do fungicida clorotalonil, também de largo uso, em substratos, obtidos de sistema de cultura protegida de tomate tutorado, em comparação com os obtidos de cultura de campo, de modo a abranger:

a) o estudo do metabolismo de acefato em metamidofós, na forma dos resíduos de ambos os inseticidas organofosforados, e influência de fatores climáticos na estufa neste processo;

b) a alteração (diminuição ou aumento) da contaminação dos resíduos dos citados pesticidas, além dos de clorotalonil, nos diversos substratos/compartimentos de tal sistema de cultivo (fruto, folhas e solo), durante certo período de tempo de tomada de amostras, também influenciada pelos fatores climáticos na estufa;

c) comparação entre os níveis residuais encontrados nos frutos de cultura protegida em relação aos LMRs e os intervalos de segurança estabelecidos pela legislação brasileira para esses pesticidas em condições de plantio no campo.

Dessa maneira, é propósito do presente estudo obter tais dados, nas condições brasileiras, que possam contemplar, atender e fortalecer ações governamentais no sentido de proteger a saúde de consumidores e a de trabalhadores profissionalmente expostos. 


\section{REVISÃO DE LITERATURA}

\subsection{Resíduos de pesticidas em culturas protegidas}

As condições de condução das culturas protegidas é fator determinante na persistência de resíduos de agrotóxicos nos produtos agrícolas.

Em um importante estudo, Leidy et al. (1978) estudaram a ocorrência de resíduos de acefato e de metamidofós em cultura de tomate de estufa. $O$ acefato foi aplicado em doses simples e múltiplas e os resíduos nos frutos foram determinados várias vezes após os tratamentos (até 7 dias). Nas amostras de 4 dias, os resíduos de acefato, foram comparáveis aos dos nas amostras de 1 dia, nas 3 dosagens estudadas, indicando baixa dissipação. Os resíduos de metamidofós, seu metabólito, foram encontrados em todas as amostras, já a partir daquelas de 1 dia, mas em níveis de cerca de 8-10 vezes inferiores aos de acefato, e foram semelhantemente persistentes. Os resultados mostraram também que os resíduos totais (acefato + metamidofós) foram significativamente maiores após 4 aplicações espaçadas 7 dias uma da outra do que de uma única aplicação. 
Na Grécia, um estudo foi conduzido por Aplada-Sarlis et al (1994), em tomate de estufa, para avaliação dos resíduos do fungicida procimidone e do acaricida propargite. Foi observado que os de procimidone foram muito persistentes e uma redução significativa de seus níveis foi constatada apenas após 35 dias decorridos da última aplicação ( 6 tratamentos), com acumulação significante após essas aplicações repetidas. Os resíduos de propargite foram considerados decrescer vagarosamente com 0 decurso do tempo. Recomendam, ainda, os autores que o intervalo de segurança, na Grécia, que é de 3 dias, deveria ser reconsiderado, especialmente para procimidone.

Já Cabras et al. (1985), estudando o comportamento de alguns resíduos de pesticidas em tomate protegido, encontraram persistência considerável dos de deltametrina, permetrina, dicofol e pirazofós, com acúmulo dos resíduos após aplicações repetidas. Igualmente, estes autores, sugerem reconsideração dos parâmetros toxicológicos (LMRs) e intervalos de segurança por parte das autoridades italianas.

Um estudo de comparação entre resíduos de captan remanescentes em tomate protegido e de campo foi realizado por Frank et al. (1987). Pela observação dos autores, após 4 aplicações, tanto no campo com na estufa, 10 dias decorridos da última aplicação, os valores encontrados nos frutos de estufa eram de 10 a 20 vezes maiores do que os de campo (!!) de $0,2-1 \mathrm{mg}^{\mathrm{kg}}{ }^{-1}$, comparado com $0,02-0,5 \mathrm{mg} \cdot \mathrm{kg}^{-1}$ (ppm), respectivamente.

Na Espanha, Gil-Garcia et al. (1997) determinaram o efeito do tipo de estufa, dose aplicada e condições climáticas na degradação de metomil em cultura de tomate protegida. A análise da variância mostrou que as doses não afetam a resposta. Entretanto, os resíduos foram mais persistentes em estufa de teto plano do que em de cobertura na forma de telhado, e maiores no inverno do que na primavera, nas mesmas demais condições. 
Resíduos de mancozeb, maneb e etilenotiouréia (ETU), determinados em tomate, a partir de material colhido no campo e em estufa, foram relatados por Von Stryk \& Jarvis (1978), em um estudo realizado no Canadá. Os fungicidas foram aplicados em 5-8 ocasiões e seus resíduos, bem como os de ETU, foram sempre consideravelmente maiores nos tomates de estufa.(!)

Aguilera-del Real et al. (1997) estudaram o comportamento dos resíduos de endosulfan em tomate, pimentão e pepino cultivados em ambiente protegido. Observaram que, em todos os casos, um comportamento de reação cinética de primeira ordem foi encontrado, com 1/2vida de 20,1 dias para o tomate (a maior delas), mostrando serem os resíduos mais persistentes nessa solanácea.

Ainda, na Itália, Meloni et al. (1984), estudando resíduos de diversos fungicidas (tiran, cimoxamil, benomil, vinclozolin e BMC), em alface cultivada em estufa, verificaram que eles não foram encontrados nas folhas internas até os níveis de quantificação, mas o foram, entretanto, em níveis considerados muito altos nas folhas externas, aventando comentários de que, em tratamento nas estufas, os intervalos de segurança, para estes casos, não são suficientes para garantir que os resíduos estejam, na colheita, dentro dos LMRs, estabelecidos pela lei italiana.

O comportamento dos resíduos do inseticida carbamato pirimicarb e de seus metabólitos, em alface de estufa, foi estudado por Cabras et al. (1990). Foi observado pelos autores rápida degradação dos compostos envolvidos, decorridos 10 dias após aplicação de pirimicarb. Indicam ainda, que a volatilização parece não representar uma rota importante no desaparecimento dos resíduos do composto original (pirimicarb), assim julgado pela rápida transformação a seus metabólitos. 
O destino dos resíduos de pirimicarb em pêssego e nectarina, cultivados na estufa e no campo foi estudado por Cabras et al. (1995). O inseticida, aplicado em 3 oportunidades, teve seus resíduos monitorados por 25 dias. Na estufa, eles foram considerados estáveis/persistentes, enquanto que no campo tiveram degradação moderada. O comportamento foi semelhante em ambas as frutas, e os metabólitos não foram encontrados durante todo o período de duração dos experimentos.

Mônico-Pifarré \& Xirau-Vayreda (1990) avaliaram a acumulação de resíduos de benomil em morango, cultivado em condições de proteção e de campo. Os dados obtidos como carbendazin (MBC) indicaram que os resíduos deste metabólito não se acumulam nos frutos, tanto no campo como na estufa.

A dissipação dos fungicidas vinclozolin e triadimefon foi estudada em estufas por Nylsson \& Nybrant (1996). A dissipação de vinclozolin foi também estudada em câmara climatizada. Nos experimentos em estufa, os fungicidas foram aplicados em pulverização a baixo e a alto volume, enquanto que no de câmara climatizada o fungicida, no caso vinclozolin, foi aplicado com o uso de uma pipeta. As concentrações encontradas foram maiores no solo do que nas folhas. As no ar foram maiores imediatamente após a aplicação a baixo volume do que a alto, como era de se esperar, mas decresceu rapidamente. O experimento em câmara climatizada não mostrou diferenças significativas na dissipação dos resíduos entre diferentes condições climáticas, com temperaturas na faixa de $18-26^{\circ} \mathrm{C}$ e um deficit de pressão de vapor entre 0,26 e 0,79 Kpa.

Ainda em estufa, Nagami (1996), pesquisando resíduos de procimidone, aplicado em pulverização, em plantas de morango, espinafre e rabanete, entre outras, observou que esse fungicida foi bastante persistente no 
solo e nas folhagens das plantas estudadas, considerando mesmo que seu comportamento é semelhante ao dos antigos inseticidas organoclorados.

Valverde-Garcia et al. (1993), por meio de três diferentes métodos multi- resíduos, estudaram a degradação de resíduos de buprofezin em beringela cultivada em estufa. Os resultados indicaram um grau constante de degradação nos frutos e período de 1/zida de 4,6 dias.

Resíduos de fungicidas etileno-bisditiocarbamatos (EBDC) e dinocap, em cultura protegida de pepino, foram estudados por Ripley et al. (1985), no Canadá. As análises realizadas no fruto todo revelaram que os eles não excederam os LMRs estabelecidos pela lei canadense, que são de $0,1 \mathrm{mg} \cdot \mathrm{kg}^{-1}$ (ppm) e $7 \mathrm{mg} \mathrm{kg}^{-1}$ (ppm), respectivamente para dinocap e mancozeb. Os autores ainda consideram que é satisfatório o intervalo de segurança de 3 dias para os EBDCs e defendem uma redução no parâmetro estabelecido para dinocap na lei (30 dias).

Também no Canadá, Frank et al. (1989) relataram estudo de resíduos do fungicida pirazofós em crisântemo, cultivado em estufa e em câmara climatizada, e pulverizado na dosagem de $450 \mathrm{mg} \cdot \mathrm{L}^{-1}$ do ingrediente ativo. Sob condições de câmara climatizada o fungicida teve sua 1/2vida calculada entre 19 e 25 dias; nas condições de estufa não foram encontrados indicadores de uma degradação significativa do pirazofós. Os autores sugerem, também, uma recomendação de que os trabalhadores usem luvas quando manuseando as plantas na estufa.

O comportamento de fungicidas do grupo das acilanilidas, tais como furalaxil e benalaxil, foi estudado por Cabras et al. (1985) em tomate cultivado em estufa e pulverizados uma ou cinco vezes (intervalos de 21 dias). Segundo os autores, ambos os fungicidas mostraram acumulação de resíduos, mas 
sempre em concentrações abaixo dos respectivos LMRs, mesmo antes do vencimento dos intervalos de segurança estabelecidos.

A retenção de depósitos de clorotalonil e mancozeb em superfície foliar de melão em condições de cultura protegida foi estudada por Suheri \& Latin (1991), usando-se Alternaria cucumerina como indicador biológico e a inibição da germinação de seus esporos como resposta para avaliação. Os bio-ensaios foram conduzidos com plantas expostas æ̀ condições secas e de alta umidade. Uma relação linear foi obtida entre a inibição da germinação dos esporos e o tempo de exposição para todos os tratamentos. As diferenças em retenção entre os tratamentos foram despresíveis sob condições secas. Entretanto, foram observadas diferenças significativas na retenção, após as plantas serem expostas às condições de alta umidade. O grau de dissipação de mancozeb foi significativamente maior do que o de clorotalonil.

Um interessante trabalho de Kleier (1994) revela a importância da radiação solar na fotodecomposição de pesticidas e seus resíduos sob condições de campo e de estufa. Segundo o autor, quando aplicado no campo os pesticidas devem agir sob condições mais adversas, e imprevisíveis e, nesse mistér, um dos fatores mais importantes é a luz solar, especialmente a radiação ultra-violeta; esta é absorvida por muitos pesticidas, sendo suficientemente energética para iniciar a fotodegradação. Por outro lado, os pesticidas aplicados na estufa estão mais protegidos de muitos fatores adversos prevalecentes no campo, principalmente da luz solar. 


\subsection{Acefato/metamidofós e clorotalonil}

O acefato é um inseticida organofosforado, quimicamente conhecido como 0,S-dimetil-N-acetil fosforamidotioato (Andrei, 1999). Possui $\mathrm{DL}_{50}$ de $945 \mathrm{mg} / \mathrm{kg}$ para machos de ratos albinos e $866 \mathrm{mg} / \mathrm{kg}$ para fêmeas; $\mathrm{DL}_{50}$ aguda dérmica $>2.000 \mathrm{mg} / \mathrm{kg}$ para coelhos (Tomlin, 1995). Tem propriedades físico-químicas tais como, pressão de vapor 0,226 $\mathrm{mPA}\left(24^{\circ} \mathrm{C}\right)$; $\mathrm{K}_{\mathrm{ow}}=0,13$; solubilidade em água $790 \mathrm{~g} / \mathrm{L}$, em acetona 151 , etanol $>100$, acetato de etila 35 , benzeno 16 , hexano 0,1 (todos em $\mathrm{g} / \mathrm{L}, 20^{\circ} \mathrm{C}$ ) (Tomlin, 1995). No meio ambiente é metabolizado a metamidofós (Tomlin, 1995). No Brasil, é comercializado com os nomes de Orthene 750 BR, Acefato Fersol 750 PS, entre outros (Andrei, 1999), estando registrado para uso em 18 culturas, especialmente para hortaliças, entre as quais a de tomate, nesta com LMR de 0,5 mg. $\mathrm{kg}^{-1}$ (ppm) e intervalo de segurança de 7 dias (Agrofit, 2002a).

O metamidofós é um inseticida acaricida organofosforado, quimicamente conhecido como O,S-dimetil-fosforamidotioato (Andrei, 1999). Possui DL $_{50}$ aguda oral de $20 \mathrm{mg} / \mathrm{kg}$ para ratos albinos, de $10-30 \mathrm{mg} / \mathrm{kg}$ para coelhos, $\mathrm{DL}_{50}$ aguda dérmica de $130 \mathrm{mg} / \mathrm{kg}$ para ratos albinos (Tomlin, 1995), portanto um inseticida muito mais tóxico do que o composto (acefato) que o origina. Tem propriedades físico-químicas tais como, pressão de vapor 2,3 mPA $\left(20^{\circ} \mathrm{C}\right) ; \mathrm{pK}_{\text {ow }}=8 \times 10^{-1}$; solubilidade em água $>200 \mathrm{~g} / \mathrm{L}\left(20^{\circ} \mathrm{C}\right)$, isopropanol $>$ 200 , diclorometano $<200$, tolueno $2-5$, hexano $0,1-1$ (todos em $\mathrm{g} / \mathrm{L}, 20^{\circ} \mathrm{C}$ ) (Tomlin, 1995). No Brasil, é comercializado com os nomes de Tamaron BR, Hamidop 600, Metamidofos Fersol 600, entre outros (Andrei, 1999), estando registrado para uso em 12 culturas, especialmente para hortaliças, entre as quais a de tomate, nesta com LMR de $0,3 \mathrm{mg} \cdot \mathrm{kg}^{-1}$ (ppm) e intervalo de segurança de 21 dias (Agrofit, 2002b). 
Estudando a dissipação dos resíduos de metamidofós em tomate, Freitas Junior \& Rigitano (1994) observaram que eles decresceram de 0,78 para $0,34 \mathrm{mg} \cdot \mathrm{kg}^{-1}$ (ppm) e de 2,76 a 1,13 $\mathrm{mg}^{\mathrm{kg}}{ }^{-1}$ (ppm) no período de 1 a 21 dias após 1 e 3 aplicações, respectivamente, tendo o LMR estabelecido pela legislação brasileira sido atingido aos 18 dias após uma aplicação; entretanto, no caso de três aplicações, os resíduos aos 21 dias (intervalo de segurança) decorridos da última aplicação, foram maiores do que o LMR. Sugerem, ainda, os autores que, "sendo comuns aplicações semanais deste inseticida para a proteção de culturas de tomate, o intervalo de segurança estabelecido neste caso é inadequado, e que necessita ser revisto pelas autoridades responsáveis". (!)

A fim de contribuir parcialmente para a avaliação da exposição ocupacional, Evaristo \& Baptista (2002) estudaram a ocorrência de resíduos deslocáveis em folhas, frutos e solo de lavoura de tomate estaqueado tratada com metamidofós. Observaram, nos três substratos, que os resíduos decresceram rapidamente e que os no solo ( $R L_{50}$ 2,7-2,9 dias) foram mais persistentes do que os na folha $\left(R_{50} 0,7-0,9 \mathrm{dia}\right)$ e do que os no fruto (neste, não foi possível calcular $R L_{50}$ pois foram encontrados resíduos apenas nas duas primeiras colheitas de amostras/zero e $1 \mathrm{dia}$ ).

O clorotalonil é um fungicida derivado da ftalonitrila, quimicamente conhecido como tetracloroisoftalonitrila (Andrei, 1999). Possui DL50 maior que $10.000 \mathrm{mg} / \mathrm{kg}$ para ratos e é altamente irritante para os olhos (Tomlin, 1995). Tem propriedades físico-químicas tais como, pressão de vapor 0,076 mPA $\left(25^{\circ} \mathrm{C}\right) ; \mathrm{K}_{\mathrm{ow}}=2,89$; solubilidade em água $0,9 \mathrm{mg} / \mathrm{L}\left(25^{\circ} \mathrm{C}\right)$, em xileno 80 , ciclohexanona, dimetilformamida 30 , dimetil sulfóxido 20 , querosene $<10$ (todos em $\mathrm{g} / \mathrm{L}, 25^{\circ} \mathrm{C}$ ) (Tomlin, 1995). No Brasil, é comercializado com os nomes de Bravonil 500, Daconil BR, Dacostar 500, Vanox 500 SC, entre outros (Andrei, 1999), estando registrado para uso em 22 culturas, especialmente para 
hortaliças e fruteiras, entre as quais a de tomate, nesta com LMR de $1,0 \mathrm{mg} \cdot \mathrm{kg}^{-1}$ ppm) e intervalo de segurança de 7 dias (Agrofit, 2002c).

A avaliação de resíduos de clorotalonil em tomate e em tomate processado na forma de suco, foi relatada por Frank et al. (1991). Eles, os resíduos, foram determinados em níveis acima de $0,1 \mathrm{mg} \cdot \mathrm{kg}^{-1}(\mathrm{ppm})$ nos frutos colhidos oito dias após a aplicação e abaixo deste valor, no suco.

Valverde-Garcia et al. (1993) estudaram a ocorrência de resíduos de clorotalonil em tomate, pepino e pimentão cultivados em estufa, na Espanha. Os autores obtiveram meias-vida de persistência de 11,5; 5,3 e 7,3 dias, respectivamente para essas hortaliças.

Mais recentemente, Brioski (2001) estudou a ocorrência de resíduos de clorotalonil em frutos e folhas de tomate, com aplicação do fungicida em doses repetidas (4 aplicações) na dosagem recomendada (150 g i.a/100 L água) e na mesma dose apenas uma vez, além da dose dobrada (300 g i.a/100 L água), também em uma única ocasião. As amostras de frutos e folhas foram colhidas um dia antes da aplicação conjunta (-1) e aos zero, 1, 2, 3, 5, 7 e 14 dias após. Os valores médios de 1/2vida de degradação dos resíduos em frutos e folhas, foram 1,6 e 2 dias, respectivamente, mostrando rápida redução dos depósitos, mais lenta, entretanto, nas folhas. As meias-vida de persistência (resíduos) para os mesmos substratos foram muito semelhantes, também: 11,6 e 11,1 dias, respectivamente. Os resíduos encontrados nos frutos, após cinco dias da aplicação, foram menores do que o LMR oficial $\left(1 \mathrm{mg} \cdot \mathrm{kg}^{-1}\right)$ na dose de tratamento recomendada. Nos outros dois casos (uma aplicação da dose dobrada e quatro aplicações da dose recomendada) eles encontravam-se em níveis acima da tolerância oficial, mesmo ao término do período de carência ( 7 dias). 


\section{MATERIAL E MÉTODOS}

\subsection{Limites de quantificação, porcentagens de recuperação e descrição do método de análises de resíduos de acefato, metamidofós e clorotalonil em amostras de fruto, folha e solo}

Para os estudos dos limites de quantificação e porcentagens de recuperação de acefato, metamidofós e clorotalonil foram fortificadas amostras de fruto e de solo, de modo a se obter concentrações nos níveis: $10 ; 5 ; 1 ; 0,5$; 0,$1 ; 0,05$ e 0,01 mg.kg ${ }^{-1}$ (ppm); em folhas: $100 ; 50 ; 10 ; 5 ; 1 ; 0,5$ e 0,1 mg.kg-1 (ppm), para os três pesticidas. Nos estudos, todos os níveis de fortificação, para os diversos substratos, foram feitos em triplicata. Foram fortificadas 63 amostras, a saber: 21 níveis dos três substratos $\times 3$ repetições, totalizando-se 189 análises dos três pesticidas. 


\subsubsection{Método para análises de resíduos de acefato, metamidofós e de clorotalonil em fruto, folha e solo}

\subsubsection{Fruto e folha}

O método de análises foi adaptado de Andersson \& Palsheden (1998), que consta da extração dos resíduos dos três pesticidas com acetato de etila em presença de $\mathrm{Na}_{2} \mathrm{SO}_{4}$. Uma alíquota do extrato é concentrada por evaporação e os resíduos ressuspendidos em uma mistura de acetato de etila/ciclohexano; a seguir procede-se a limpeza por técnica de cromatografia de permeação em gel (GPC), sendo a eluição procedida com a citada mistura. Após nova concentração, o extrato é ressuspendido em acetona; segue-se determinação quantitativa, realizada por técnica de cromatografia em fase gasosa, usando-se cromatógrafo Varian, modelo Star $3400 \mathrm{Cx}$, equipado com detector fotométrico de chama pulsante (PFPD), provido de filtro específico para fósforo para os inseticidas organofosforados (acefato e metamidofós) e cromatógrafo HP, modelo 6890 , provido de detector de captura de elétrons $(\mu$ $\mathrm{ECD}, \mathrm{Ni}^{63}$ ) para o fungicida (clorotalonil).

\section{A Aparelhos/Equipamentos}

- cromatógrafo de gás, Varian, modelo Star 3400 Cx, equipado com detector fotométrico de chama pulsante (PFPD), filtro específico para fósforo de 526 nm e injetor automático;

- cromatógrafo de gás, HP, modelo 6890, equipado com detector de captura de elétrons $\left(\mu-\mathrm{ECD}, \mathrm{Ni}^{63}\right)$;

- workstation HP, modelo Kayak XA, software versão A.06.03,

- $\quad$ workstation Varian, modelo Star, software versão 5.51; 
- coluna cromatográfica, megabore BPX-35, 30 m comprimento, diâmetro 0,53 $\mathrm{mm}$ e 1,0 $\mu \mathrm{m}$ espessura do filme (acefato e metamidofós);

- coluna cromatográfica, megabore, HP-608, 30 m comprimento, diâmetro $0,53 \mathrm{~mm}$ e $0,5 \mu \mathrm{m}$ espessura do filme (clorotalonil);

- triturador Ultra-turrax, Heidolph, modelo DIA.900;

- $\quad$ evaporador TurboVap LV, Zymark, modelo LV;

- cromatógrafo líquido, HP, modelo 1100, acoplado ao injetor/coletor de frações;

- colunas (duas, ligadas em série) PLGel, para cromatografia de permeação em gel, $300 \times 7,5 \mathrm{~mm} \phi$;

- bomba binária, Gilson, modelo 321;

- injetor/coletor de frações, Gilson, modelo 215 para cromatografia de permeação em gel;

- $\quad$ agitador/homogeneizador, Minishaker, modelo MS-1;

- multiprocessador Sire Cutter;

- centrífuga, Revan, modelo Ciclo C-l;

- balança analítica, Mettler, modelo H10;

- balança analítica, Sartorius, modelo Basic;

- $\quad$ pipetador de graduação regulável, Pipetman, Gilson P 10 mL;

- ultra-som, Mini-som.

\section{B Solventes/Reagentes}

- acetona, PA-ACS, destilada em destilador de vidro;

- acetato de etila, nanograde, Mallinckrodt;

- ciclohexano, PA-ACS, destilado em destilador de vidro;

- hexano, nanograde, Mallinckrodt;

- $\mathrm{Na}_{2} \mathrm{SO}_{4}$, anidro granulado, $\mathrm{QM}$;

- sílica-gel, dessecante azul; 
- padrão analítico de acefato;

- padrão analítico de metamidofós;

- padrão analítico de clorotalonil.

\section{Vidrarias e outros materiais}

- $\quad$ micro-seringa, $10 \mu \mathrm{l}$, Hamilton;

- frascos de vidro com tampa rosqueável de $200 \mathrm{~mL}$, Duran-Schott;

- $\quad$ manifold, 6 bicos;

- $\quad$ provetas graduadas, 25, 50 e $100 \mathrm{~mL}$;

- $\quad$ pipetas graduadas, 1,5 e $10 \mathrm{~mL}$;

- erlenmayers, 250 mL, Corning/Pyrex 5020;

- beakers, 150 mL, Corning/Pyrex 1000;

- tubos de centrífuga, graduado, 15 mL, Corning/Pyrex 8080;

- $\quad$ seringas hipodérmicas, B-D, plástico, $5 \mathrm{~mL}$;

- filtros de membrana, Millipore 0,20 $\mu$ (Millex FG);

- tubos de centrífuga, polipropileno, $50 \mathrm{~mL}$, Corning 25330-50;

- vials, vidro, 1,5 mL, próprios para uso no injetor automático;

- filtro de sílica-gel;

- pipetas de Pasteur;

- $\quad$ suportes de para tubos de centrífuga. 


\section{Preparação das soluções padrão}

Inicialmente são preparadas soluções estoque de acefato, metamidofós e clorotalonil em acetona. Para tanto, os padrões analíticos dos pesticidas são solubilizados no citado solvente, de modo a fornecer concentração exata de $1 \mathrm{mg} \cdot \mathrm{mL}^{-1}$ (soluções estoque). As soluções padrão para estudos de fortificações e injeções nos sistemas cromatográficos GLC/PFPD (acefato e metamidofós) e GLC/ECD (clorotalonil), são preparadas a partir das soluções estoque com diluições feitas, igualmente em acetona.

\section{E Fortificações}

Para os estudos de fortificação/recuperação as amostras (frutos, folhas) foram fortificadas, juntando-se $1 \mathrm{~mL}$ das soluções de concentrações apropriadas, obtidas por diluições sucessivas, a partir das soluções estoque, em sub-amostras de $10 \mathrm{~g}$ cada uma dos substratos obtidos de frutos ou folhas triturados/homogeneizados, sabidamente nunca anteriormente contaminados.

\section{F Extração}

F.01. Pesar $10 \mathrm{~g}$ da amostra homogeneizada, adequadamente fortificada, colocar um tubo Duran-Schott, juntar $50 \mathrm{~mL}$ de acetato de etila, $10 \mathrm{~g}$ de $\mathrm{Na}_{2} \mathrm{SO}_{4} \mathrm{e}$ triturar no aparelho Ultra-turrax durante 2 minutos a 26.000 rpm.

F.02. Centrifugar a $2.500 \mathrm{rpm}$ por 5 minutos para melhor separar a fase líquida do material em suspensão.

F.03. Transferir alíquota de $10 \mathrm{~mL}$ do sobrenadante (equivalente a $2 \mathrm{~g}$ da amostra original) para tubo de centrífuga de $50 \mathrm{~mL}$.

F.04. Evaporar em manifold, em banho-maria a $45-50^{\circ} \mathrm{C}$, com auxílio de ar movente, previamente seco em filtro de sílica-gel dessecante azul, até secar. 


\section{G Limpeza}

G.01. Ressuspender os resíduos dos três pesticidas em $1 \mathrm{~mL}$ de mistura de acetato de etila/ciclohexano $(1 / 1, v / v)$, lavando muito bem as paredes internas do tubo de polipropileno, recolhendo o extrato em tubo de centrifuga de $15 \mathrm{~mL}$.

G.02. Agitar em aparelho agitador/homogenizador Minishaker por cerca de 1 minuto, e deixar em ultra-som também por cerca de 1 minuto.

G.03. Filtrar o extrato em filtro de membrana Millipore de malha de $0,20 \mu$, com auxílio de uma seringa hipodérmica de $5 \mathrm{~mL}$, transferindo o extrato para vials próprios de uso no GPC;

G.04. Injetar o extrato no aparelho GPC e operar o equipamento com fase móvel da mesma mistura de acetato de etila/ciclohexano, com fluxo de $1 \mathrm{~mL}$. $\mathrm{min}^{-}$ ${ }^{1}$, descartando os eluados durante os primeiros 22 minutos e coletando a fração em eluição nos 5 minutos subsequentes em um tubo de centrífuga de $15 \mathrm{~mL}$.

G.05. Evaporar os extratos contidos nos tubos de centrífuga em TurboVap LV sob leve corrente de $\mathrm{N}_{2}$ a $40^{\circ} \mathrm{C}$, até secar.

\section{H Determinação quantitativa}

H.01. Ressuspender os resíduos provenientes de G.05. em volume exato de 1 $\mathrm{mL}$ de acetona.

H.02. Transferir os extratos para vials próprios de uso nos injetores automáticos dos cromatógrafos, com auxílio de pipetas de Pasteur.

H.03. Injetar alíquotas nos cromatógrafos, modo "splitless", com programação linear de temperaturas (rampas). 
H.04. Condições de operação dos cromatógrafos:

H.04.01. Acefato e metamidofós (GLC/PFPD)

Temperaturas:

injetor: $220^{\circ} \mathrm{C}$

coluna: $120^{\circ} \mathrm{C}$, mantém 7 minutos,

$280^{\circ} \mathrm{C} @ 27,5^{\circ} \mathrm{C} / \mathrm{min} .$, mantém 4 minutos;

detector: $300^{\circ} \mathrm{C}$

Fluxos dos gases:

He: $5 \mathrm{~mL} \cdot \mathrm{min}^{-1}$.

$\operatorname{Ar} 1: 17 \mathrm{~mL} \cdot \mathrm{min}^{-1}$.

Ar 2: 10 mL. $\mathrm{min}^{-1}$.

$\mathrm{H}_{2}: 14 \mathrm{~mL} \cdot \mathrm{min}^{-1}$.

Tempos de retenção:

acefato $\quad 5$ minutos 30 segundos

metamidofós 4 minutos 30 segundos

H.04.02. Clorotalonil (GPC/ECD)

Temperaturas:

injetor: $200^{\circ} \mathrm{C}$

coluna: $150^{\circ} \mathrm{C}$, mantém zero minuto,

200ㄷ, @ 10 C/min, mantém 1 minuto, 280 C, @ 45ㄷ/min, mantém 3 minutos.

detector: $300 \cong \mathrm{C}$

Fluxos dos gases:

$\mathrm{H}_{2}$ (arraste) $=5,3 \mathrm{~mL} \cdot \mathrm{min}^{-1}$;

$\mathrm{N}_{2}$ (make up) $=30$ mL.min-1.

Tempos de retenção: 5 minutos 45 segundos (frutos e folhas)

6 minutos 05 segundos (solo) 


\section{Cálculo das porcentagens de recuperação e resíduos}

$$
\% \text { de recuperação }=\frac{\text { mam } \times 100}{m t a} \text {, onde }
$$

mam = massa do analito na amostra fortificada, em ng, obtida por processamento do cromatograma pelo workstation; $\mathrm{mta}=$ massa teórica injetada do analito, em ng.

e

resíduo $\mathrm{mg} \cdot \mathrm{kg}^{-1}(\mathrm{ppm})=\frac{\mathrm{mp} 1 \cdot \mathrm{mam}}{\mathrm{mp}_{2} \cdot \text { Mam }}$, onde

$\mathrm{mp}_{1}=$ massa injetada do padrão em ng;

mam = massa do analito na amostra, em ng, obtida por processamento do cromatograma pelo workstation;

$\mathrm{mp}_{2}=$ massa do analito no padrão, em ng, obtida igualmente, por processamento do cromatograma pelo workstation;

Mam = massa da amostra injetada em mg. 


\subsubsection{Solo}

Os estudos de fortificação/recuperação com amostras de solo, tiveram sua preparação, determinação quantitativa e cálculo das porcentagens de recuperação e resíduos em tudo muito semelhantes aos procedimentos descritos para frutos e folhas, diferindo, entretanto, quanto às operações de extração dos resíduos dos três pesticidas, æ̀ quais foram executadas em extrator acelerado de solvente (marca Dionex, modelo ASE 300). Assim, as operações quanto a extração dos resíduos podem ser assim descritas:

\section{F Extração}

F.01. Tomar amostra $20 \mathrm{~g}$ de solo (seco ao ar) adequadamente fortificada, colocar na célula de extração, juntar $\mathrm{Na}_{2} \mathrm{SO}_{4}$ suficiente para completar o volume da célula.

F.02. Extrair em ASE 300, usando-se acetato de etila, operando o aparelho a $100^{\circ} \mathrm{C}$ e pressão positiva de 1.500 psi, por cerca de 15 minutos, obtendo-se os extratos coletados nos frascos de uso próprio do aparelho (cerca de $120 \mathrm{~mL}$ ).

F.03. Evaporar em TurboVap II (evaporador Zymark, modelo TurboVap II), sob leve fluxo de $\mathrm{N}_{2}$ a $40^{\circ} \mathrm{C}$, até secar.

Prosseguir como em G.01., do método descrito para frutos e folhas, até o final. 


\subsection{Experimento 1- Estufa}

O Experimento 1 foi conduzido em condições de estufa (cultura protegida), pertencente ao Sítio Pinheirinho, no Município de Piracicaba-SP, SP-137, Km 26, Rodovia Fausto Santomauro (Piracicaba - Rio Claro). A instalação deu-se em 15/maio/2002, sendo usada o cultivar Caqui, em bom estado de desenvolvimento vegetativo, sendo a cultura tutorada (tomate envarado).

O delineamento experimental foi de blocos ao acaso com 4 tratamentos e 3 repetições. $O$ isolamento entre blocos deu-se por bordaduras constituídas de duas linhas duplas de plantas, sendo as parcelas separadas dentro do bloco por 10 plantas em linhas duplas. A unidade experimental (parcela) foi constituída de 15 metros de linhas duplas espaçadas $50 \mathrm{~cm}$ entre si e, igualmente, $50 \mathrm{~cm}$ entre plantas.

O inseticida usado foi o Orthene $750 \mathrm{BR}$ (750 g do ingrediente ativo acefato. $\mathrm{kg}^{-1}$ do produto comercial), em formulação de pó solúvel. $\mathrm{O}$ fungicida foi o Dacostar 500 (500 g do ingrediente ativo clorotalonil. $\mathrm{L}^{-1}$ do produto comercial) em formulação de suspensão concentrada. Os tratamentos experimentais foram os seguintes:

A - testemunha

B - uma (1) única aplicação na dosagem de $100 \mathrm{~g}$ de Orthene 750 BR.100 L-1 de água (100 g p.c..100 $\mathrm{L}^{-1}$ de água) (75 g i.a. acefato.100 $\mathrm{L}^{-1}$ de água) mais $400 \mathrm{~mL}$ de Dacostar $500.100 \mathrm{~L}^{-1}$ de água $\left(400 \mathrm{~mL}\right.$ p.c..100 $\mathrm{L}^{-1}$ de água) (200 g i.a. clorotalonil. $100 \mathrm{~L}^{-1}$ de água; 
C - uma (1) única aplicação na dosagem de $200 \mathrm{~g}$ de Orthene 750 BR.100 $\mathrm{L}^{-1}$ de água (200 g p.c..100 $\mathrm{L}^{-1}$ de água) (150 g i.a. acefato. $100 \mathrm{~L}^{-1}$ de água) mais $800 \mathrm{~mL}$ de Dacostar $500 / .100 \mathrm{~L}^{-1}$ de água $\left(800 \mathrm{~mL}\right.$ p.c.. $100 \mathrm{~L}^{-1}$ de água) (400 g i.a. clorotalonil. $100 \mathrm{~L}^{-1}$ de água;

D - quatro (4) aplicações na dosagem de $100 \mathrm{~g}$ de Orthene 750 BR.100 L ${ }^{-1}$ de água (100 g p.c.. $100 \mathrm{~L}^{-1}$ de água) ( $75 \mathrm{~g}$ i.a. acefato. $100 \mathrm{~L}^{-1}$ de água) mais $400 \mathrm{~mL}$ de Dacostar $500.100 \mathrm{~L}^{-1}$ de água (400 mL p.c..100 L $\mathrm{L}^{-1}$ de água) (200 g i.a. clorotalonil. $100 \mathrm{~L}^{-1}$ de água.

As aplicações foram realizadas com auxílio de um pulverizador costal mantido a pressão constante de $80 \mathrm{PSI}$ com $\mathrm{CO}_{2}$, com volume de calda de 1000 L.ha $^{-1}$ da mistura, como recomendado, e suficiente para saturação da parte aérea.

A primeira aplicação do tratamento $D\left(75 \mathrm{~g}\right.$ i.a. acefato. $100 \mathrm{~L}^{-1}$ mais $200 \mathrm{~g}$ i.a. clorotalonil. $100 \mathrm{~L}^{-1}, 4$ aplicações) ocorreu no início do período de maturação dos frutos, em 15/maio/2002 e as demais em intervalos subsequentes de 7 dias, sendo na última ocasião, também aplicados os tratamentos com uma única aplicação $B\left(75 \mathrm{~g}\right.$ i.a. acefato. $100 \mathrm{~L}^{-1}$ mais $200 \mathrm{~g}$ i.a. clorotalonil. $100 \mathrm{~L}^{-1}, 1$ aplicação) e $\mathrm{C}\left(150 \mathrm{~g}\right.$ i.a. acefato. $100 \mathrm{~L}^{-1}$ mais $400 \mathrm{~g}$ i.a. clorotalonil. $100 \mathrm{~L}^{-1}, 1$ aplicação).

Durante a realização do experimento foram tomados dados das condições climáticas, a saber: temperatura máxima média, temperatura mínima média, umidade relativa máxima média do ar na estufa, umidade relativa mínima média do ar na estufa e precipitação atmosférica no período, obtidos no próprio local, para correlação com os níveis de resíduos dos três analitos e com o metabolismo de acefato em seu metabólito metamidofós (Tabela 1). 
As amostras foram colhidas com (-1), zero, 1, 3, 7, 14 e 21 dias após a última (ou única) aplicação, sendo a primeira amostragem em 04/junho e a ultima em 26/junho/2002 . Foram amostrados frutos, folhas e solo para as análises, sendo colhidas 252 amostras, a saber: 4 tratamentos $\times 3$ repetições $x$ 3 substratos $\times 7$ colheitas, e foram, pois, assim, realizadas 756 análises dos três analitos.

As amostras de fruto foram constituídas por 12 unidades cada uma e as de folha por 12 ramos (folhas compostas), tomadas ao acaso de cada parcela, buscando-se respeitar sua distribuição espacial nas plantas, de modo a tornar as amostras tão representativas quanto possível. As amostras de solo foram tomadas na região do escorrimento da calda pela copa do tomateiro, onde os trabalhadores pisam para realizarem a colheita e outros tratos culturais, igualmente em número de 12 e colhidas ao acaso ao longo das parcelas; foi, para isto, usado uma área padrão, quadrada de $20 \times 20 \mathrm{~cm}$, feita em ferro, adaptada para este fim, de modo a amostrar somente a superfície do solo (aproximadamente $1 \mathrm{~cm}$ ).

Tabela 1. Condições climáticas ocorrentes no Sítio Pinheirinho, durante a realização do Experimento 1 (estufa), Piracicaba-SP.

\begin{tabular}{cccccc}
\hline $\begin{array}{c}\text { Período } \\
2002\end{array}$ & $\begin{array}{c}\text { Temperatura } \\
\text { máxima } \\
\text { média }\left({ }^{\circ} \mathrm{C}\right)\end{array}$ & $\begin{array}{c}\text { Temperatura } \\
\text { mínima } \\
\text { média }\left({ }^{\circ} \mathrm{C}\right)\end{array}$ & $\begin{array}{c}\text { Umidade } \\
\text { relativa máxima } \\
\text { média do ar na } \\
\text { estufa }(\%)\end{array}$ & $\begin{array}{c}\text { Umidade } \\
\text { relativa mínima } \\
\text { média do ar na } \\
\text { estufa }(\%)\end{array}$ & $\begin{array}{c}\text { Precipitação } \\
\text { atmosférica } \\
\text { total }(\mathrm{mm})\end{array}$ \\
\hline $\begin{array}{c}15 \mathrm{a} \\
\text { 31/maio } \\
01 \text { a } \\
\text { 26/junho }\end{array}$ & 29,4 & 12,7 & 83 & 49 & 84 \\
\hline
\end{tabular}




\subsection{Experimento 2-Campo}

O Experimento 2 foi conduzido em condições de campo na Estação Experimental da Hokko do Brasil Indústria Química e Agropecuária Ltda, localizada no município de Pereiras-SP, SP-143, Rodovia Floriano Camargo, Km 8,5.

A instalação deu-se em 02/julho/2002, sendo usada o cultivar Angela, em bom estado de desenvolvimento vegetativo, sendo a cultivar tutorada (tomate envarado). $O$ delineamento experimental utilizado, o isolamento das parcelas por bordaduras, os tratamentos e repetições, a dimensão e o espaçamento das parcelas, o inseticida e o fungicida, suas dosagens, vazão, equipamento e suas demais condições de trabalho foram em tudo muito semelhantes ao descrito anteriormente, para o experimento de estufa.

A primeira aplicação do tratamento $D\left(75 \mathrm{~g}\right.$ i.a. acefato. $100 \mathrm{~L}^{-1}$ mais $200 \mathrm{~g}$ i.a. clorotalonil. $100 \mathrm{~L}^{-1}, 4$ aplicações) ocorreu no início do período de maturação dos frutos, em 02/julho/2002 e as demais em intervalos subsequentes de 7 dias, sendo na última ocasião, também aplicados os tratamentos com uma única aplicação $B\left(75 \mathrm{~g}\right.$ i.a. acefato. $100 \mathrm{~L}^{-1}$ mais $200 \mathrm{~g}$ i.a. clorotalonil. $100 \mathrm{~L}^{-1}, 1$ aplicação) e C (150 g i.a. acefato. $100 \mathrm{~L}^{-1}$ mais $400 \mathrm{~g}$ i.a. clorotalonil. $100 \mathrm{~L}^{-1}, 1$ aplicação).

Durante a realização do experimento foram tomados os dados meteorológicos, obtidos na própria Estação Experimental a saber: temperatura máxima média, temperatura mínima média, umidade relativa máxima média do ar, umidade relativa mínima média do ar e precipitação atmosférica para correlação com os níveis de resíduos dos 3 analitos e com o metabolismo de acefato em seu metabólito metamidofós (Tabela 2 ). 
As amostras foram colhidas com (-1), zero, 1, 3, 7, 14, e 21 dias após a última (ou única ) aplicação, sendo a primeira amostragem em 22/julho/2002 e a última em 14/agosto/2002. Foram amostrados frutos, folhas e solo para as análises, sendo colhidas 252 amostras, a saber: 4 tratamentos $\times 3$ repetições $x$ 3 substratos $\times 7$ colheitas, e foram, pois, assim, realizadas 756 análises dos três analitos. No caso das amostras de frutos, a operação de coleta ao acaso foi prejudicada, devido a intenso ataque da broca-pequena-do-fruto, Neoleucinodes elegantalis (Guenée, 1854) (Lepidoptera, Crambidae).

A sistemática de colheita de amostras foi, também, em tudo muito semelhante àdescrita anteriormente para o Experimento 1 (estufa).

Tabela 2. Condições climáticas ocorrentes na Estação Experimental da Hokko do Brasil Indústria Química e Agropecuária Ltda., durante a realização do Experimento 2 (campo), Pereiras-SP.

\begin{tabular}{cccccc}
\hline $\begin{array}{c}\text { Período } \\
2002\end{array}$ & $\begin{array}{c}\text { Temperatura } \\
\text { máxima } \\
\text { média }\left({ }^{\circ} \mathrm{C}\right)\end{array}$ & $\begin{array}{c}\text { Temperatura } \\
\text { mínima } \\
\text { média }\left({ }^{\circ} \mathrm{C}\right)\end{array}$ & $\begin{array}{c}\text { Umidade } \\
\text { relativa máxima } \\
\text { média do ar na } \\
\text { estufa }(\%)\end{array}$ & $\begin{array}{c}\text { Umidade } \\
\text { relativa mínima } \\
\text { média do ar na } \\
\text { estufa }(\%)\end{array}$ & $\begin{array}{c}\text { Precipitação } \\
\text { atmosférica } \\
\text { total }(\mathrm{mm})\end{array}$ \\
\hline $\begin{array}{c}15 \mathrm{a} \\
\text { 31/maio } \\
01 \text { a } \\
\text { 26/junho }\end{array}$ & 24,8 & 12,4 & 96 & 53 & 26 \\
\hline
\end{tabular}




\section{RESULTADOS E DISCUSSÃO}

4.1 Limites de quantificação e porcentagens de recuperação dos método de análises de resíduos de acefato, metamidofós e clorotalonil em amostras de fruto, folha e solo

Os resultados obtidos nos estudos de fortificação/recuperação de acefato, metamidofós e clorotalonil em amostras de frutos, folhas e solo são apresentadas nas Tabelas 3 a 5 .

Os cromatogramas das fortificações dos limites de quantificação $\left(0,05 \mathrm{mg} \cdot \mathrm{kg}^{-1}\right.$ para fruto e solo e $0,5 \mathrm{mg} \cdot \mathrm{kg}^{-1}$ para folha $)$, bem como os padrões das respectivas concentrações, são mostrados nas Figuras 1 a 6 . 
Tabela 3. Porcentagens (\%) de recuperação de resíduos de acefato, metamidofós e clorotalonil em amostras fortificadas de tomate.

\begin{tabular}{cccc}
\hline $\begin{array}{c}\text { Níveis de fortificação } \\
\left(\mathrm{mg}_{\mathrm{kg}}{ }^{-1}\right)(\mathrm{ppm})\end{array}$ & \multicolumn{3}{c}{ Recuperação (\%) (média de 3 repetições) } \\
acefato & $85 \pm 5 \%$ & $83 \pm 5 \%$ & $76 \pm 4 \%$ \\
\hline 10 & $93 \pm 4 \%$ & $84 \pm 5 \%$ & $79 \pm 7 \%$ \\
5 & $101 \pm 4 \%$ & $90 \pm 8 \%$ & $76 \pm 9 \%$ \\
0,5 & $95 \pm 2 \%$ & $87 \pm 1 \%$ & $85 \pm 9 \%$ \\
0,1 & $117 \pm 6 \%$ & $106 \pm 6 \%$ & $104 \pm 24 \%$ \\
0,05 & $116 \pm 3 \%$ & $111 \pm 9 \%$ & $103 \pm 18 \%$ \\
0,01 & $<\mathrm{LOQ}$ & $<\mathrm{LOQ}$ & $<\mathrm{LOQ}$
\end{tabular}

$\mathrm{LOQ}$ = limite de quantificação (quando a \% de recuperação está situada fora do intervalo de $70-120 \%)$.

Tabela 4. Porcentagens (\%) de recuperação de resíduos de acefato, metamidofós e clorotalonil em amostras fortificadas de folhas de tomateiro.

\begin{tabular}{cccc}
\hline $\begin{array}{c}\text { Níveis de fortificação } \\
\left(\mathrm{mg}^{-1}{ }^{-1}\right)(\mathrm{ppm})\end{array}$ & \multicolumn{3}{c}{ Recuperação (\%) média de 3 repetições) } \\
acefato & metamidofós & clorotalonil \\
\hline 100 & $76 \pm 2 \%$ & $77 \pm 6 \%$ & $85 \pm 12 \%$ \\
50 & $74 \pm 7 \%$ & $78 \pm 1 \%$ & $91 \pm 6 \%$ \\
10 & $76 \pm 3 \%$ & $83 \pm 4 \%$ & $75 \pm 2 \%$ \\
5 & $81 \pm 2 \%$ & $97 \pm 7 \%$ & $80 \pm 15 \%$ \\
1 & $112 \pm 5 \%$ & $100 \pm 7 \%$ & $74 \pm 6 \%$ \\
0,5 & $117 \pm 8 \%$ & $109 \pm 5 \%$ & $74 \pm 4 \%$ \\
0,1 & $<$ LOQ & $<$ LOQ & $<$ LOQ \\
\hline LOQ = limite de quantificação (quando a \% de recuperação está fora do \\
intervalo de 70-120\%).
\end{tabular}


Tabela 5. Porcentagens (\%) de recuperação de resíduos de acefato metamidofós e clorotalonil em amostras fortificadas de solo.

\begin{tabular}{cccc}
\hline $\begin{array}{c}\text { Níveis de fortificação } \\
\left(\mathrm{mg}_{\mathrm{kg}}{ }^{-1}\right)(\mathrm{ppm})\end{array}$ & \multicolumn{2}{c}{ Recuperação (\%) média de 3 repetições) } \\
Acefato & metamidofós & clorotalonil \\
\hline 10 & $77 \pm 5 \%$ & $81 \pm 3 \%$ & $73 \pm 3 \%$ \\
5 & $73 \pm 3 \%$ & $79 \pm 9 \%$ & $84 \pm 1 \%$ \\
1 & $75 \pm 8 \%$ & $90 \pm 4 \%$ & $87 \pm 6 \%$ \\
0,5 & $80 \pm 9 \%$ & $98 \pm 7 \%$ & $97 \pm 10 \%$ \\
0,1 & $105 \pm 7 \%$ & $92 \pm 1 \%$ & $101 \pm 5 \%$ \\
0,05 & $116 \pm 3 \%$ & $117 \pm 1 \%$ & $116 \pm 10 \%$ \\
0,01 & $<\mathrm{LOQ}$ & $<\mathrm{LOQ}$ & $<\mathrm{LOQ}$ \\
\hline
\end{tabular}

$\mathrm{LOQ}=$ limite de quantificação (quando a \% de recuperação está situada fora do intervalo de $70-120 \%)$.

Nas condições experimentais, o método analítico mostra-se satisfatório para as análises de resíduos dos três pesticidas, com limites de quantificação (LOQ) em frutos e em solo ao nível de $0,05 \mathrm{mg} \mathrm{kg}^{-1}$ (ppm) e em folhas ao de 0,5 $\mathrm{mg} . \mathrm{kg}^{-1}$ (ppm). Abaixo destes valores, os materiais interferentes, eluídos nos cromatogramas, prejudicam consideravelmente a resolução destes. Desse modo, o método para análises multi-resíduos de Andersson \& Palshelden (1998), descrito para frutas e verduras (inclusive para tomate para análises dos três analitos), confirma sua aplicabilidade, bem como mostra-se, também, exeqüível para amostras folhas e de solo e para os três analitos. 


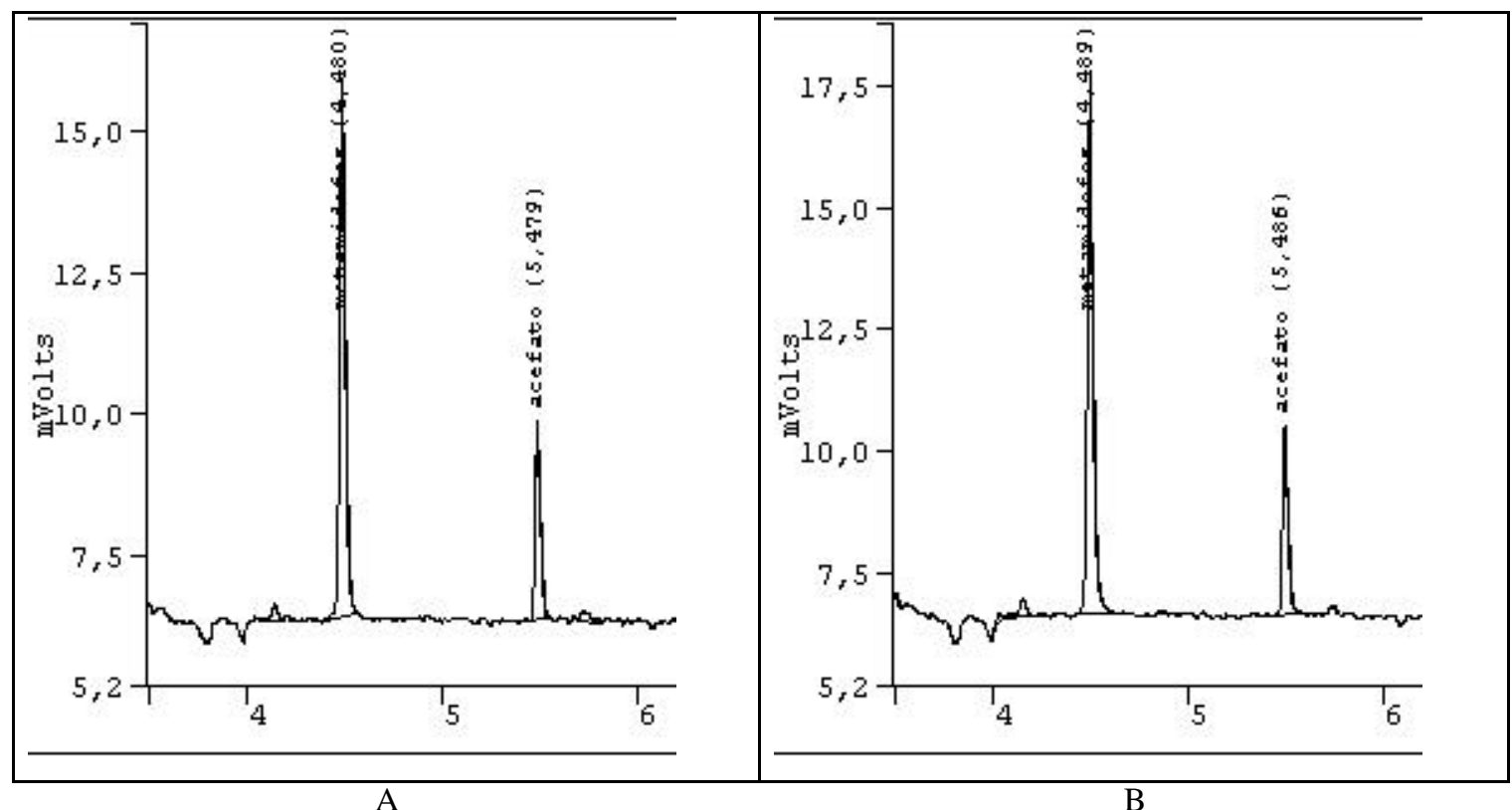

Figura 1 - Cromatograma de extrato de fruto de tomate/fortificação acefato e metamidofós. A) fortificação de $0,05 \mathrm{mg} \cdot \mathrm{kg}^{-1} 1 \mu \mathrm{L}-2 \mathrm{mg}-100 \mathrm{pg}$ (mt); B) padrões de metamidofós e acefato $1 \mu \mathrm{L}-100 \mathrm{pg}$.

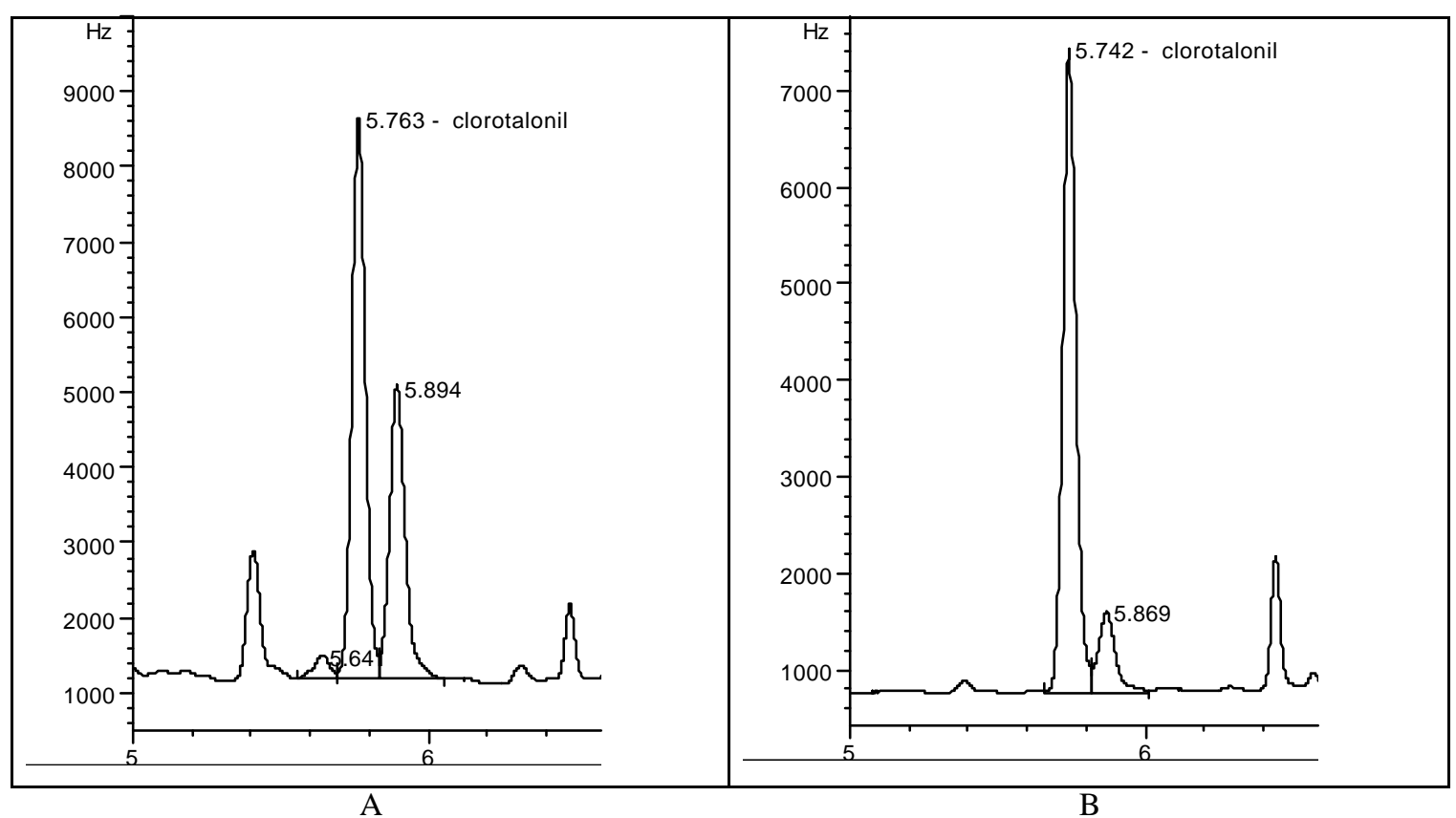

Figura 2 - Cromatograma de extrato de fruto de tomate /fortificação clorotalonil. A) fortificação de $0,05 \mathrm{mg} \cdot \mathrm{kg}^{-1} 2 \mu \mathrm{L}-0,1 \mathrm{mg}-5 \mathrm{pg}(\mathrm{mt})$; B) padrão clorotalonil $2 \mu \mathrm{L}-10$ pg. 


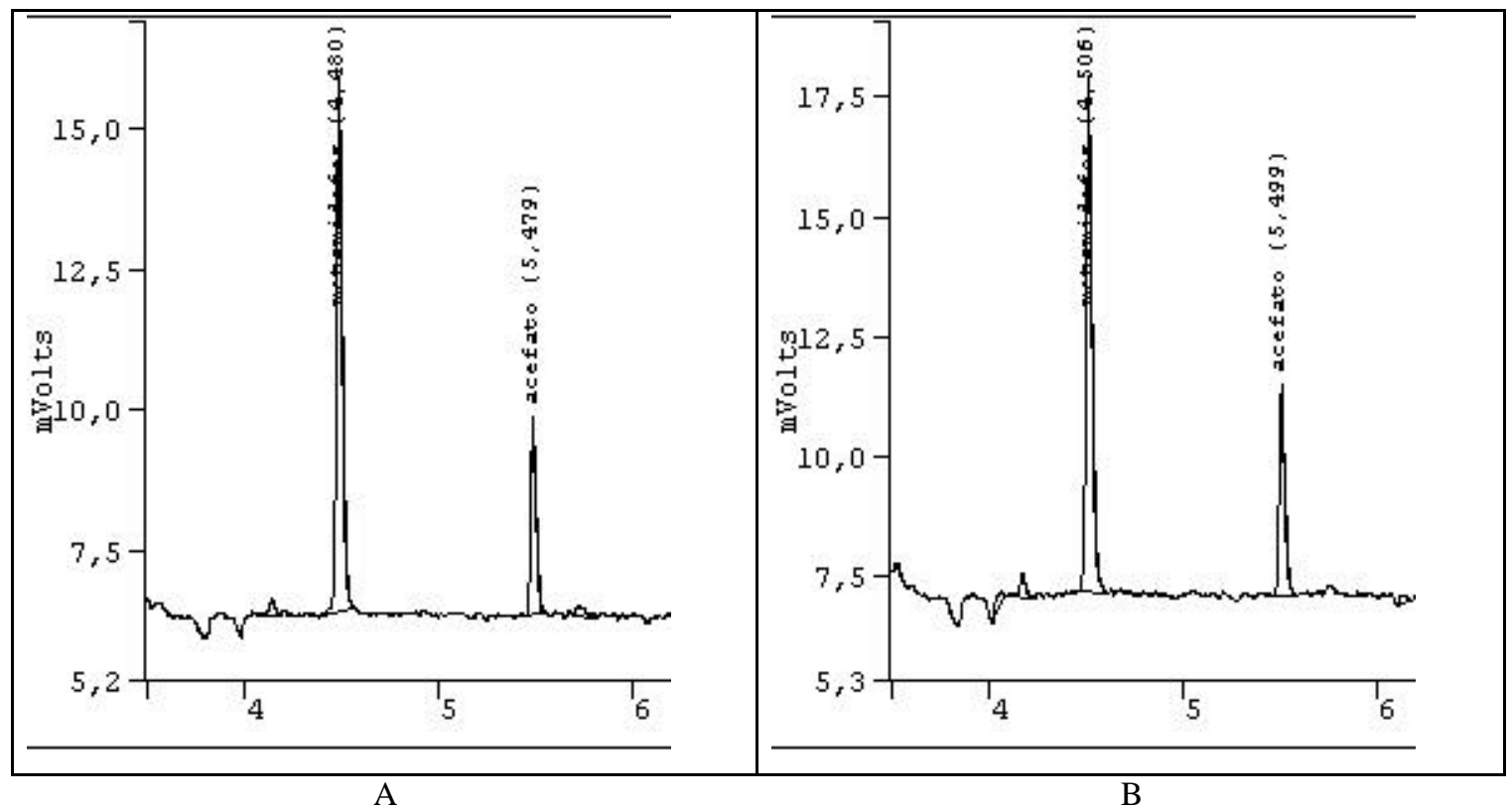

Figura 3 - Cromatograma de extrato de folhas de tomate/fortificação acefato e metamidofós. A) fortificação de 0,5 mg. $\mathrm{kg}^{-1} 1 \mu \mathrm{L}-0,2 \mathrm{mg}-100 \mathrm{pg}$ (mt); B) padrões de metamidofós e acefato $1 \mu \mathrm{L}-100 \mathrm{pg}$.

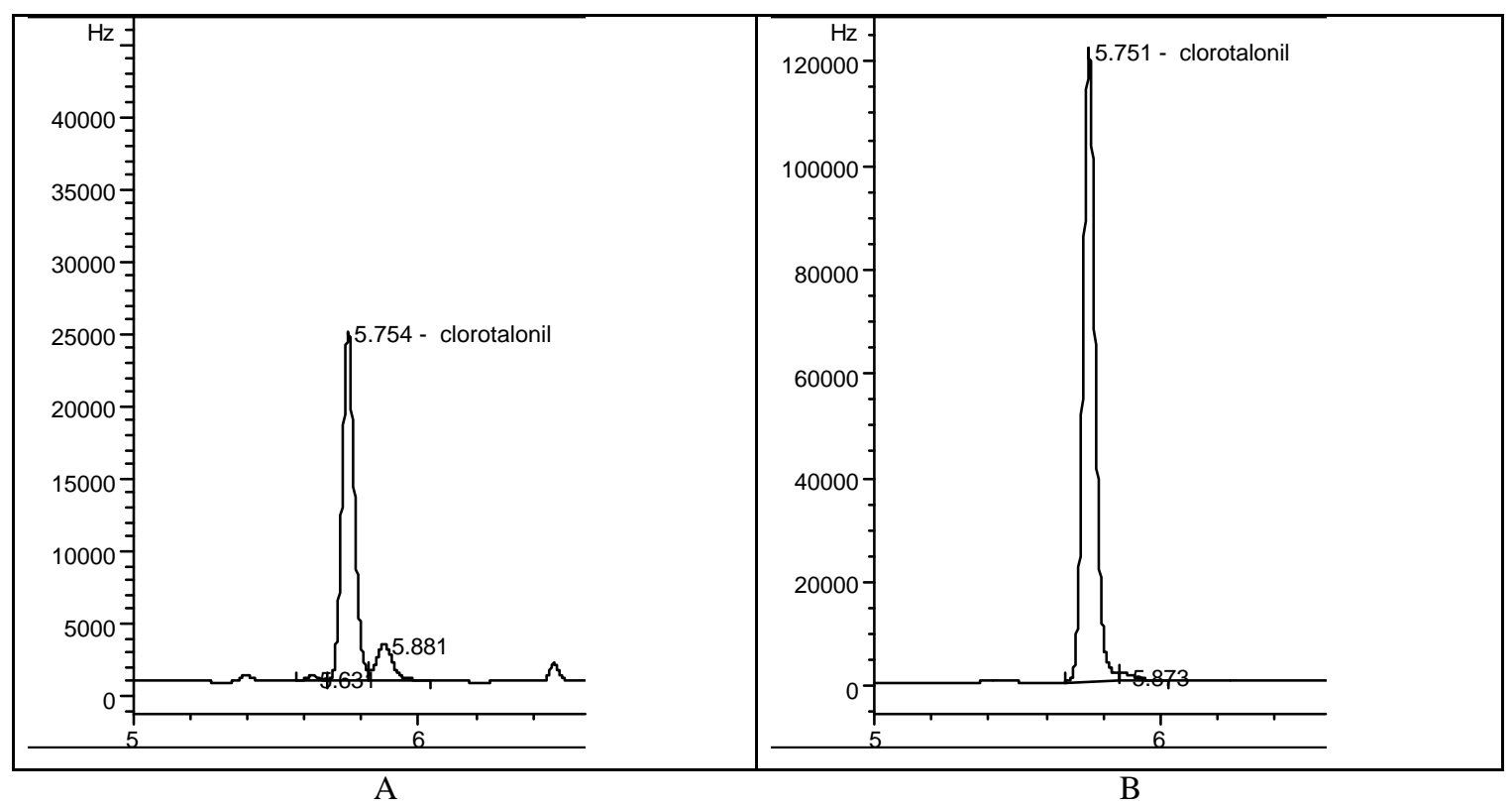

Figura 4 - Cromatograma de extrato de folhas de tomate/fortificação clorotalonil. A) fortificação de $0,5 \mathrm{mg} \cdot \mathrm{kg}^{-1} 2 \mu \mathrm{L}-0,1 \mathrm{mg}-50 \mathrm{pg}(\mathrm{mt})$; B) padrão clorotalonil $2 \mu \mathrm{L}-100 \mathrm{pg}$. 

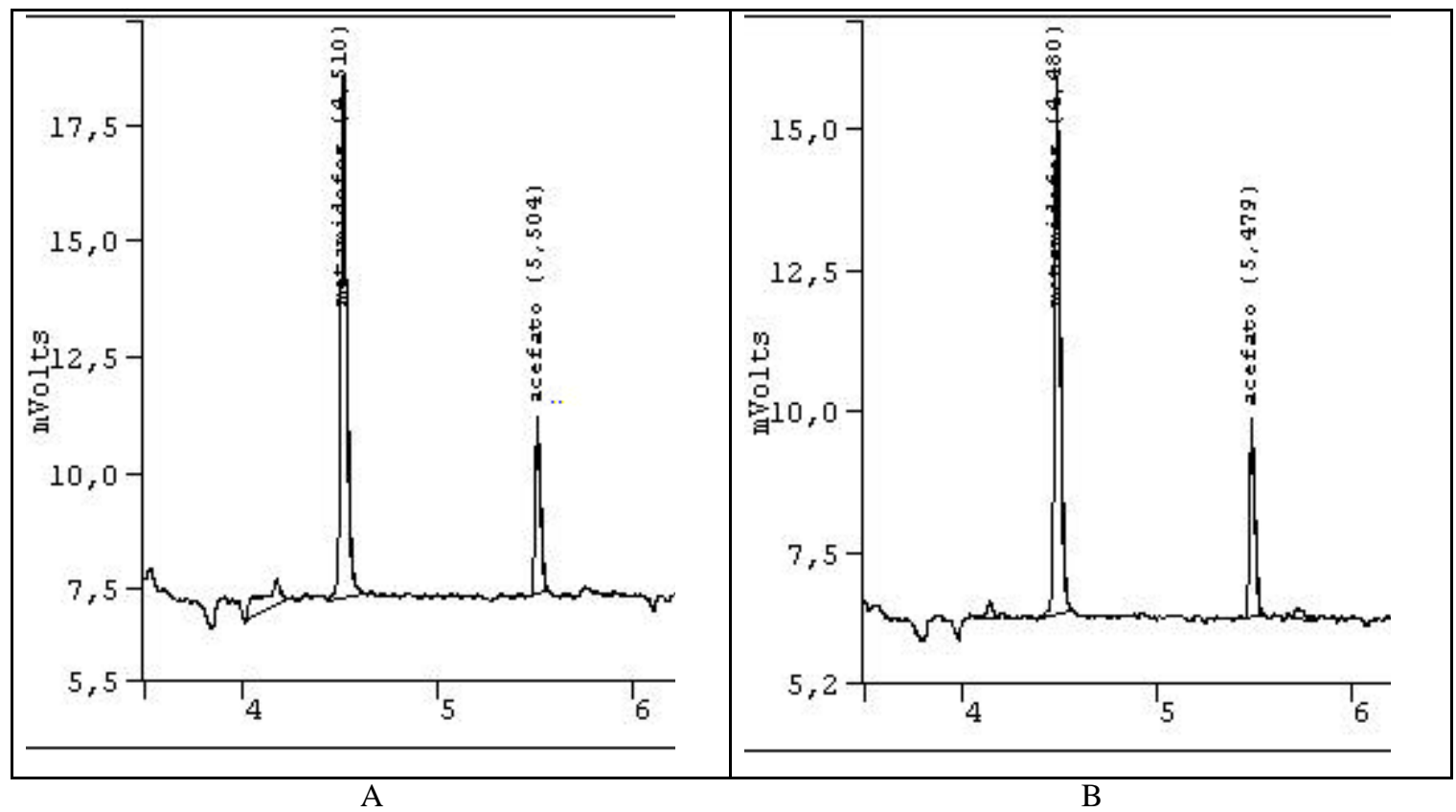

Figura 5 - Cromatograma de extrato de solo/fortificação acefato e metamidofós. A)fortificação de $0,05 \mathrm{mg} \cdot \mathrm{kg}^{-1} 1 \mu \mathrm{L}-2 \mathrm{mg}-100 \mathrm{pg}(\mathrm{mt})$; B) padrões de metamidofós e acefato $1 \mu \mathrm{L}-100 \mathrm{pg}$.

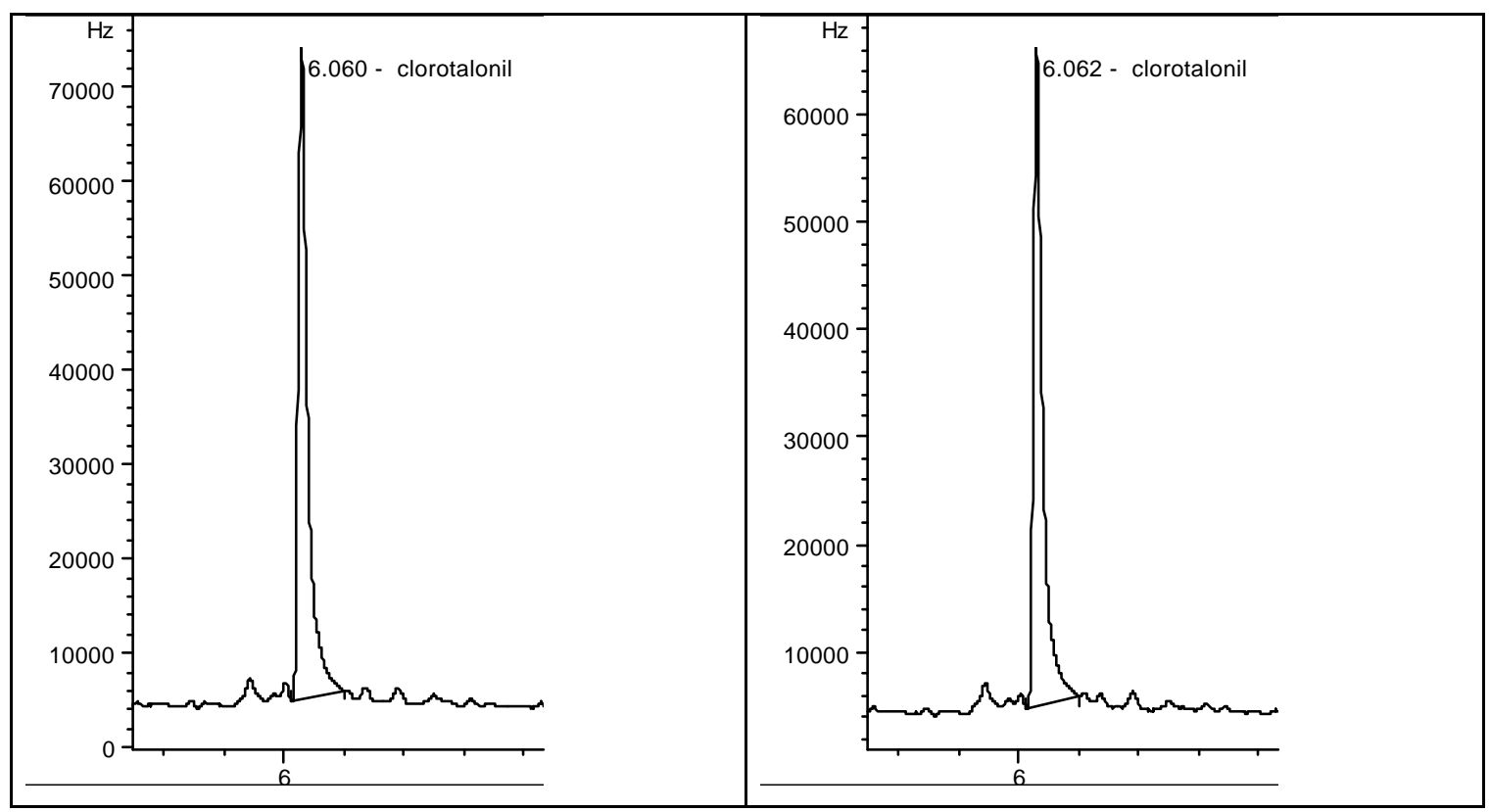

Figura 6 - Cromatograma de extrato de solo/fortificação clorotalonil.A) fortificação de $0,05 \mathrm{mg} \cdot \mathrm{kg}^{-1} 1 \mu \mathrm{L}-0,4 \mathrm{mg}-20 \mathrm{pg}(\mathrm{mt})$; B) padrão clorotalonil $1 \mu \mathrm{L}-20 \mathrm{pg}$. 


\subsection{Experimento 1 - Estufa}

Os resultados obtidos para o experimento em estufa acham-se nas

Tabelas de 6 a 14. Cromatogramas relativos às análises são apresentados nas Figuras de 7 a 18. 
Tabela 6. Resíduos de acefato em tomate (frutos). Experimento 1 (estufa), Piracicaba-SP (maio-junho/2002).

\begin{tabular}{|c|c|c|c|c|c|}
\hline \multirow{2}{*}{ Tratamento } & \multirow{2}{*}{ DAT } & \multicolumn{3}{|c|}{ Repetições $\mathrm{mg} \cdot \mathrm{kg}^{-1}(\mathrm{ppm})$} & \multirow{2}{*}{$\begin{array}{c}\mathrm{m} \pm \mathrm{s} \\
\mathrm{mg} \cdot \mathrm{kg}^{-1}(\mathrm{ppm}\end{array}$} \\
\hline & & 1 & 2 & 3 & \\
\hline \multirow{7}{*}{ testemunha } & -1 & $<0,05$ & $<0,05$ & $<0,05$ & $<0,05$ \\
\hline & 0 & $<0,05$ & $<0,05$ & $<0,05$ & $<0,05$ \\
\hline & 1 & $<0,05$ & $<0,05$ & $<0,05$ & $<0,05$ \\
\hline & 3 & $<0,05$ & $<0,05$ & $<0,05$ & $<0,05$ \\
\hline & 7 & $<0,05$ & $<0,05$ & $<0,05$ & $<0,05$ \\
\hline & 14 & $<0,05$ & $<0,05$ & $<0,05$ & $<0,05$ \\
\hline & 21 & $<0,05$ & $<0,05$ & $<0,05$ & $<0,05$ \\
\hline \multirow{7}{*}{$\begin{array}{l}75 \text { g i.a. / } 100 \mathrm{~L}^{-1} \\
1 \text { aplicação }\end{array}$} & -1 & $<0,05$ & $<0,05$ & $<0,05$ & $<0,05$ \\
\hline & 0 & 0,12 & 0,16 & 0,12 & $0,13+0,02$ \\
\hline & 1 & 0,08 & 0,09 & 0,13 & $0,1 \pm 0,02$ \\
\hline & 3 & 0,05 & 0,05 & 0,05 & 0,05 \\
\hline & 7 & 0,55 & 0,24 & 0,19 & $0,33 \pm 0,20$ \\
\hline & 14 & 0,09 & 0,09 & 0,07 & $0,08 \pm 0,01$ \\
\hline & 21 & $<0,05$ & $<0,05$ & $<0,05$ & $<0,05$ \\
\hline \multirow{7}{*}{$\begin{array}{l}150 \text { g i.a. / } 100 \mathrm{~L}^{-1} \\
1 \text { aplicação }\end{array}$} & -1 & $<0,05$ & $<0,05$ & $<0,05$ & $<0,05$ \\
\hline & 0 & 0,24 & 0,17 & 0,20 & $0,20 \pm 0,04$ \\
\hline & 1 & 0,13 & 0,13 & 0,13 & 0,13 \\
\hline & 3 & 0,09 & 0,23 & 0,14 & $0,15 \pm 0,07$ \\
\hline & 7 & 0,23 & 0,24 & 0,31 & $0,26 \pm 0,04$ \\
\hline & 14 & 0,18 & 0,11 & 0,07 & $0,12 \pm 0,06$ \\
\hline & 21 & $<0,05$ & $<0,05$ & $<0,05$ & $<0,05$ \\
\hline \multirow{7}{*}{$\begin{array}{l}75 \mathrm{~g} \text { i.a. } / 100 \mathrm{~L}^{-1} \\
4 \text { aplicações }\end{array}$} & -1 & 0,17 & 0,18 & 0,16 & $0,17 \pm 0,01$ \\
\hline & 0 & 0,23 & 0,19 & 0,52 & $0,31 \pm 0,18$ \\
\hline & 1 & 0,53 & 0,24 & 0,33 & $0,37 \pm 0,15$ \\
\hline & 3 & 0,3 & 0,25 & 0,16 & $0,24 \pm 0,07$ \\
\hline & 7 & 0,42 & 0,40 & 0,41 & $0,41 \pm 0,01$ \\
\hline & 14 & 0,08 & 0,13 & 0,05 & $0,09 \pm 0,04$ \\
\hline & 21 & $<0,05$ & $<0,05$ & $<0,05$ & $<0,05$ \\
\hline
\end{tabular}


Tabela 7. Resíduos de metamidofós em tomate (frutos). Experimento 1 (estufa), Piracicaba-SP (maio-junho/2002).

\begin{tabular}{|c|c|c|c|c|c|}
\hline \multirow{2}{*}{ Tratamento } & \multirow{2}{*}{ DAT } & \multicolumn{3}{|c|}{ Repetições $\mathrm{mg} \mathrm{kg}^{-1}$ (ppm) } & \multirow{2}{*}{$\begin{array}{c}\mathrm{m} \pm \mathrm{s} \\
\mathrm{mg} \cdot \mathrm{kg}^{-1}(\mathrm{ppm})\end{array}$} \\
\hline & & 1 & 2 & 3 & \\
\hline \multirow{7}{*}{ testemunha } & -1 & $<0,05$ & $<0,05$ & $<0,05$ & $<0,05$ \\
\hline & 0 & $<0,05$ & $<0,05$ & $<0,05$ & $<0,05$ \\
\hline & 1 & $<0,05$ & $<0,05$ & $<0,05$ & $<0,05$ \\
\hline & 3 & $<0,05$ & $<0,05$ & $<0,05$ & $<0,05$ \\
\hline & 7 & $<0,05$ & $<0,05$ & $<0,05$ & $<0,05$ \\
\hline & 14 & $<0,05$ & $<0,05$ & $<0,05$ & $<0,05$ \\
\hline & 21 & $<0,05$ & $<0,05$ & $<0,05$ & $<0,05$ \\
\hline \multirow{7}{*}{$\begin{array}{l}75 \mathrm{~g} \text { i.a. (acefato) / } \\
100 \mathrm{~L}^{-1} 1 \text { aplicação }\end{array}$} & -1 & $<0,05$ & $<0,05$ & $<0,05$ & $<0,05$ \\
\hline & 0 & $<0,05$ & $<0,05$ & $<0,05$ & $<0,05$ \\
\hline & 1 & $<0,05$ & $<0,05$ & $<0,05$ & $<0,05$ \\
\hline & 3 & $<0,05$ & $<0,05$ & $<0,05$ & $<0,05$ \\
\hline & 7 & $<0,05$ & $<0,05$ & $<0,05$ & $<0,05$ \\
\hline & 14 & $<0,05$ & $<0,05$ & $<0,05$ & $<0,05$ \\
\hline & 21 & $<0,05$ & $<0,05$ & $<0,05$ & $<0,05$ \\
\hline \multirow{7}{*}{$\begin{array}{l}150 \text { g i.a. (acefato) / } \\
100 L^{-1} 1 \text { aplicação }\end{array}$} & -1 & $<0,05$ & $<0,05$ & $<0,05$ & $<0,05$ \\
\hline & 0 & $<0,05$ & $<0,05$ & $<0,05$ & $<0,05$ \\
\hline & 1 & $<0,05$ & $<0,05$ & $<0,05$ & $<0,05$ \\
\hline & 3 & $<0,05$ & $<0,05$ & $<0,05$ & $<0,05$ \\
\hline & 7 & $<0,05$ & $<0,05$ & $<0,05$ & $<0,05$ \\
\hline & 14 & $<0,05$ & $<0,05$ & $<0,05$ & $<0,05$ \\
\hline & 21 & $<0,05$ & $<0,05$ & $<0,05$ & $<0,05$ \\
\hline \multirow{7}{*}{$\begin{array}{l}75 \text { g i.a. (acefato) / } \\
100 \mathrm{~L}^{-1} 4 \text { aplicações }\end{array}$} & -1 & $<0,05$ & $<0,05$ & $<0,05$ & $<0,05$ \\
\hline & 0 & $<0,05$ & $<0,05$ & 0,09 & 0,09 \\
\hline & 1 & 0,10 & 0,09 & 0,09 & $0,09 \pm 0,01$ \\
\hline & 3 & 0,10 & 0,08 & 0,08 & $0,09 \pm 0,01$ \\
\hline & 7 & 0,12 & 0,10 & 0,12 & $0,11 \pm 0,01$ \\
\hline & 14 & 0,16 & 0,09 & 0,12 & $0,12 \pm 0,03$ \\
\hline & 21 & 0,13 & 0,12 & 0,12 & 0,12 \\
\hline
\end{tabular}


Tabela 8. Resíduos de clorotalonil em tomate (frutos). Experimento 1 (estufa), Piracicaba-SP (maio-junho/2002).

\begin{tabular}{|c|c|c|c|c|c|}
\hline \multirow{2}{*}{ Tratamento } & \multirow{2}{*}{ DAT } & \multicolumn{3}{|c|}{ Repetições mg.kg ${ }^{-1}(\mathrm{ppm})$} & \multirow{2}{*}{$\begin{array}{c}\mathrm{m} \pm \mathrm{s} \\
\mathrm{mg} \cdot \mathrm{kg}^{-1}(\mathrm{ppm})\end{array}$} \\
\hline & & 1 & 2 & 3 & \\
\hline \multirow{7}{*}{ testemunha } & -1 & $<0,05$ & $<0,05$ & $<0,05$ & $<0,05$ \\
\hline & 0 & $<0,05$ & $<0,05$ & $<0,05$ & $<0,05$ \\
\hline & 1 & $<0,05$ & $<0,05$ & $<0,05$ & $<0,05$ \\
\hline & 3 & $<0,05$ & $<0,05$ & $<0,05$ & $<0,05$ \\
\hline & 7 & $<0,05$ & $<0,05$ & $<0,05$ & $<0,05$ \\
\hline & 14 & $<0,05$ & $<0,05$ & $<0,05$ & $<0,05$ \\
\hline & 21 & $<0,05$ & $<0,05$ & $<0,05$ & $<0,05$ \\
\hline \multirow{7}{*}{$\begin{array}{l}200 \text { g i.a. } / 100 \mathrm{~L}^{-1} \\
1 \text { aplicação }\end{array}$} & -1 & $<0,05$ & $<0,05$ & $<0,05$ & $<0,05$ \\
\hline & 0 & 0,23 & 0,29 & 0,12 & $0,21 \pm 0,09$ \\
\hline & 1 & 0,09 & 0,11 & 0,13 & $0,11 \pm 0,02$ \\
\hline & 3 & 0,08 & 0,12 & 0,06 & $0,09 \pm 0,03$ \\
\hline & 7 & 0,55 & 0,24 & 0,19 & $0,33 \pm 0,19$ \\
\hline & 14 & 0,14 & 0,09 & 0,1 & $0,11 \pm 0,03$ \\
\hline & 21 & 0,1 & 0,09 & 0,13 & $0,11 \pm 0,02$ \\
\hline \multirow{7}{*}{$\begin{array}{l}400 \text { g i.a. / } 100 \mathrm{~L}^{-1} \\
1 \text { aplicação }\end{array}$} & -1 & $<0,05$ & $<0,05$ & $<0,05$ & $<0,05$ \\
\hline & 0 & 0,13 & 0,6 & 0,65 & $0,46 \pm 0,29$ \\
\hline & 1 & 0,26 & 0,26 & 0,28 & $0,27 \pm 0,01$ \\
\hline & 3 & 0,17 & 0,2 & 0,15 & $0,17 \pm 0,03$ \\
\hline & 7 & 0,23 & 0,24 & 0,31 & $0,26 \pm 0,04$ \\
\hline & 14 & 0,2 & 0,17 & 0,17 & $0,18 \pm 0,02$ \\
\hline & 21 & 0,18 & 0,15 & 0,24 & $0,19 \pm 0,05$ \\
\hline \multirow{7}{*}{$\begin{array}{l}200 \mathrm{~g} \text { i.a. } / 100 \mathrm{~L}^{-1} \\
4 \text { aplicações }\end{array}$} & -1 & 0,21 & 0,46 & 0,07 & $0,25 \pm 0,20$ \\
\hline & 0 & 0,62 & 0,66 & 0,76 & $0,68 \pm 0,07$ \\
\hline & 1 & 0,42 & 0,41 & 0,46 & $0,43 \pm 0,03$ \\
\hline & 3 & 0,29 & 0,29 & 0,27 & $0,28 \pm 0,01$ \\
\hline & 7 & 0,41 & 0,40 & 0,41 & 0,41 \\
\hline & 14 & 0,39 & 0,23 & 0,33 & $0,32 \pm 0,08$ \\
\hline & 21 & 0,29 & 0,25 & 0,26 & $0,27 \pm 0,02$ \\
\hline
\end{tabular}


Tabela 9. Resíduos de acefato em folhas de tomateiro. Experimento 1 (estufa), Piracicaba-SP (maio-junho/2002).

\begin{tabular}{|c|c|c|c|c|c|}
\hline \multirow{2}{*}{ Tratamento } & \multirow{2}{*}{ DAT } & \multicolumn{3}{|c|}{ Repetições $\mathrm{mg} \mathrm{kg}^{-1}$ (ppm) } & \multirow{2}{*}{$\begin{array}{c}\mathrm{m} \pm \mathrm{s} \\
\mathrm{mg} \cdot \mathrm{kg}^{-1}(\mathrm{ppm})\end{array}$} \\
\hline & & 1 & 2 & 3 & \\
\hline \multirow{7}{*}{ testemunha } & -1 & $<0,5$ & $<0,5$ & $<0,5$ & $<0,5$ \\
\hline & 0 & $<0,5$ & $<0,5$ & $<0,5$ & $<0,5$ \\
\hline & 1 & $<0,5$ & $<0,5$ & $<0,5$ & $<0,5$ \\
\hline & 3 & $<0,5$ & $<0,5$ & $<0,5$ & $<0,5$ \\
\hline & 7 & $<0,5$ & $<0,5$ & $<0,5$ & $<0,5$ \\
\hline & 14 & $<0,5$ & $<0,5$ & $<0,5$ & $<0,5$ \\
\hline & 21 & $<0,5$ & $<0,5$ & $<0,5$ & $<0,5$ \\
\hline \multirow{7}{*}{$\begin{array}{l}75 \text { g i.a. / } 100 \mathrm{~L}^{-1} \\
1 \text { aplicação }\end{array}$} & -1 & $<0,5$ & $<0,5$ & $<0,5$ & $<0,5$ \\
\hline & 0 & 37 & 35,2 & 40,6 & $37,6 \pm 2,7$ \\
\hline & 1 & 20,8 & 25,8 & 35,8 & $27,5 \pm 7,6$ \\
\hline & 3 & 16,1 & 16,0 & 13,8 & $15,3 \pm 1,3$ \\
\hline & 7 & 14,5 & 24,8 & 19,2 & $19,5 \pm 5,1$ \\
\hline & 14 & 14,1 & 11,8 & 16,9 & $14,3 \pm 2,6$ \\
\hline & 21 & 11,5 & 9,1 & 15,8 & $12,1 \pm 3,4$ \\
\hline \multirow{7}{*}{$\begin{array}{l}150 \mathrm{~g} \text { i.a. } / 100 \mathrm{~L}^{-1} \\
1 \text { aplicação }\end{array}$} & -1 & $<0,5$ & $<0,5$ & $<0,5$ & $<0,5$ \\
\hline & 0 & 44,2 & 47,6 & 62,5 & $51,4 \pm 9,7$ \\
\hline & 1 & 27,4 & 16,8 & 71,7 & $38,6 \pm 29,1$ \\
\hline & 3 & 29,6 & 28,0 & 22,5 & $26,7 \pm 3,7$ \\
\hline & 7 & 47,0 & 26,6 & 40,4 & $38,0 \pm 10,4$ \\
\hline & 14 & 25,3 & 23,8 & 30,8 & $26,6 \pm 3,7$ \\
\hline & 21 & 19,3 & 15,9 & 18,5 & $17,9 \pm 1,7$ \\
\hline \multirow{7}{*}{$\begin{array}{l}75 \text { g i.a. / } 100 \mathrm{~L}^{-1} \\
4 \text { aplicações }\end{array}$} & -1 & 27,5 & 39,6 & 36,8 & $34,6 \pm 6,3$ \\
\hline & 0 & 67 & 70,6 & 23,4 & $53,7 \pm 26,3$ \\
\hline & 1 & 74,5 & 58,7 & 62,1 & $65,1 \pm 8,2$ \\
\hline & 3 & 44,3 & 41,6 & 34,1 & $40,0 \pm 5,3$ \\
\hline & 7 & 48,9 & 39,3 & 38,4 & $42,3 \pm 5,8$ \\
\hline & 14 & 23,1 & 32,2 & 27,7 & $27,7 \pm 4,5$ \\
\hline & 21 & 21,9 & 21,7 & 9,1 & $17,6 \pm 7,3$ \\
\hline
\end{tabular}


Tabela 10. Resíduos de metamidofós em folhas de tomateiro. Experimento 1 (estufa), Piracicaba-SP (maio-junho/2002).

\begin{tabular}{|c|c|c|c|c|c|}
\hline \multirow{2}{*}{ Tratamento } & \multirow{2}{*}{ DAT } & \multicolumn{3}{|c|}{ Repetições $\mathrm{mg} \cdot \mathrm{kg}^{-1}(\mathrm{ppm})$} & \multirow{2}{*}{$\begin{array}{c}\mathrm{m} \pm \mathrm{s} \\
M g \cdot \mathrm{kg}^{-1}(\mathrm{ppm}\end{array}$} \\
\hline & & 1 & 2 & 3 & \\
\hline \multirow{7}{*}{ testemunha } & -1 & $<0,5$ & $<0,5$ & $<0,5$ & $<0,5$ \\
\hline & 0 & $<0,5$ & $<0,5$ & $<0,5$ & $<0,5$ \\
\hline & 1 & $<0,5$ & $<0,5$ & $<0,5$ & $<0,5$ \\
\hline & 3 & $<0,5$ & $<0,5$ & $<0,5$ & $<0,5$ \\
\hline & 7 & $<0,5$ & $<0,5$ & $<0,5$ & $<0,5$ \\
\hline & 14 & $<0,5$ & $<0,5$ & $<0,5$ & $<0,5$ \\
\hline & 21 & $<0,5$ & $<0,5$ & $<0,5$ & $<0,5$ \\
\hline \multirow{7}{*}{$\begin{array}{l}75 \text { g i.a. (acefato) / } \\
100 \mathrm{~L}^{-1} 1 \text { aplicação }\end{array}$} & -1 & $<0,5$ & $<0,5$ & $<0,5$ & $<0,5$ \\
\hline & 0 & 0,5 & $<0,5$ & 0,50 & 0,50 \\
\hline & 1 & 0,82 & 0,61 & 0,89 & $0,77 \pm 0,14$ \\
\hline & 3 & 1,0 & 1,5 & 1,0 & $1,17 \pm 0,29$ \\
\hline & 7 & 1,1 & 1,5 & 1,5 & $1,4 \pm 0,23$ \\
\hline & 14 & 1,3 & 1,2 & 1,6 & $1,04 \pm 0,21$ \\
\hline & 21 & 1,3 & 1,7 & 1,7 & $1,6 \pm 0,23$ \\
\hline \multirow{7}{*}{$\begin{array}{l}150 \text { g i.a. (acefato) / } \\
100 \mathrm{~L}^{-1} 1 \text { aplicação }\end{array}$} & -1 & $<0,5$ & $<0,5$ & $<0,5$ & $<0,5$ \\
\hline & 0 & 0,50 & 0,50 & 1,4 & $0,8 \pm 0,6$ \\
\hline & 1 & 0,91 & 0,90 & 1,1 & $0,97 \pm 0,11$ \\
\hline & 3 & 2,1 & 1,7 & 2,1 & $1,97 \pm 0,23$ \\
\hline & 7 & 2,4 & 3,0 & 2,4 & $2,6 \pm 0,34$ \\
\hline & 14 & 2,5 & 2,2 & 2,5 & $2,4 \pm 0,2$ \\
\hline & 21 & 2,1 & 2,4 & 2,3 & $2,3 \pm 0,15$ \\
\hline \multirow{7}{*}{$\begin{array}{l}75 \mathrm{~g} \text { i.a. (acefato) / } \\
100 \mathrm{~L}^{-1} 4 \text { aplicações }\end{array}$} & -1 & 2,4 & 2,7 & 2,3 & $2,5 \pm 0,2$ \\
\hline & 0 & 4,4 & 3,5 & 1,6 & $3,2 \pm 1,4$ \\
\hline & 1 & 4,2 & 3,4 & 4,9 & $4,2 \pm 0,75$ \\
\hline & 3 & 4,5 & 4,9 & 3,9 & $4,4 \pm 0,5$ \\
\hline & 7 & 4,5 & 4,9 & 5,2 & $4,9 \pm 0,35$ \\
\hline & 14 & 2,7 & 3,5 & 3,0 & $3,1 \pm 0,40$ \\
\hline & 21 & 5,1 & 3,5 & 2,8 & $3,8 \pm 1,18$ \\
\hline
\end{tabular}


Tabela 11. Resíduos de clorotalonil em folhas de tomateiro. Experimento 1 (estufa), Piracicaba-SP (maio-junho/2002).

\begin{tabular}{|c|c|c|c|c|c|}
\hline \multirow{2}{*}{ Tratamento } & \multirow{2}{*}{ DAT } & \multicolumn{3}{|c|}{ Repetições mg.kg ${ }^{-1}$ (ppm) } & \multirow{2}{*}{$\begin{array}{c}\mathrm{m} \pm \mathrm{s} \\
\mathrm{mg} \cdot \mathrm{kg}^{-1}(\mathrm{ppm})\end{array}$} \\
\hline & & 1 & 2 & 3 & \\
\hline \multirow{7}{*}{ testemunha } & -1 & $<0,5$ & $<0,5$ & $<0,5$ & $<0,5$ \\
\hline & 0 & $<0,5$ & $<0,5$ & $<0,5$ & $<0,5$ \\
\hline & 1 & $<0,5$ & $<0,5$ & $<0,5$ & $<0,5$ \\
\hline & 3 & $<0,5$ & $<0,5$ & $<0,5$ & $<0,5$ \\
\hline & 7 & $<0,5$ & $<0,5$ & $<0,5$ & $<0,5$ \\
\hline & 14 & $<0,5$ & $<0,5$ & $<0,5$ & $<0,5$ \\
\hline & 21 & $<0,5$ & $<0,5$ & $<0,5$ & $<0,5$ \\
\hline \multirow{7}{*}{$\begin{array}{l}200 \mathrm{~g} \text { i.a. } / 100 \mathrm{~L}^{-1} \\
1 \text { aplicação }\end{array}$} & -1 & $<0,5$ & $<0,5$ & $<0,5$ & $<0,5$ \\
\hline & 0 & 101 & 50 & 134 & $95 \pm 42$ \\
\hline & 1 & 73 & 85 & 116 & $91 \pm 22$ \\
\hline & 3 & 64 & 55 & 37 & $52 \pm 14$ \\
\hline & 7 & 39 & 42 & 46 & $42 \pm 4$ \\
\hline & 14 & 27 & 23 & 34 & $28 \pm 5$ \\
\hline & 21 & 31 & 38 & 48 & $39 \pm 8$ \\
\hline \multirow{7}{*}{$\begin{array}{l}400 \text { g i.a. / } 100 \mathrm{~L}^{-1} \\
1 \text { aplicação }\end{array}$} & -1 & $<0,5$ & $<0,5$ & $<0,5$ & $<0,5$ \\
\hline & 0 & 161 & 209 & 249 & $206 \pm 44$ \\
\hline & 1 & 152 & 181 & 148 & $160 \pm 18$ \\
\hline & 3 & 94 & 67 & 89 & $84 \pm 14$ \\
\hline & 7 & 83 & 108 & 80 & $90 \pm 15$ \\
\hline & 14 & 84 & 59 & 72 & $71 \pm 12$ \\
\hline & 21 & 84 & 72 & 78 & $78 \pm 6$ \\
\hline \multirow{7}{*}{$\begin{array}{l}200 \mathrm{~g} \text { i.a. } / 100 \mathrm{~L}^{-1} \\
4 \text { aplicações }\end{array}$} & -1 & 152 & 217 & 133 & $167 \pm 44$ \\
\hline & 0 & 407 & 271 & 181 & $286 \pm 113$ \\
\hline & 1 & 401 & 269 & 367 & $346 \pm 68$ \\
\hline & 3 & 137 & 216 & 152 & $168 \pm 41$ \\
\hline & 7 & 254 & 238 & 201 & $231 \pm 27$ \\
\hline & 14 & 119 & 148 & 143 & $137 \pm 15$ \\
\hline & 21 & 293 & 333 & 170 & $199 \pm 122$ \\
\hline
\end{tabular}


Tabela 12. Resíduos de acefato em solo cultivado com tomate. Experimento 1 (estufa), Piracicaba-SP (maio-junho/2002).

\begin{tabular}{|c|c|c|c|c|c|}
\hline \multirow{2}{*}{ Tratamento } & \multirow{2}{*}{ DAT } & \multicolumn{3}{|c|}{ Repetições $\mathrm{mg} \cdot \mathrm{kg}^{-1}(\mathrm{ppm})$} & \multirow{2}{*}{$\begin{array}{c}\mathrm{m} \pm \mathrm{S} \\
\mathrm{mg} \cdot \mathrm{kg}^{-1}(\mathrm{ppm})\end{array}$} \\
\hline & & 1 & 2 & 3 & \\
\hline \multirow{7}{*}{ testemunha } & -1 & $<0,05$ & $<0,05$ & $<0,05$ & $<0,05$ \\
\hline & 0 & $<0,05$ & $<0,05$ & $<0,05$ & $<0,05$ \\
\hline & 1 & $<0,05$ & $<0,05$ & $<0,05$ & $<0,05$ \\
\hline & 3 & $<0,05$ & $<0,05$ & $<0,05$ & $<0,05$ \\
\hline & 7 & $<0,05$ & $<0,05$ & $<0,05$ & $<0,05$ \\
\hline & 14 & $<0,05$ & $<0,05$ & $<0,05$ & $<0,05$ \\
\hline & 21 & $<0,05$ & $<0,05$ & $<0,05$ & $<0,05$ \\
\hline \multirow{7}{*}{$\begin{array}{l}75 \text { g i.a. } / 100 \mathrm{~L}^{-1} \\
1 \text { aplicação }\end{array}$} & -1 & $<0,05$ & $<0,05$ & $<0,05$ & $<0,05$ \\
\hline & 0 & 0,22 & 0,19 & 0,27 & $0,23 \pm 0,04$ \\
\hline & 1 & 1,0 & 1,4 & 1,8 & $1,4 \pm 0,4$ \\
\hline & 3 & 1,5 & 2,2 & 1,8 & $1,8 \pm 0,35$ \\
\hline & 7 & 1,8 & 1,5 & 0,93 & $1,4 \pm 0,44$ \\
\hline & 14 & 0,25 & 0,15 & 0,76 & $0,39 \pm 0,32$ \\
\hline & 21 & 0,91 & 1,3 & 0,31 & $0,84 \pm 0,50$ \\
\hline \multirow{7}{*}{$\begin{array}{l}150 \text { g i.a. } / 100 \mathrm{~L}^{-1} \\
1 \text { aplicação }\end{array}$} & -1 & $<0,05$ & $<0,05$ & $<0,05$ & $<0,05$ \\
\hline & 0 & 0,72 & 0,76 & 0,82 & $0,77 \pm 0,05$ \\
\hline & 1 & 2,1 & 2,5 & 2,9 & $2,5 \pm 0,4$ \\
\hline & 3 & 3,5 & 3,8 & 4,7 & $4,0 \pm 0,62$ \\
\hline & 7 & 2,0 & 1,2 & 5,7 & $3,0 \pm 2,40$ \\
\hline & 14 & 0,80 & 2,1 & 2,1 & $1,7 \pm 0,75$ \\
\hline & 21 & 5,5 & 1,6 & 2,8 & $3,3 \pm 2,0$ \\
\hline \multirow{7}{*}{$\begin{array}{l}75 \mathrm{~g} \text { i.a. } / 100 \mathrm{~L}^{-1} \\
4 \text { aplicações }\end{array}$} & -1 & 0,19 & 0,36 & 0,28 & $0,28 \pm 0,08$ \\
\hline & 0 & 1,5 & 1,1 & 0,48 & $1,0 \pm 0,51$ \\
\hline & 1 & 2,6 & 3,1 & 3,6 & $3,1 \pm 0,5$ \\
\hline & 3 & 4,8 & 3,0 & 3,3 & $3,7 \pm 0,96$ \\
\hline & 7 & 1,2 & 2,6 & 3,2 & $2,3 \pm 1,0$ \\
\hline & 14 & 3,8 & 0,92 & 0,75 & $1,8 \pm 1,71$ \\
\hline & 21 & 2,9 & 3,7 & 5,5 & $4,0 \pm 1,3$ \\
\hline
\end{tabular}


Tabela 13. Resíduos de metamidofós em solo cultivado com tomate. Experimento 1 (estufa), Piracicaba-SP (maio-junho/2002).

\begin{tabular}{|c|c|c|c|c|c|}
\hline \multirow{2}{*}{ Tratamento } & \multirow{2}{*}{ DAT } & \multicolumn{3}{|c|}{ Repetições $\mathrm{mg} \mathrm{kg}^{-1}$ (ppm) } & \multirow{2}{*}{$\begin{array}{c}\mathrm{M} \pm \mathrm{s} \\
\mathrm{mg} \cdot \mathrm{kg}^{-1}(\mathrm{ppm})\end{array}$} \\
\hline & & 1 & 2 & 3 & \\
\hline \multirow{7}{*}{ testemunha } & -1 & $<0,05$ & $<0,05$ & $<0,05$ & $<0,05$ \\
\hline & 0 & $<0,05$ & $<0,05$ & $<0,05$ & $<0,05$ \\
\hline & 1 & $<0,05$ & $<0,05$ & $<0,05$ & $<0,05$ \\
\hline & 3 & $<0,05$ & $<0,05$ & $<0,05$ & $<0,05$ \\
\hline & 7 & $<0,05$ & $<0,05$ & $<0,05$ & $<0,05$ \\
\hline & 14 & $<0,05$ & $<0,05$ & $<0,05$ & $<0,05$ \\
\hline & 21 & $<0,05$ & $<0,05$ & $<0,05$ & $<0,05$ \\
\hline \multirow{7}{*}{$\begin{array}{l}75 \text { g i.a. (acefato) / } \\
100 \mathrm{~L}^{-1} 1 \text { aplicação }\end{array}$} & -1 & $<0,05$ & $<0,05$ & $<0,05$ & $<0,05$ \\
\hline & 0 & $<0,05$ & $<0,05$ & $<0,05$ & $<0,05$ \\
\hline & 1 & $<0,05$ & $<0,05$ & $<0,05$ & $<0,05$ \\
\hline & 3 & $<0,05$ & $<0,05$ & $<0,05$ & $<0,05$ \\
\hline & 7 & $<0,05$ & $<0,05$ & $<0,05$ & $<0,05$ \\
\hline & 14 & $<0,05$ & $<0,05$ & $<0,05$ & $<0,05$ \\
\hline & 21 & $<0,05$ & $<0,05$ & $<0,05$ & $<0,05$ \\
\hline \multirow{7}{*}{$\begin{array}{l}150 \text { g i.a. (acefato) / } \\
100 \text { L }^{-1} 1 \text { aplicação }\end{array}$} & -1 & $<0,05$ & $<0,05$ & $<0,05$ & $<0,05$ \\
\hline & 0 & $<0,05$ & $<0,05$ & $<0,05$ & $<0,05$ \\
\hline & 1 & $<0,05$ & $<0,05$ & $<0,05$ & $<0,05$ \\
\hline & 3 & $<0,05$ & $<0,05$ & $<0,05$ & $<0,05$ \\
\hline & 7 & $<0,05$ & $<0,05$ & $<0,05$ & $<0,05$ \\
\hline & 14 & $<0,05$ & $<0,05$ & $<0,05$ & $<0,05$ \\
\hline & 21 & $<0,05$ & $<0,05$ & $<0,05$ & $<0,05$ \\
\hline \multirow{7}{*}{$\begin{array}{l}75 \text { g i.a. (acefato) / } \\
100 \mathrm{~L}^{-1} 4 \text { aplicações }\end{array}$} & -1 & $<0,05$ & $<0,05$ & $<0,05$ & $<0,05$ \\
\hline & 0 & $<0,05$ & $<0,05$ & $<0,05$ & $<0,05$ \\
\hline & 1 & $<0,05$ & $<0,05$ & $<0,05$ & $<0,05$ \\
\hline & 3 & $<0,05$ & $<0,05$ & $<0,05$ & $<0,05$ \\
\hline & 7 & $<0,05$ & $<0,05$ & $<0,05$ & $<0,05$ \\
\hline & 14 & $<0,05$ & $<0,05$ & $<0,05$ & $<0,05$ \\
\hline & 21 & $<0,05$ & $<0,05$ & $<0,05$ & $<0,05$ \\
\hline
\end{tabular}


Tabela 14. Resíduos de clorotalonil em solo cultivado com tomate. Experimento 1 (estufa), Piracicaba-SP (maio-junho/2002).

\begin{tabular}{|c|c|c|c|c|c|}
\hline \multirow{2}{*}{ Tratamento } & \multirow{2}{*}{ DAT } & \multicolumn{3}{|c|}{ Repetições mg.kg ${ }^{-1}$ (ppm) } & \multirow{2}{*}{$\begin{array}{c}\mathrm{m} \pm \mathrm{s} \\
\mathrm{mg} \cdot \mathrm{kg}^{-1}(\mathrm{ppm})\end{array}$} \\
\hline & & 1 & 2 & 3 & \\
\hline \multirow{7}{*}{ testemunha } & -1 & $<0,05$ & $<0,05$ & $<0,05$ & $<0,05$ \\
\hline & 0 & $<0,05$ & $<0,05$ & $<0,05$ & $<0,05$ \\
\hline & 1 & $<0,05$ & $<0,05$ & $<0,05$ & $<0,05$ \\
\hline & 3 & $<0,05$ & $<0,05$ & $<0,05$ & $<0,05$ \\
\hline & 7 & $<0,05$ & $<0,05$ & $<0,05$ & $<0,05$ \\
\hline & 14 & $<0,05$ & $<0,05$ & $<0,05$ & $<0,05$ \\
\hline & 21 & $<0,05$ & $<0,05$ & $<0,05$ & $<0,05$ \\
\hline \multirow{7}{*}{$\begin{array}{l}200 \text { g i.a. / } 100 \mathrm{~L}^{-1} \\
1 \text { aplicação }\end{array}$} & -1 & $<0,05$ & $<0,05$ & $<0,05$ & $<0,05$ \\
\hline & 0 & 0,60 & 0,72 & 1,0 & $0,77 \pm 0,20$ \\
\hline & 1 & 4,7 & 5,0 & 4,9 & $4,9 \pm 0,15$ \\
\hline & 3 & 4,9 & 4,4 & 4,2 & $4,5 \pm 0,36$ \\
\hline & 7 & 8,2 & 2,1 & 4,5 & $4,9 \pm 3,0$ \\
\hline & 14 & 1,3 & 0,9 & 1,9 & $1,4 \pm 0,47$ \\
\hline & 21 & 1,9 & 1,9 & 1,5 & $1,7 \pm 0,20$ \\
\hline \multirow{7}{*}{$\begin{array}{l}400 \text { g i.a. / } 100 \mathrm{~L}^{-1} \\
1 \text { aplicação }\end{array}$} & -1 & $<0,05$ & $<0,05$ & $<0,05$ & $<0,05$ \\
\hline & 0 & 2,2 & 0,86 & 1,9 & $1,6 \pm 0,70$ \\
\hline & 1 & 7,9 & 8,5 & 9,2 & $8,6+0,64$ \\
\hline & 3 & 5,7 & 12,9 & 7,8 & $8,5 \pm 3,2$ \\
\hline & 7 & 8,9 & 2,7 & 7,3 & $6,3 \pm 3,2$ \\
\hline & 14 & 7,8 & 8,9 & 4,5 & $7,1 \pm 2,2$ \\
\hline & 21 & 5,8 & 5,0 & 11 & $7,0 \pm 3,4$ \\
\hline & -1 & 1,6 & 1,3 & 3,3 & $2,1 \pm 1,06$ \\
\hline & 0 & 3,2 & 2,4 & 2,6 & $2,7 \pm 0,41$ \\
\hline & 1 & 9,5 & 10,5 & 11 & $10 \pm 0,75$ \\
\hline 200 g i.a. / $100 L^{-1}$ & 3 & 8,6 & 9,3 & 11 & $9,6 \pm 1,2$ \\
\hline 4 aplicações & 7 & 3,2 & 7,1 & 14 & $8,1 \pm 5,5$ \\
\hline & 14 & 11 & 3,7 & 5,4 & $6,7 \pm 3,8$ \\
\hline & 21 & 8,2 & 9,0 & 12 & $9,9 \pm 1,8$ \\
\hline
\end{tabular}




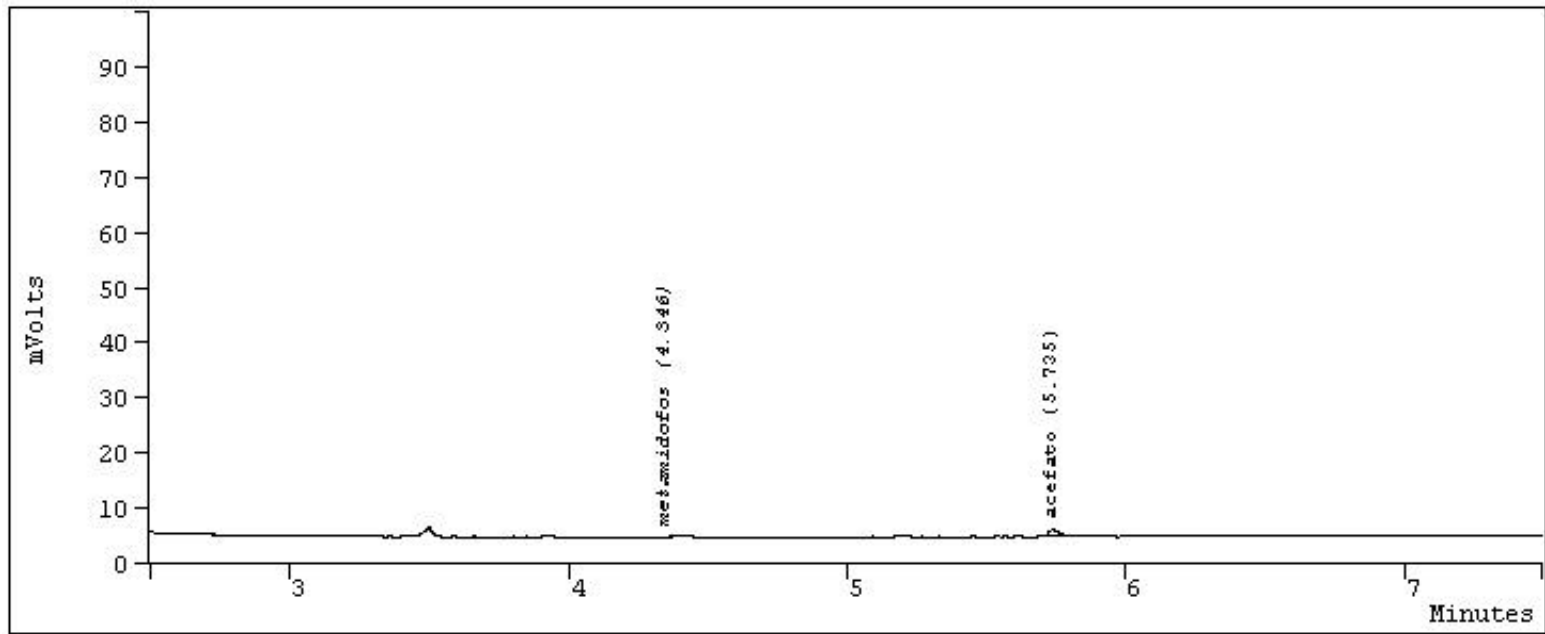

Figura 7 - Cromatograma de amostra testemunha/acefato e metamidofós, tomate estufa. $2 \mu \mathrm{L}-1 \mathrm{mg}$

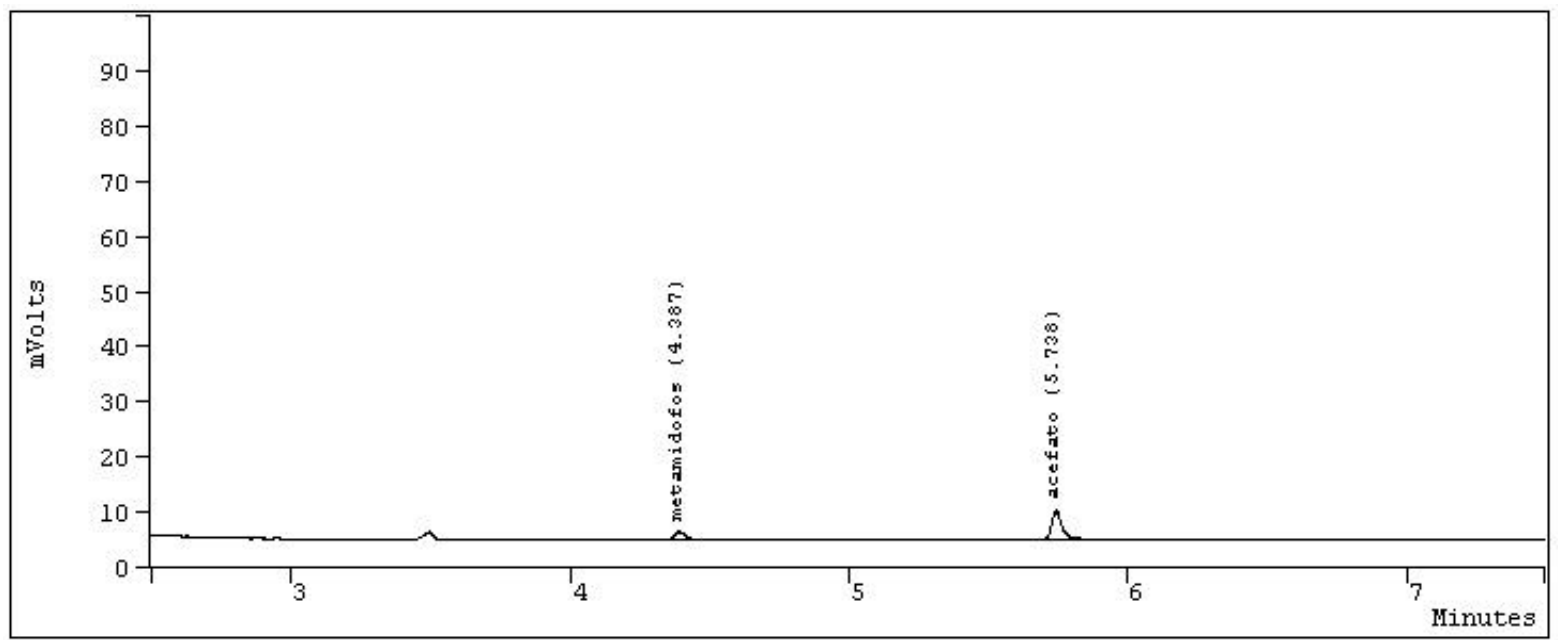

Figura 8 - Cromatograma de amostra tratamento $75 \mathrm{~g}$ i.a.. $100 \mathrm{~L}^{-1}$ (4 aplicações), acefato e metamidofós, tomate estufa. $2 \mu \mathrm{L}-1 \mathrm{mg}$ 


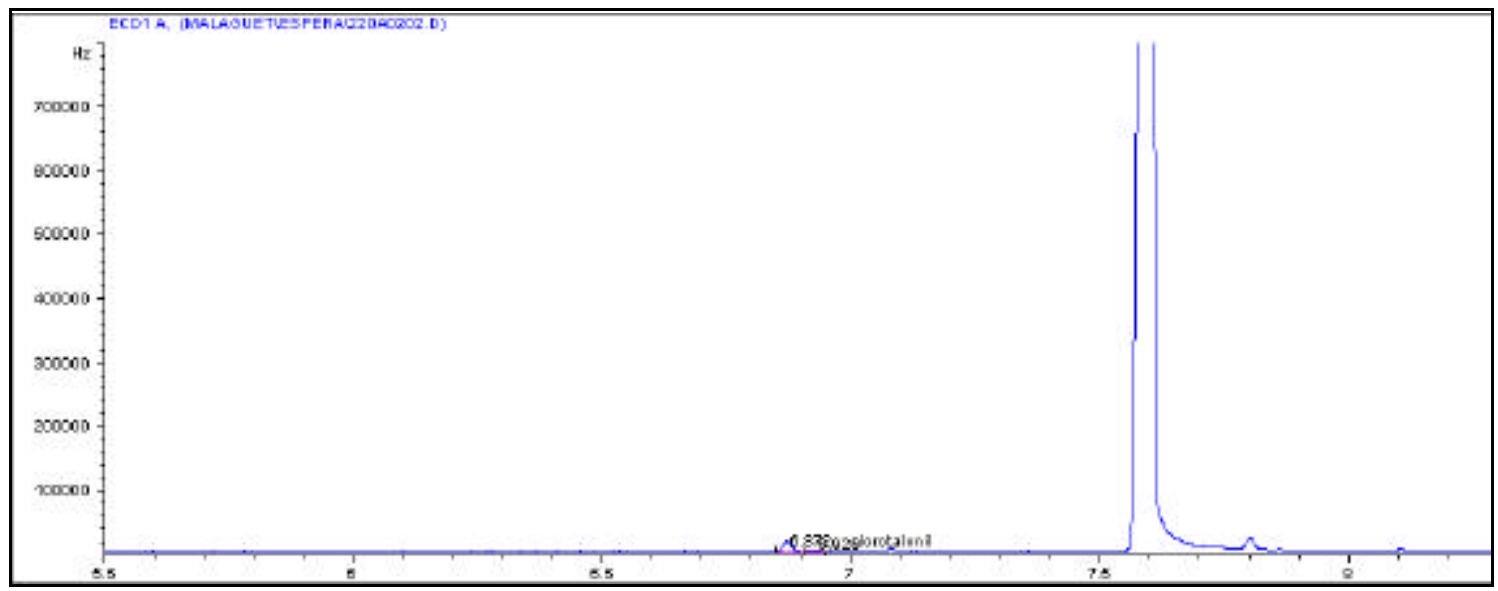

Figura 9 - Cromatograma de amostra testemunha/clorotalonil, tomate estufa. 1 $\mu \mathrm{L}-0,5 \mathrm{mg}$

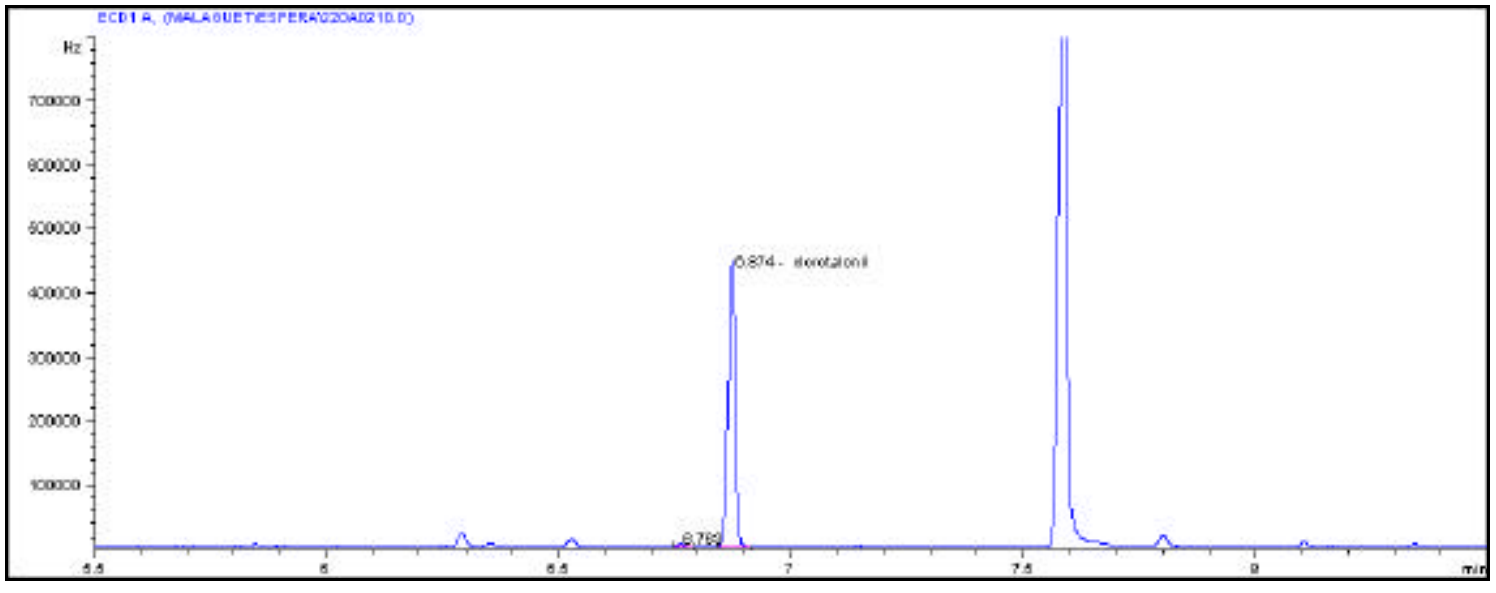

Figura 10 - Cromatograma de amostra tratamento $200 \mathrm{~g}$ i.a.. $100 \mathrm{~L}^{-1}$ (4 aplicações) clorotalonil, tomate estufa . $2 \mu \mathrm{L}-0,5 \mathrm{mg}$ 


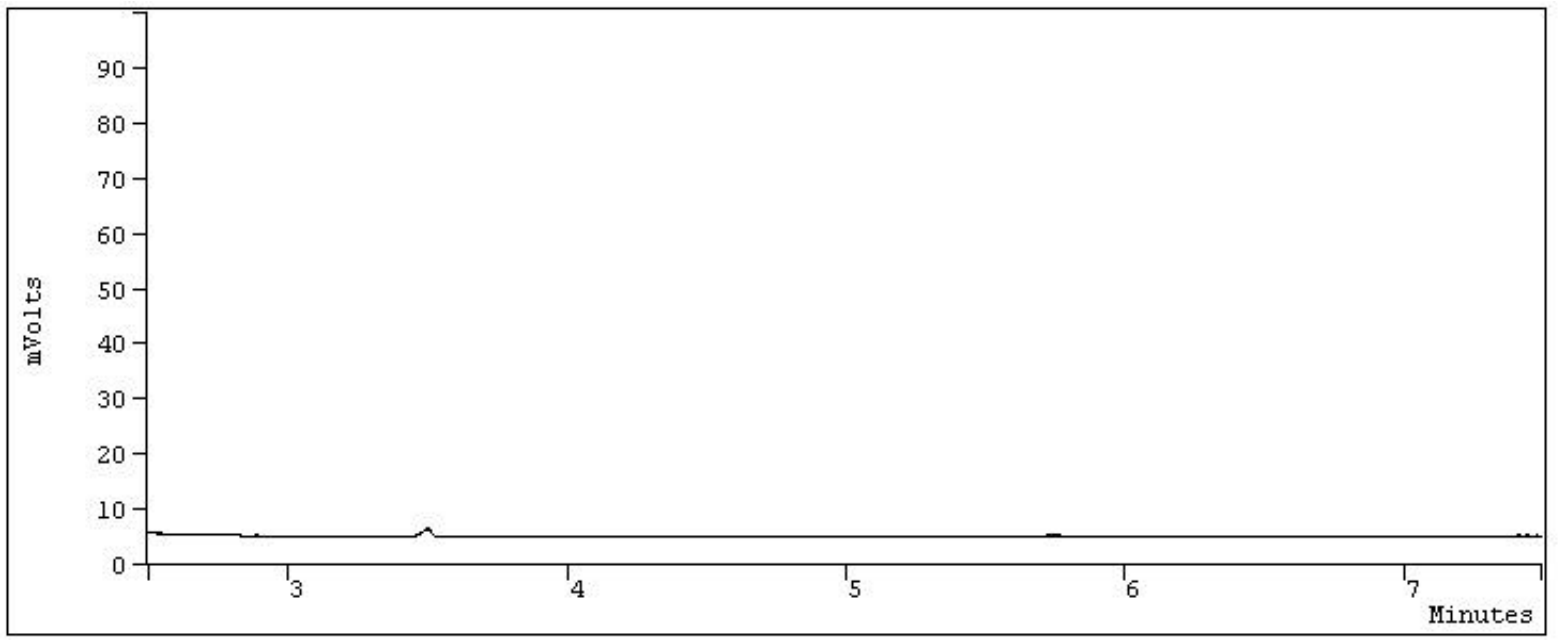

Figura 11 - Cromatograma de amostra testemunha/acefato e metamidofós, folha estufa. $2 \mu \mathrm{L}-1 \mathrm{mg}$

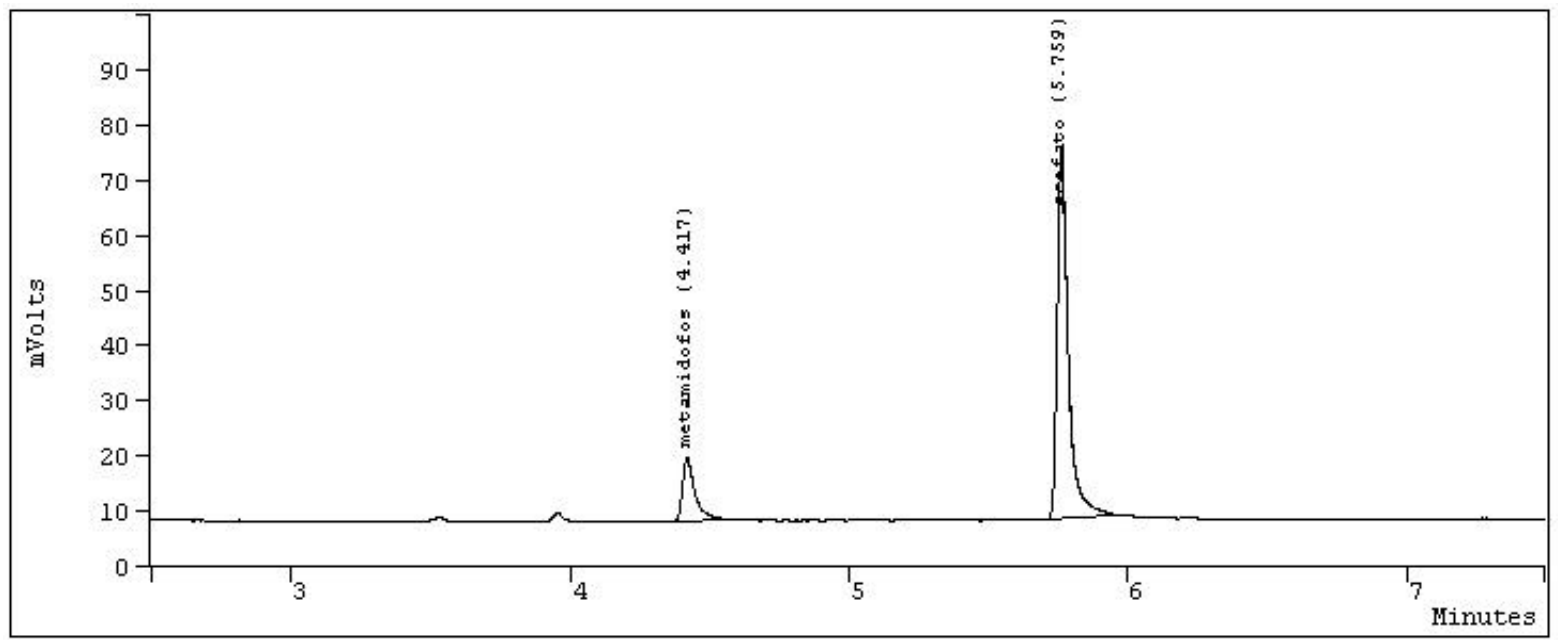

Figura 12 - Cromatograma de amostra tratamento $75 \mathrm{~g}$ i.a..100 $\mathrm{L}^{-1}$ (4 aplicações) acefato e metamidofós, folha estufa. $2 \mu \mathrm{L}-0,1 \mathrm{mg}$ 


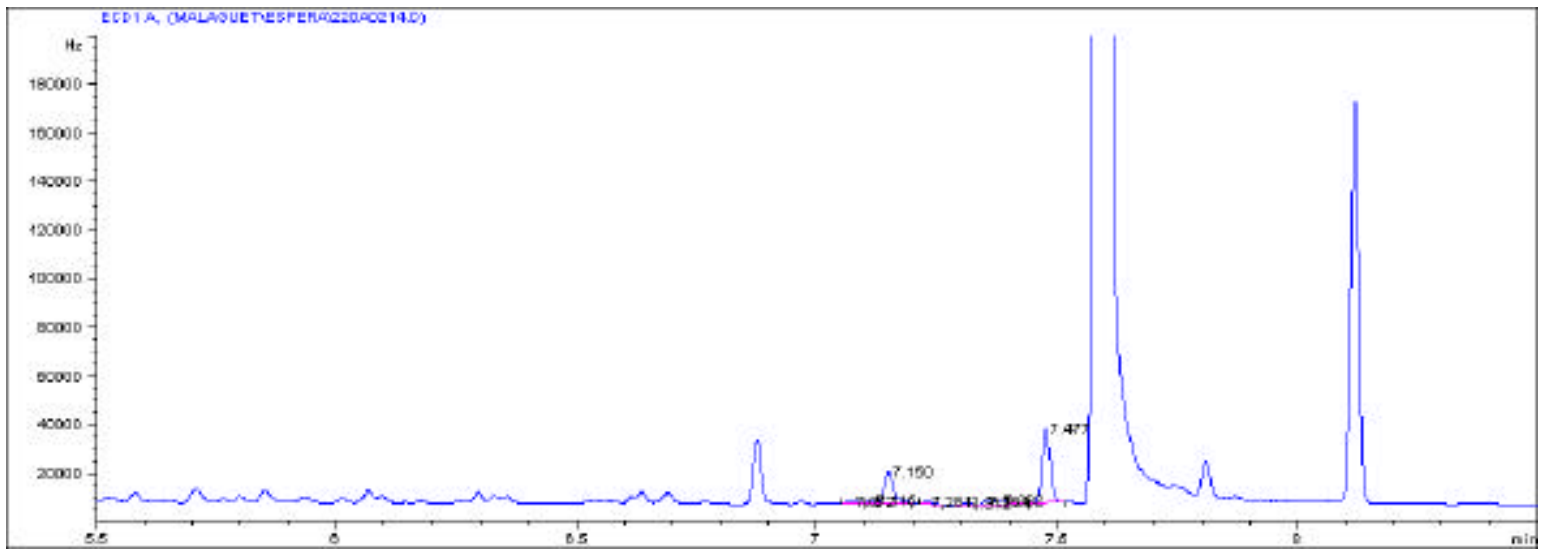

Figura 13 - Cromatograma de amostra testemunha/clorotalonil, folha estufa. $2 \mu \mathrm{L}-$ $0,5 \mathrm{mg}$

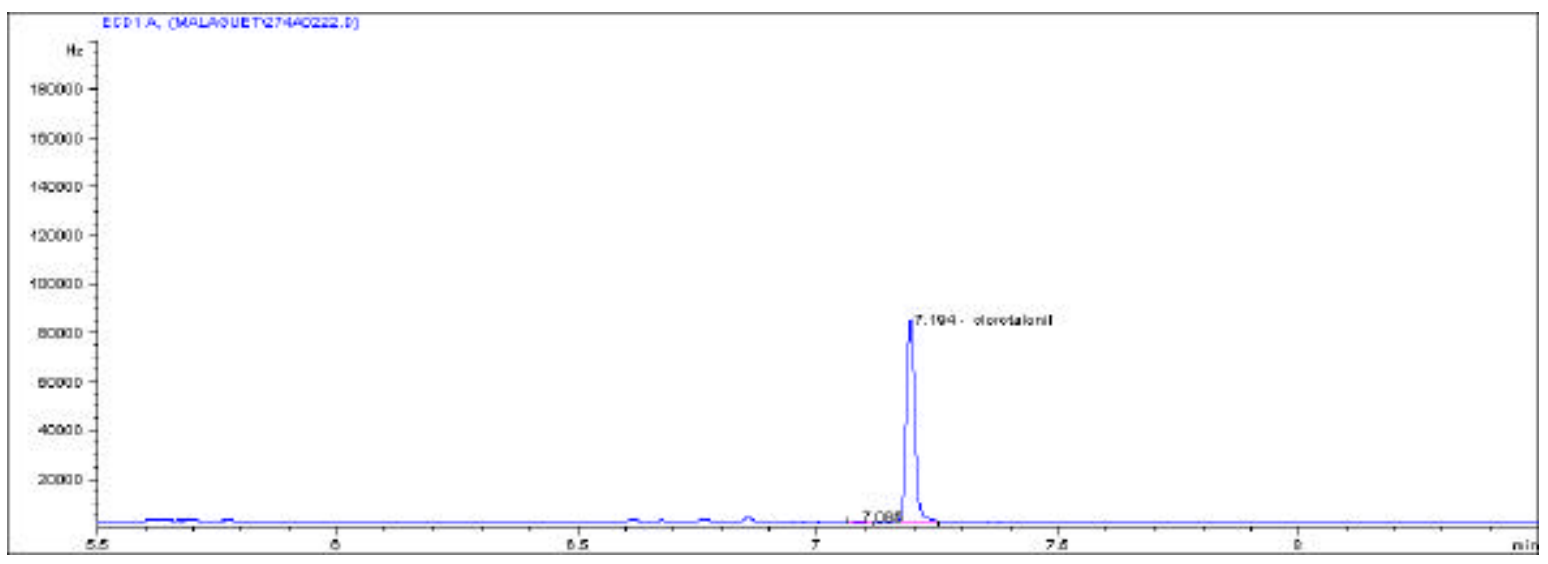

Figura 14 - Cromatograma de amostra tratamento $200 \mathrm{~g}$ i.a..100 $\mathrm{L}^{-1}$ (4 aplicações) clorotalonil, folha estufa. $2 \mu \mathrm{L}-0,1 \mu \mathrm{g}$ 


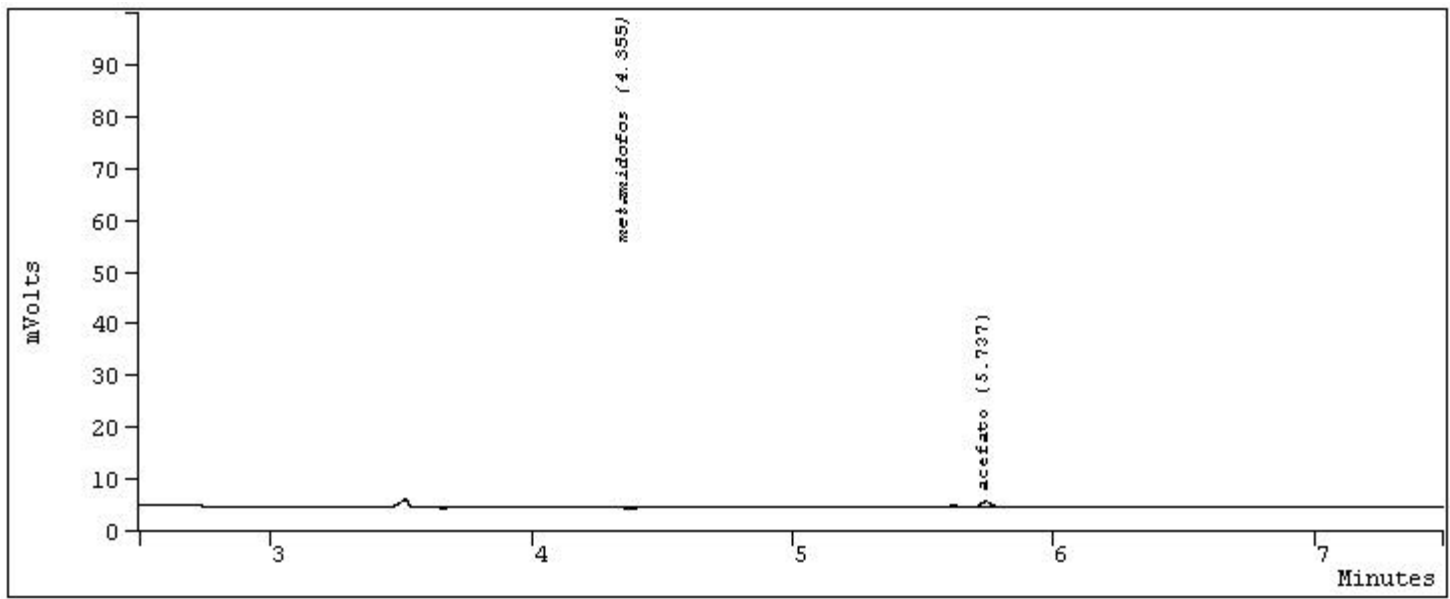

Figura 15 - Cromatograma de amostra testemunha/acefato e metamidofós, solo estufa. $2 \mu \mathrm{L}-5 \mathrm{mg}$

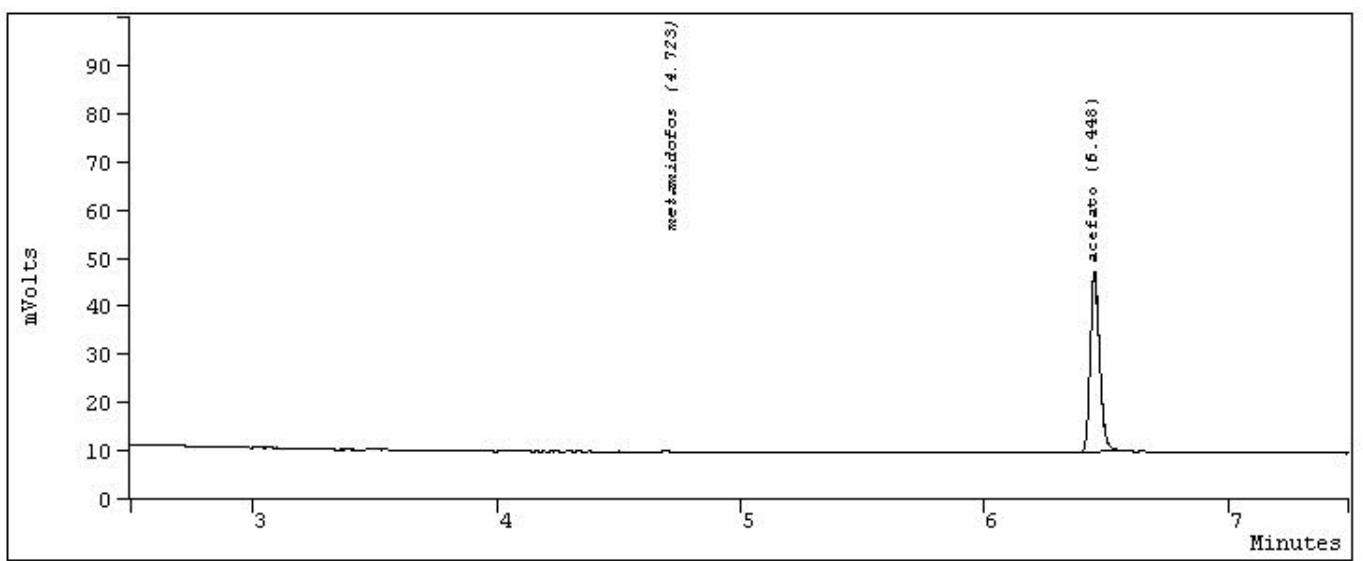

Figura 16 - Cromatograma de amostra tratamento $75 \mathrm{~g}$ i.a.. $100 \mathrm{~L}^{-1}$ (4 aplicações) acefato e metamidofós, solo estufa. $2 \mu \mathrm{L}-5 \mathrm{mg}$ 


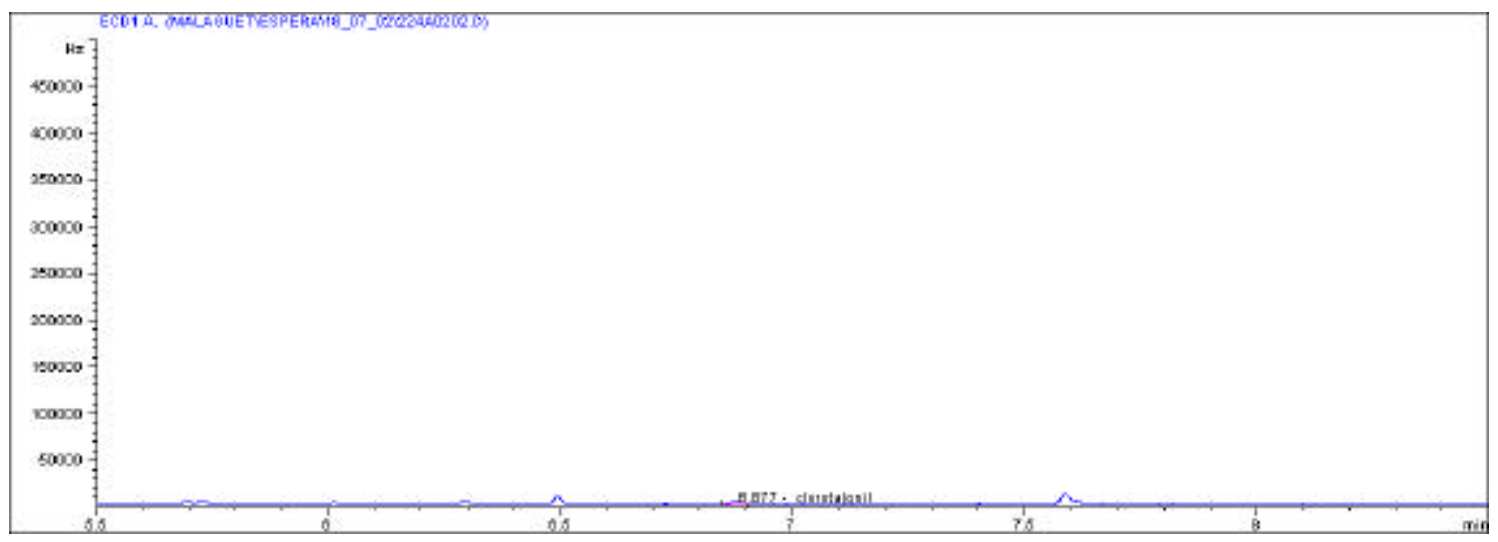

Figura 17 - Cromatograma de amostra testemunha/clorotalonil, solo estufa. $2 \mu \mathrm{L}$ $-0,01 \mathrm{mg}$

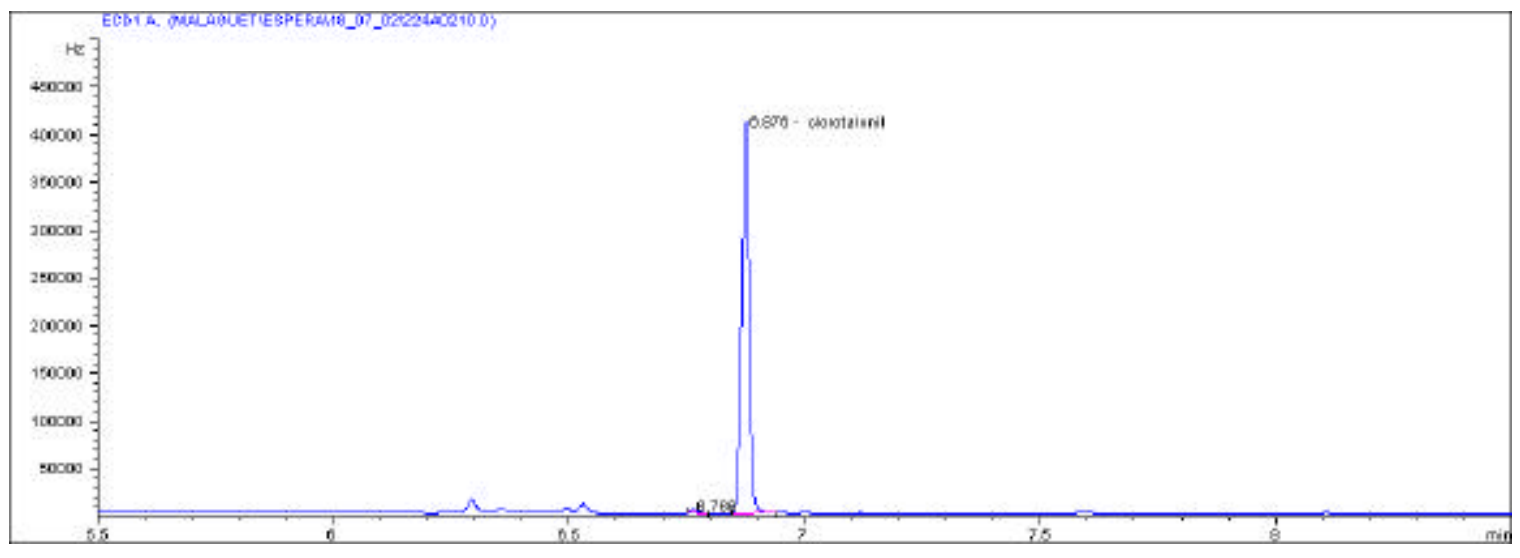

Figura 18 - Cromatograma de amostra tratamento $200 \mathrm{~g}$ i.a..100 $\mathrm{L}^{-1}$ (4 aplicações) clorotalonil, solo estufa. $2 \mu \mathrm{L}-0,01 \mathrm{mg}$ 
Conforme observa-se na Tabela 6 , os resíduos de acefato no fruto estiveram sempre abaixo do $\operatorname{LMR}\left(0,5 \mathrm{mg} \cdot \mathrm{kg}^{-1}, \mathrm{ppm}\right)$ em qualquer dosagem e/ou época de amostragem, inclusive no período de carência (7 dias). Com respeito aos tratamentos de uma só aplicação (75 e $150 \mathrm{~g}$ i.a...100 $\left.\mathrm{L}^{-1}\right)$, verificase que, a velocidade de dissipação na estufa foi cerca de 2 vezes no período de 14 dias em ambos os casos (0,13 - 0,08 e 0,20 - 0,12 mg.kg-1, respectivamente), permanecendo estáveis até 7 dias. Com respeito ao tratamento de 4 aplicações, os dados revelam um efeito de sobreposição das aplicações $\left(0,17 \mathrm{mg} \cdot \mathrm{kg}^{-1}\right.$, amostragem de $\left.-1 \mathrm{dia}\right)$, com acréscimo na tomada de zero dia após a última aplicação, como era de se esperar, degradando-se mais rapidamente $\left(0,31 \mathrm{mg} \cdot \mathrm{kg}^{-1}\right)$ em relação aos tratamentos de uma aplicação citados anteriormente, no que respeita o seu grau de dissipação $(0,31-0,09$ mg. $\mathrm{kg}^{-1}, 3,4$ vezes) no mesmo período. O aumento dos resíduos nas amostras de 7 dias pode ser explicado pela tomada de frutos de posição mais elevada do que no início e, desse modo, constituírem-se em material mais exposto à aplicações, aliado ao fato de que frutos menores como eles possuem maior superfície específica em relação a seu volume, podendo desse modo apresentar maiores resíduos, como de fato aconteceu.

Os dados da Tabela 7 revelam que, mesmo em condições de estufa, o metabolismo de acefato a metamidofós não foi acentuado, e apenas observado nas amostras do tratamento de 4 aplicações, já a partir do dia seguinte após a última aplicação (amostras de 1 dia), permanecendo estáveis até a última colheita $\left(0,09-0,12 \mathrm{mg} \cdot \mathrm{kg}^{-1}\right)$. Tal observação foi também corroborada por Leidy et al. (1978). O fato do metabolismo não ter ocorrido em alto grau é confortador, uma vez que o produto de conversão, metamidofós, é mais tóxico do que o que Ihe deu origem (acefato) (Tomlin, 1995). De qualquer modo, também os resíduos de metamidofós sempre estiveram inferiores ao $\operatorname{LMR}\left(0,3 \mathrm{mg} \cdot \mathrm{kg}^{-1}\right)$, durante todo o período do estudo que abrangeu, inclusive, o período de carência (21 dias). 
Os resíduos de clorotalonil nos frutos mostraram comportamento bem proporcional, de acordo com as doses aplicadas, em todo o período de colheita das amostras, em todos os tratamentos e foram estáveis durante o estudo (Tabela 8). Observação semelhante com esse fungicida foi relatada por Suheri \& Latin (1991), trabalhando com melão e usando Alternaria cucumirina como indicador biológico e a inibição da germinação dos esporos como resposta para avaliação. Os valores dos resíduos de clorotalonil e sua perda, mostraram ser este fungicida mais persistente do que o acefato, comparados os graus de dissipação de ambos: os do fungicida foram muito semelhantes nas amostras de 14 e 21 dias; os do inseticida decresceram a níveis inferiores ao LOQ $(<0,05$ $\mathrm{mg} \cdot \mathrm{kg}^{-1}$ ) ao final do período de tomada das amostras. A explicação pode estar relacionada ao fato de que o acefato é inseticida sistêmico e, dessa maneira, sua dissipação depende quase que exclusivamente de fatores enzimáticos da planta; em referência a clorotalonil, fungicida de contato, este permaneceu protegido das intempéries do tempo, na estufa, e, assim, sua dissipação foi muito restrita. As mesmas considerações aventadas para o aumento dos resíduos de acefato nas amostras de 7 dias valem também para o fungicida.

Nos frutos, os resíduos nas amostras testemunhas, para os 3 analitos estiveram sempre abaixo do LOQ $\left(<0,05 \mathrm{mg} \cdot \mathrm{kg}^{-1}\right)$, o que mostra que as parcelas testemunhas foram muito bem protegidas contra a contaminação cruzada de deriva das aplicações.

Assim como nos frutos, os resíduos de acefato nas folhas mostraramse razoavelmente estáveis nos diversos tratamentos até a colheita de 7 dias (Tabela 9), com valores variando de, na média; cerca de $38-54$ mg. $\mathrm{kg}^{-1}$ (zero dia) e 20 - 42 mg. $\mathrm{kg}^{-1}$ (7 dias), decrescendo mais rapidamente após. Foram, como esperado, muito maiores do que nos frutos, porquanto as folhas achamse mais expostas durante as operações de pulverização(ões), além de terem as folhas superfícies específicas muito maiores do que os frutos. 
Os dados da Tabela 10 revelam que os resíduos de metamidofós foram encontrados também em valores muito maiores do que nos frutos (10 30 vezes, no tratamento com 4 aplicações), sendo encontradas em todas as amostras que receberam aplicação(ões) na estufa e durante todo o período de tomada. Tais resultados acham-se coerentes, não só porque os de acefato nas folhas foram maiores, conforme comentado, mas, também, porque os dados indicam maior atividade de metabolismo nas folhas, atingindo seus maiores valores aos 7 dias e permanecendo estáveis até o final. Isso pode indicar maior potencial de exposição do trabalhador rural quando tem que retornar à estufa $e$ trabalhar em contato com as plantas e suas folhas (para realizar tarefas como amarrá-las nas estacas, etc), embora tais níveis mais elevados sejam desejáveis de um ponto de vista de controle de pragas.

Os resultados com clorotalonil (Tabela 11) mostram que seus resíduos foram encontrados em níveis numericamente bem maiores do que os de acefato e de metamidofós (5 -15 vezes em relação a acefato), especialmente, também, em razão do uso de maior quantidade do ingrediente ativo na calda de pulverização. De qualquer modo, os dados tiveram grande variabilidade, indicando, talvez, necessidade de amostragem de maior quantidade de material.

Também nas folhas, como no caso dos frutos apontado anteriormente, os resíduos nas amostras testemunhas, para os 3 analitos, estiveram sempre abaixo do $L O Q\left(<0,5 \mathrm{mg} \cdot \mathrm{kg}^{-1}\right)$, o que revela estarem as parcelas testemunhas muito bem protegidas contra a contaminação cruzada de deriva das aplicações, o que é, por vezes, de difícil garantia. 
Pelos dados da Tabela 12, observa-se que os resíduos de acefato no solo da estufa estiveram em níveis intermediários entre o fruto e a folha (cerca de 2 - 8 vezes maiores do que no fruto) e que foram quase sempre mais altos nas amostras de 3 dias, permanecendo estáveis a partir de então provavelmente, entre outras causas, como resultado de sua não metabolização a metamidofós. $O$ acréscimo nas amostras de zero para 1 dia observado nos diversos tratamentos ( 3 - 7 vezes) revela que pode ter havido escorrimento da parte aérea para o solo durante o período de 24 horas subseqüentes ì aplicações.

A Tabela 13, mostra que não houve metabolismo de acefato para produzir metamidofós no solo da estufa durante os 21 dias de colheita das amostras, comprovado pelos dados, em todas elas, inferiores ao LOQ do método $\left(<0,05 \mathrm{mg} \cdot \mathrm{kg}^{-1}\right)$.

Com respeito aos resíduos de clorotalonil (Tabela 14), verifica-se que, no solo eles aumentaram bastante na amostragem de 1 dia, (4 - 7 vezes nos tratamentos de aplicação), novamente, talvez devido a escorrimento da calda da saturação da folhagem (zero dia) até a amostragem seguinte (24 horas).

Também as mesmas considerações acerca do bom isolamento das parcelas, assim julgado por resíduos inferiores ao respectivo LOQ dos três analitos $\left(<0,05 \mathrm{mg} \cdot \mathrm{kg}^{-1}\right)$ são também válidas. 


\subsection{Experimento 2 - Campo}

Os resultados acham-se nas Tabelas 15 a 23. Cromatogramas relativos æ̀̀ análises são apresentados nas Figuras 19 a 30. Comparações entre resíduos de acefato, metamidofós e clorotalonil em cultura de estufa e de campo são dispopstas nas Figuras 31 a 37. 
Tabela 15. Resíduos de acefato em tomate (frutos). Experimento 2 (campo), Pereiras-SP (julho-agosto/2002).

\begin{tabular}{|c|c|c|c|c|c|}
\hline \multirow{2}{*}{ Tratamento } & \multirow{2}{*}{ DAT } & \multicolumn{3}{|c|}{ Repetições $\mathrm{mg} \cdot \mathrm{kg}^{-1}(\mathrm{ppm})$} & \multirow{2}{*}{$\begin{array}{c}\mathrm{m} \pm \mathrm{s} \\
\mathrm{mg} \cdot \mathrm{kg}^{-1}(\mathrm{ppm})\end{array}$} \\
\hline & & 1 & 2 & 3 & \\
\hline \multirow{7}{*}{ testemunha } & -1 & $<0,05$ & $<0,05$ & $<0,05$ & $<0,05$ \\
\hline & 0 & $<0,05$ & $<0,05$ & $<0,05$ & $<0,05$ \\
\hline & 1 & $<0,05$ & $<0,05$ & $<0,05$ & $<0,05$ \\
\hline & 3 & $<0,05$ & $<0,05$ & $<0,05$ & $<0,05$ \\
\hline & 7 & $<0,05$ & $<0,05$ & $<0,05$ & $<0,05$ \\
\hline & 14 & $<0,05$ & $<0,05$ & $<0,05$ & $<0,05$ \\
\hline & 21 & $<0,05$ & $<0,05$ & $<0,05$ & $<0,05$ \\
\hline \multirow{7}{*}{$\begin{array}{l}75 \mathrm{~g} \text { i.a. } / 100 \mathrm{~L}^{-1} \\
1 \text { aplicação }\end{array}$} & -1 & $<0,05$ & $<0,05$ & $<0,05$ & $<0,05$ \\
\hline & 0 & 0,09 & 0,12 & 0,14 & $0,12 \pm 0,03$ \\
\hline & 1 & 0,08 & $<0,05$ & 0,12 & $0,10 \pm 0,03$ \\
\hline & 3 & 0,12 & 0,11 & 0,1 & $0,11 \pm 0,01$ \\
\hline & 7 & 0,06 & 0,06 & $<0,05$ & $0,3 \pm 0,2$ \\
\hline & 14 & 0,14 & 0,12 & $<0,05$ & $0,13 \pm 0,01$ \\
\hline & 21 & $<0,05$ & $<0,05$ & $<0,05$ & $<0,05$ \\
\hline \multirow{7}{*}{$\begin{array}{l}150 \text { g i.a. } / 100 \mathrm{~L}^{-1} \\
1 \text { aplicação }\end{array}$} & -1 & $<0,05$ & $<0,05$ & $<0,05$ & $<0,05$ \\
\hline & 0 & 0,28 & 0,22 & 0,39 & $0,30 \pm 0,09$ \\
\hline & 1 & 0,15 & 0,07 & 0,07 & $0,10 \pm 0,05$ \\
\hline & 3 & 0,11 & 0,12 & 0,17 & $0,13 \pm 0,03$ \\
\hline & 7 & $<0,05$ & 0,11 & 0,16 & $0,3 \pm 0,04$ \\
\hline & 14 & 0,1 & 0,08 & 0,05 & $0,2 \pm 0,02$ \\
\hline & 21 & $<0,05$ & 0,08 & 0,05 & $0,07 \pm 0,02$ \\
\hline \multirow{7}{*}{$\begin{array}{l}75 \mathrm{~g} \text { i.a. } / 100 \mathrm{~L}^{-1} \\
4 \text { aplicações }\end{array}$} & -1 & $<0,05$ & $<0,05$ & $<0,05$ & $<0,05$ \\
\hline & 0 & 0,19 & 0,2 & 0,42 & $0,27 \pm 0,13$ \\
\hline & 1 & 0,23 & 0,12 & 0,26 & $0,20 \pm 0,07$ \\
\hline & 3 & 0,24 & 0,24 & 0,2 & $0,23 \pm 0,02$ \\
\hline & 7 & 0,16 & 0,14 & 0,2 & $0,4 \pm 0,01$ \\
\hline & 14 & 0,23 & 0,14 & 0,19 & $0,3 \pm 0,08$ \\
\hline & 21 & $<0,05$ & 0,14 & 0,19 & $0,17 \pm 0,04$ \\
\hline
\end{tabular}


Tabela 16. Resíduos de metamidofós em tomate (frutos). Experimento 2 (campo), Pereiras-SP (julho-agosto/2002).

\begin{tabular}{|c|c|c|c|c|c|}
\hline \multirow{2}{*}{ Tratamento } & \multirow{2}{*}{ DAT } & \multicolumn{3}{|c|}{ Repetições mg.kg ${ }^{-1}$ (ppm) } & \multirow{2}{*}{$\begin{array}{c}\mathrm{m} \pm \mathrm{s} \\
\mathrm{Mg} \cdot \mathrm{kg}^{-1}(\mathrm{ppm})\end{array}$} \\
\hline & & 1 & 2 & 3 & \\
\hline \multirow{7}{*}{ testemunha } & -1 & $<0,05$ & $<0,05$ & $<0,05$ & $<0,05$ \\
\hline & 0 & $<0,05$ & $<0,05$ & $<0,05$ & $<0,05$ \\
\hline & 1 & $<0,05$ & $<0,05$ & $<0,05$ & $<0,05$ \\
\hline & 3 & $<0,05$ & $<0,05$ & $<0,05$ & $<0,05$ \\
\hline & 7 & $<0,05$ & $<0,05$ & $<0,05$ & $<0,05$ \\
\hline & 14 & $<0,05$ & $<0,05$ & $<0,05$ & $<0,05$ \\
\hline & 21 & $<0,05$ & $<0,05$ & $<0,05$ & $<0,05$ \\
\hline \multirow{7}{*}{$\begin{array}{l}75 \text { g i.a. (acefato) / } \\
100 \text { L }^{-1} 1 \text { aplicação }\end{array}$} & -1 & $<0,05$ & $<0,05$ & $<0,05$ & $<0,05$ \\
\hline & 0 & $<0,05$ & $<0,05$ & $<0,05$ & $<0,05$ \\
\hline & 1 & $<0,05$ & $<0,05$ & $<0,05$ & $<0,05$ \\
\hline & 3 & $<0,05$ & $<0,05$ & $<0,05$ & $<0,05$ \\
\hline & 7 & $<0,05$ & $<0,05$ & $<0,05$ & $<0,05$ \\
\hline & 14 & $<0,05$ & $<0,05$ & $<0,05$ & $<0,05$ \\
\hline & 21 & $<0,05$ & $<0,05$ & $<0,05$ & $<0,05$ \\
\hline \multirow{7}{*}{$\begin{array}{l}150 \text { g i.a. (acefato) / } \\
100 \text { L }^{-1} 1 \text { aplicação }\end{array}$} & -1 & $<0,05$ & $<0,05$ & $<0,05$ & $<0,05$ \\
\hline & 0 & $<0,05$ & $<0,05$ & 0,05 & $<0,05$ \\
\hline & 1 & $<0,05$ & $<0,05$ & $<0,05$ & $<0,05$ \\
\hline & 3 & 0,05 & $<0,05$ & 0,05 & $<0,05$ \\
\hline & 7 & $<0,05$ & $<0,05$ & $<0,05$ & $<0,05$ \\
\hline & 14 & $<0,05$ & 0,05 & 0,05 & $<0,05$ \\
\hline & 21 & $<0,05$ & $<0,05$ & $<0,05$ & $<0,05$ \\
\hline \multirow{7}{*}{$\begin{array}{l}75 \text { g i.a. (acefato) / } \\
100 \mathrm{~L}^{-1} 4 \text { aplicações }\end{array}$} & -1 & $<0,05$ & $<0,05$ & $<0,05$ & $<0,05$ \\
\hline & 0 & $<0,05$ & $<0,05$ & 0,09 & $<0,05$ \\
\hline & 1 & $<0,05$ & $<0,05$ & $<0,05$ & $<0,05$ \\
\hline & 3 & 0,09 & 0,11 & 0,13 & $0,11 \pm 0,02$ \\
\hline & 7 & $<0,05$ & $<0,05$ & $<0,05$ & $<\overline{0,05}$ \\
\hline & 14 & $<0,05$ & 0,06 & 0,08 & $<0,05$ \\
\hline & 21 & $<0,05$ & 0,06 & 0,08 & $<0,05$ \\
\hline
\end{tabular}


Tabela 17. Resíduos de clorotalonil em tomate (frutos). Experimento 2 (campo), Pereiras-SP (julho-agosto/2002).

\begin{tabular}{|c|c|c|c|c|c|}
\hline \multirow{2}{*}{ Tratamento } & \multirow{2}{*}{ DAT } & \multicolumn{3}{|c|}{ Repetições $\mathrm{mg} \mathrm{kg}^{-1}(\mathrm{ppm})$} & \multirow{2}{*}{$\begin{array}{c}\mathrm{m} \pm \mathrm{s} \\
\mathrm{mg} \cdot \mathrm{kg}^{-1}(\mathrm{ppm})\end{array}$} \\
\hline & & 1 & 2 & 3 & \\
\hline \multirow{7}{*}{ testemunha } & -1 & $<0,05$ & $<0,05$ & $<0,05$ & $<0,05$ \\
\hline & 0 & $<0,05$ & $<0,05$ & $<0,05$ & $<0,05$ \\
\hline & 1 & $<0,05$ & $<0,05$ & $<0,05$ & $<0,05$ \\
\hline & 3 & $<0,05$ & $<0,05$ & $<0,05$ & $<0,05$ \\
\hline & 7 & $<0,05$ & $<0,05$ & $<0,05$ & $<0,05$ \\
\hline & 14 & $<0,05$ & $<0,05$ & $<0,05$ & $<0,05$ \\
\hline & 21 & $<0,05$ & $<0,05$ & $<0,05$ & $<0,05$ \\
\hline \multirow{7}{*}{$\begin{array}{l}200 \text { g i.a. } / 100 \mathrm{~L}^{-1} \\
1 \text { aplicação }\end{array}$} & -1 & $<0,05$ & $<0,05$ & $<0,05$ & $<0,05$ \\
\hline & 0 & 0,09 & 0,15 & 0,07 & $0,10 \pm 0,04$ \\
\hline & 1 & 0,1 & 0,12 & 0,24 & $0,15 \pm 0,08$ \\
\hline & 3 & 0,1 & 0,22 & 0,14 & $0,15 \pm 0,06$ \\
\hline & 7 & 0,16 & 0,22 & 0,17 & $0,18 \pm 0,03$ \\
\hline & 14 & 0,05 & 0,05 & 0,06 & $0,05 \pm 0,01$ \\
\hline & 21 & 0,05 & 0,06 & 0,06 & $0,06 \pm 0,01$ \\
\hline \multirow{7}{*}{$\begin{array}{l}400 \text { g i.a. } / 100 \mathrm{~L}^{-1} \\
1 \text { aplicação }\end{array}$} & -1 & $<0,05$ & $<0,05$ & $<0,05$ & $<0,05$ \\
\hline & 0 & 0,09 & 0,38 & 0,13 & $0,20 \pm 0,16$ \\
\hline & 1 & 0,34 & 0,1 & 0,65 & $0,36 \pm 0,28$ \\
\hline & 3 & 0,32 & 0,38 & 0,2 & $0,30 \pm 0,09$ \\
\hline & 7 & 0,32 & 0,34 & 0,61 & $0,42 \pm 0,16$ \\
\hline & 14 & 0,05 & 0,11 & 0,2 & $0,12 \pm 0,08$ \\
\hline & 21 & 0,12 & 0,14 & 0,17 & $0,14 \pm 0,03$ \\
\hline \multirow{7}{*}{$\begin{array}{l}200 \text { g i.a. } / 100 \mathrm{~L}^{-1} \\
4 \text { aplicações }\end{array}$} & -1 & 0,2 & 0,14 & 0,09 & $0,14 \pm 0,06$ \\
\hline & 0 & 0,32 & 0,29 & 0,5 & $0,37 \pm 0,11$ \\
\hline & 1 & 0,63 & 0,7 & 0,31 & $0,55 \pm 0,21$ \\
\hline & 3 & 0,41 & 0,35 & 0,61 & $0,46 \pm 0,14$ \\
\hline & 7 & 0,28 & 0,33 & 0,32 & $0,31 \pm 0,03$ \\
\hline & 14 & 0,05 & 0,21 & 0,32 & $0,19 \pm 0,14$ \\
\hline & 21 & 0,32 & 0,27 & 0,2 & $0,26 \pm 0,06$ \\
\hline
\end{tabular}


Tabela 18. Resíduos de acefato em folhas de tomateiro. Experimento 2 (campo), Pereiras-SP (julho-agosto/2002).

\begin{tabular}{|c|c|c|c|c|c|}
\hline \multirow{2}{*}{ Tratamento } & \multirow{2}{*}{ DAT } & \multicolumn{3}{|c|}{ Repetições $\mathrm{mg} \mathrm{kg}^{-1}(\mathrm{ppm})$} & \multirow{2}{*}{$\begin{array}{c}\mathrm{m} \pm \mathrm{s} \\
\mathrm{mg} \cdot \mathrm{kg}^{-1}(\mathrm{ppm})\end{array}$} \\
\hline & & 1 & 2 & 3 & \\
\hline \multirow{7}{*}{ testemunha } & -1 & $<0,5$ & $<0,5$ & $<0,5$ & $<0,5$ \\
\hline & 0 & $<0,5$ & $<0,5$ & $<0,5$ & $<0,5$ \\
\hline & 1 & $<0,5$ & $<0,5$ & $<0,5$ & $<0,5$ \\
\hline & 3 & $<0,5$ & $<0,5$ & $<0,5$ & $<0,5$ \\
\hline & 7 & $<0,5$ & $<0,5$ & $<0,5$ & $<0,5$ \\
\hline & 14 & $<0,5$ & $<0,5$ & $<0,5$ & $<0,5$ \\
\hline & 21 & $<0,5$ & $<0,5$ & $<0,5$ & $<0,5$ \\
\hline \multirow{7}{*}{$\begin{array}{l}75 \mathrm{~g} \text { i.a. } / 100 \mathrm{~L}^{-1} \\
1 \text { aplicação }\end{array}$} & -1 & $<0,5$ & $<0,5$ & $<0,5$ & $<0,5$ \\
\hline & 0 & 15 & 21 & 7,0 & \multirow{2}{*}{$\begin{array}{l}14 \pm 7,0 \\
11 \pm 1,8\end{array}$} \\
\hline & 1 & 13 & 12 & 9,6 & \\
\hline & 3 & 7,5 & 5,6 & 6,1 & $6,4 \pm 1,0$ \\
\hline & 7 & 4,1 & 4,0 & 3,2 & $3,8 \pm 0,52$ \\
\hline & 14 & 0,86 & 0,88 & 1,0 & $0,91 \pm 0,08$ \\
\hline & 21 & 1,4 & 1,2 & 0,80 & $1,1 \pm 0,30$ \\
\hline & -1 & $<0,5$ & $<0,5$ & $<0,5$ & $<0,5$ \\
\hline & 0 & 36 & 19 & 17 & $24 \pm 10$ \\
\hline & 1 & 21 & 25 & 27 & $24 \pm 2,8$ \\
\hline 150 g i.a. / $100 \mathrm{~L}^{-1}$ & 3 & 12 & 12 & 13 & $12 \pm 0,83$ \\
\hline 1 aplicação & 7 & 11 & 8,6 & 10 & $10 \pm 1,1$ \\
\hline & 14 & 1,9 & 2,0 & 2,0 & $1,9 \pm 0,07$ \\
\hline & 21 & 2,4 & 2,3 & 1,5 & $2,1 \pm 0,50$ \\
\hline \multirow{7}{*}{$\begin{array}{l}75 \mathrm{~g} \text { i.a. } / 100 \mathrm{~L}^{-1} \\
4 \text { aplicações }\end{array}$} & -1 & 17 & 21 & 29 & $22 \pm 6,2$ \\
\hline & 0 & 22 & 35 & 28 & $28 \pm 6,5$ \\
\hline & 1 & 43 & 28 & 50 & $40 \pm 11$ \\
\hline & 3 & 18 & 25 & 28 & $23 \pm 5,1$ \\
\hline & 7 & 16 & 16 & 12 & $14 \pm 2,5$ \\
\hline & 14 & 3,8 & 3,6 & 5,5 & $4,3 \pm 1,0$ \\
\hline & 21 & 4,9 & 5,6 & 7,5 & $6,0 \pm 1,3$ \\
\hline
\end{tabular}


Tabela 19. Resíduos de metamidofós em folhas de tomateiro. Experimento 2 (campo), Pereiras-SP (julho-agosto/2002).

\begin{tabular}{|c|c|c|c|c|c|}
\hline \multirow{2}{*}{ Tratamento } & \multirow{2}{*}{ DAT } & \multicolumn{3}{|c|}{ Repetições $\mathrm{mg} \cdot \mathrm{kg}^{-1}(\mathrm{ppm})$} & \multirow{2}{*}{$\begin{array}{c}\mathrm{m} \pm \mathrm{s} \\
\mathrm{mg} \cdot \mathrm{kg}^{-1}(\mathrm{ppm})\end{array}$} \\
\hline & & 1 & 2 & 3 & \\
\hline \multirow{7}{*}{ Testemunha } & -1 & $<0,5$ & $<0,5$ & $<0,5$ & $<0,5$ \\
\hline & 0 & $<0,5$ & $<0,5$ & $<0,5$ & $<0,5$ \\
\hline & 1 & $<0,5$ & $<0,5$ & $<0,5$ & $<0,5$ \\
\hline & 3 & $<0,5$ & $<0,5$ & $<0,5$ & $<0,5$ \\
\hline & 7 & $<0,5$ & $<0,5$ & $<0,5$ & $<0,5$ \\
\hline & 14 & $<0,5$ & $<0,5$ & $<0,5$ & $<0,5$ \\
\hline & 21 & $<0,5$ & $<0,5$ & $<0,5$ & $<0,5$ \\
\hline \multirow{7}{*}{$\begin{array}{l}75 \text { g i.a. (acefato) / } \\
100 \mathrm{~L}^{-1} 1 \text { aplicação }\end{array}$} & -1 & $<0,5$ & $<0,5$ & $<0,5$ & $<0,5$ \\
\hline & 0 & 0,67 & 0,79 & 0,4 & $0,62 \pm 0,20$ \\
\hline & 1 & 0,7 & 0,69 & 0,68 & $0,69 \pm 0,01$ \\
\hline & 3 & 0,66 & 0,47 & 0,49 & $0,54 \pm 0,1$ \\
\hline & 7 & 0,76 & 0,68 & 0,61 & $0,7 \pm 0,08$ \\
\hline & 14 & 1 & 0,91 & 0,99 & $1,0 \pm 0,05$ \\
\hline & 21 & $<0,5$ & $<0,5$ & $<0,5$ & $<0,5$ \\
\hline \multirow{7}{*}{$\begin{array}{l}150 \text { g i.a. (acefato) / } \\
100 \mathrm{~L}^{-1} 1 \text { aplicação }\end{array}$} & -1 & $<0,5$ & $<0,5$ & $<0,5$ & $<0,5$ \\
\hline & 0 & 1,43 & 1,01 & 1,07 & $1,2 \pm 0,23$ \\
\hline & 1 & 1,2 & 1,26 & 1,45 & $1,3 \pm 0,13$ \\
\hline & 3 & 0,95 & 0,8 & 1,08 & $0,94 \pm 0,14$ \\
\hline & 7 & 1,11 & 0,97 & 1,18 & $1,1 \pm 0,11$ \\
\hline & 14 & 1,2 & 1,16 & 1,21 & $1,2 \pm 0,03$ \\
\hline & 21 & $<0,5$ & 0,29 & 0,35 & $0,32 \pm 0,04$ \\
\hline \multirow{7}{*}{$\begin{array}{l}75 \mathrm{~g} \text { i.a. (acefato) / } \\
100 \mathrm{~L}^{-1} 4 \text { aplicações }\end{array}$} & -1 & 2,27 & 2,14 & 3,74 & $2,7 \pm 0,89$ \\
\hline & 0 & 2,09 & 2,92 & 2,4 & $2,5 \pm 0,42$ \\
\hline & 1 & 3,77 & 3,3 & 4,99 & $4,0 \pm 0,87$ \\
\hline & 3 & 1,97 & 2,67 & 3 & $2,5 \pm 0,53$ \\
\hline & 7 & 1,71 & 1,93 & 1,52 & $1,7 \pm 0,21$ \\
\hline & 14 & 1,45 & 1,44 & 1,74 & $1,5 \pm 0,17$ \\
\hline & 21 & 0,89 & 0,97 & 0,85 & $0,90 \pm 0,10$ \\
\hline
\end{tabular}


Tabela 20. Resíduos de clorotalonil em folhas de tomateiro. Experimento 2 (campo), Pereiras-SP (julho-agosto/2002).

\begin{tabular}{|c|c|c|c|c|c|}
\hline \multirow{2}{*}{ Tratamento } & \multirow{2}{*}{ DAT } & \multicolumn{3}{|c|}{ Repetições $\mathrm{mg} \mathrm{kg}^{-1}(\mathrm{ppm})$} & \multirow{2}{*}{$\begin{array}{c}\mathrm{m} \pm \mathrm{s} \\
\mathrm{mg} \cdot \mathrm{kg}^{-1}(\mathrm{ppm})\end{array}$} \\
\hline & & 1 & 2 & 3 & \\
\hline \multirow{7}{*}{ Testemunha } & -1 & $<0,5$ & $<0,5$ & $<0,5$ & $<0,5$ \\
\hline & 0 & $<0,5$ & $<0,5$ & $<0,5$ & $<0,5$ \\
\hline & 1 & $<0,5$ & $<0,5$ & $<0,5$ & $<0,5$ \\
\hline & 3 & $<0,5$ & $<0,5$ & $<0,5$ & $<0,5$ \\
\hline & 7 & $<0,5$ & $<0,5$ & $<0,5$ & $<0,5$ \\
\hline & 14 & $<0,5$ & $<0,5$ & $<0,5$ & $<0,5$ \\
\hline & 21 & $<0,5$ & $<0,5$ & $<0,5$ & $<0,5$ \\
\hline \multirow{7}{*}{$\begin{array}{l}200 \text { g i.a. } / 100 \mathrm{~L}^{-1} \\
1 \text { aplicação }\end{array}$} & -1 & $<0,5$ & $<0,5$ & $<0,5$ & $<0,5$ \\
\hline & 0 & 25,6 & 54,9 & 16,4 & $32 \pm 20$ \\
\hline & 1 & 28,0 & 63,8 & 22,4 & $38 \pm 22$ \\
\hline & 3 & 24,4 & 18,6 & 3,5 & $15 \pm 10$ \\
\hline & 7 & 9,2 & 11,4 & 2,4 & $7,7 \pm 4,7$ \\
\hline & 14 & 3,0 & 4,35 & 7,1 & $4,8 \pm 2,08$ \\
\hline & 21 & 1,72 & 1,42 & 1,3 & $1,5 \pm 0,22$ \\
\hline \multirow{7}{*}{$\begin{array}{l}400 \text { g i.a. } / 100 \mathrm{~L}^{-1} \\
1 \text { aplicação }\end{array}$} & -1 & $<0,5$ & $<0,5$ & $<0,5$ & $<0,5$ \\
\hline & 0 & 110 & 36,4 & 39,9 & $62 \pm 41$ \\
\hline & 1 & 119 & 59,6 & 66,6 & $82 \pm 32$ \\
\hline & 3 & 44,8 & 35,3 & 56,1 & $45 \pm 10$ \\
\hline & 7 & 35,3 & 29,5 & 42,8 & $39 \pm 6,7$ \\
\hline & 14 & 10,6 & 9,9 & 11,3 & $10 \pm 0,7$ \\
\hline & 21 & 7,0 & 7,1 & 5,0 & $6,4 \pm 1,2$ \\
\hline \multirow{7}{*}{$\begin{array}{l}200 \text { g i.a. } / 100 \mathrm{~L}^{-1} \\
4 \text { aplicações }\end{array}$} & -1 & 27,6 & 119 & 72,1 & $73 \pm 46$ \\
\hline & 0 & 58,1 & 95,6 & 119 & $91 \pm 31$ \\
\hline & 1 & 128 & 89,0 & 119,8 & $112 \pm 20$ \\
\hline & 3 & 72,3 & 74,2 & 69,7 & $72 \pm 2,2$ \\
\hline & 7 & 64,3 & 59,1 & 28,4 & $50 \pm 19$ \\
\hline & 14 & 19,1 & 14,9 & 25,0 & $19 \pm 5,0$ \\
\hline & 21 & 12,9 & 13,1 & 30,8 & $19 \pm 10$ \\
\hline
\end{tabular}


Tabela 21. Resíduos de acefato em solo cultivado com tomate. Experimento 2 (campo), Pereiras-SP (julho-agosto/2002).

\begin{tabular}{|c|c|c|c|c|c|}
\hline \multirow{2}{*}{ Tratamento } & \multirow{2}{*}{ DAT } & \multicolumn{3}{|c|}{ Repetições $\mathrm{mg} \mathrm{kg}^{-1}(\mathrm{ppm})$} & \multirow{2}{*}{$\begin{array}{c}\mathrm{m} \pm \mathrm{s} \\
\mathrm{mg} \cdot \mathrm{kg}^{-1}(\mathrm{ppm})\end{array}$} \\
\hline & & 1 & 2 & 3 & \\
\hline \multirow{7}{*}{ Testemunha } & -1 & $<0,05$ & $<0,05$ & $<0,05$ & $<0,05$ \\
\hline & 0 & $<0,05$ & $<0,05$ & $<0,05$ & $<0,05$ \\
\hline & 1 & $<0,05$ & $<0,05$ & $<0,05$ & $<0,05$ \\
\hline & 3 & $<0,05$ & $<0,05$ & $<0,05$ & $<0,05$ \\
\hline & 7 & $<0,05$ & $<0,05$ & $<0,05$ & $<0,05$ \\
\hline & 14 & $<0,05$ & $<0,05$ & $<0,05$ & $<0,05$ \\
\hline & 21 & $<0,05$ & $<0,05$ & $<0,05$ & $<0,05$ \\
\hline \multirow{7}{*}{$\begin{array}{l}75 \mathrm{~g} \text { i.a. } / 100 \mathrm{~L}^{-1} \\
1 \text { aplicação }\end{array}$} & -1 & $<0,05$ & $<0,05$ & $<0,05$ & $<0,05$ \\
\hline & 0 & 0,1 & 0,17 & 0,11 & $0,13 \pm 0,04$ \\
\hline & 1 & 0,21 & 0,31 & 0,23 & $0,25 \pm 0,05$ \\
\hline & 3 & $<0,05$ & $<0,05$ & $<0,05$ & $<0,05$ \\
\hline & 7 & 0,37 & 0,27 & 0,29 & $0,31 \pm 0,05$ \\
\hline & 14 & $<0,05$ & $<0,05$ & $<0,05$ & $<0,05$ \\
\hline & 21 & $<0,05$ & $<0,05$ & $<0,05$ & $<0,05$ \\
\hline \multirow{7}{*}{$\begin{array}{l}150 \text { g i.a. / } 100 \mathrm{~L}^{-1} \\
1 \text { aplicação }\end{array}$} & -1 & $<0,05$ & $<0,05$ & $<0,05$ & $<0,05$ \\
\hline & 0 & 0,15 & 0,18 & 0,22 & $0,18 \pm 0,04$ \\
\hline & 1 & 0,14 & 0,31 & 0,11 & $0,19 \pm 0,11$ \\
\hline & 3 & 0,11 & 0,09 & 0,13 & $0,11 \pm 0,02$ \\
\hline & 7 & 0,46 & 0,98 & 0,44 & $0,63 \pm 0,31$ \\
\hline & 14 & $<0,05$ & $<0,05$ & $<0,05$ & $<0,05$ \\
\hline & 21 & $<0,05$ & $<0,05$ & $<0,05$ & $<0,05$ \\
\hline \multirow{7}{*}{$\begin{array}{l}75 \mathrm{~g} \text { i.a. } / 100 \mathrm{~L}^{-1} \\
4 \text { aplicações }\end{array}$} & -1 & 0,36 & 0,04 & 0,09 & $0,16 \pm 0,17$ \\
\hline & 0 & 0,43 & 0,09 & 0,21 & $0,24 \pm 0,17$ \\
\hline & 1 & 0,37 & 0,19 & 0,13 & $0,23 \pm 0,12$ \\
\hline & 3 & 0,14 & 0,25 & 0,15 & $0,18 \pm 0,06$ \\
\hline & 7 & 0,47 & 0,45 & 0,66 & $0,53 \pm 0,12$ \\
\hline & 14 & $<0,05$ & $<0,05$ & $<0,05$ & $<0,05$ \\
\hline & 21 & $<0,05$ & 0,07 & $<0,05$ & $<0,05$ \\
\hline
\end{tabular}


Tabela 22. Resíduos de metamidofós em solo cultivado com tomate. Experimento 2 (campo), Pereiras-SP, julho-agosto/2002).

\begin{tabular}{|c|c|c|c|c|c|}
\hline \multirow{2}{*}{ Tratamento } & \multirow{2}{*}{ DAT } & \multicolumn{3}{|c|}{ Repetições mg.kg ${ }^{-1}$ (ppm) } & \multirow{2}{*}{$\begin{array}{c}\mathrm{m} \pm \mathrm{s} \\
\mathrm{mg} \cdot \mathrm{kg}^{-1}(\mathrm{ppm})\end{array}$} \\
\hline & & 1 & 2 & 3 & \\
\hline \multirow{7}{*}{ testemunha } & -1 & $<0,05$ & $<0,05$ & $<0,05$ & $<0,05$ \\
\hline & 0 & $<0,05$ & $<0,05$ & $<0,05$ & $<0,05$ \\
\hline & 1 & $<0,05$ & $<0,05$ & $<0,05$ & $<0,05$ \\
\hline & 3 & $<0,05$ & $<0,05$ & $<0,05$ & $<0,05$ \\
\hline & 7 & $<0,05$ & $<0,05$ & $<0,05$ & $<0,05$ \\
\hline & 14 & $<0,05$ & $<0,05$ & $<0,05$ & $<0,05$ \\
\hline & 21 & $<0,05$ & $<0,05$ & $<0,05$ & $<0,05$ \\
\hline \multirow{7}{*}{$\begin{array}{l}75 \text { g i.a. (acefato) / } \\
100 \mathrm{~L}^{-1} 1 \text { aplicação }\end{array}$} & -1 & $<0,05$ & $<0,05$ & $<0,05$ & $<0,05$ \\
\hline & 0 & $<0,05$ & $<0,05$ & $<0,05$ & $<0,05$ \\
\hline & 1 & $<0,05$ & $<0,05$ & $<0,05$ & $<0,05$ \\
\hline & 3 & $<0,05$ & $<0,05$ & $<0,05$ & $<0,05$ \\
\hline & 7 & $<0,05$ & $<0,05$ & $<0,05$ & $<0,05$ \\
\hline & 14 & $<0,05$ & $<0,05$ & $<0,05$ & $<0,05$ \\
\hline & 21 & $<0,05$ & $<0,05$ & $<0,05$ & $<0,05$ \\
\hline \multirow{7}{*}{$\begin{array}{l}150 \text { g i.a. (acefato) / } \\
100 L^{-1} 1 \text { aplicação }\end{array}$} & -1 & $<0,05$ & $<0,05$ & $<0,05$ & $<0,05$ \\
\hline & 0 & $<0,05$ & $<0,05$ & $<0,05$ & $<0,05$ \\
\hline & 1 & $<0,05$ & $<0,05$ & $<0,05$ & $<0,05$ \\
\hline & 3 & $<0,05$ & $<0,05$ & $<0,05$ & $<0,05$ \\
\hline & 7 & $<0,05$ & $<0,05$ & $<0,05$ & $<0,05$ \\
\hline & 14 & $<0,05$ & $<0,05$ & $<0,05$ & $<0,05$ \\
\hline & 21 & $<0,05$ & $<0,05$ & $<0,05$ & $<0,05$ \\
\hline \multirow{7}{*}{$\begin{array}{l}75 \text { g i.a. (acefato) / } \\
100 \mathrm{~L}^{-1} 4 \text { aplicações }\end{array}$} & -1 & $<0,05$ & $<0,05$ & $<0,05$ & $<0,05$ \\
\hline & 0 & $<0,05$ & $<0,05$ & $<0,05$ & $<0,05$ \\
\hline & 1 & $<0,05$ & $<0,05$ & $<0,05$ & $<0,05$ \\
\hline & 3 & $<0,05$ & $<0,05$ & $<0,05$ & $<0,05$ \\
\hline & 7 & $<0,05$ & $<0,05$ & $<0,05$ & $<0,05$ \\
\hline & 14 & $<0,05$ & $<0,05$ & $<0,05$ & $<0,05$ \\
\hline & 21 & $<0,05$ & $<0,05$ & $<0,05$ & $<0,05$ \\
\hline
\end{tabular}


Tabela 23. Resíduos de clorotalonil em solo cultivado com tomate. Experimento 2 (campo), Pereiras-SP (julho-agosto/2002).

\begin{tabular}{|c|c|c|c|c|c|}
\hline \multirow{2}{*}{ Tratamento } & \multirow{2}{*}{ DAT } & \multicolumn{3}{|c|}{ Repetições $\mathrm{mg} \mathrm{kg}^{-1}(\mathrm{ppm})$} & \multirow{2}{*}{$\begin{array}{c}\mathrm{m} \pm \mathrm{s} \\
\mathrm{mg} \cdot \mathrm{kg}^{-1}(\mathrm{ppm})\end{array}$} \\
\hline & & 1 & 2 & 3 & \\
\hline \multirow{7}{*}{ testemunha } & -1 & $<0,05$ & $<0,05$ & $<0,05$ & $<0,05$ \\
\hline & 0 & $<0,05$ & $<0,05$ & $<0,05$ & $<0,05$ \\
\hline & 1 & $<0,05$ & $<0,05$ & $<0,05$ & $<0,05$ \\
\hline & 3 & $<0,05$ & $<0,05$ & $<0,05$ & $<0,05$ \\
\hline & 7 & $<0,05$ & $<0,05$ & $<0,05$ & $<0,05$ \\
\hline & 14 & $<0,05$ & $<0,05$ & $<0,05$ & $<0,05$ \\
\hline & 21 & $<0,05$ & $<0,05$ & $<0,05$ & $<0,05$ \\
\hline \multirow{7}{*}{$\begin{array}{l}200 \text { g i.a. } / 100 \mathrm{~L}^{-1} \\
1 \text { aplicação }\end{array}$} & -1 & $<0,05$ & $<0,05$ & $<0,05$ & $<0,05$ \\
\hline & 0 & 1,57 & 3,29 & 2,24 & $2,3 \pm 0,87$ \\
\hline & 1 & 2,46 & 2,23 & 1,75 & $2,1 \pm 0,36$ \\
\hline & 3 & 1,55 & 2,1 & 2,17 & $1,9 \pm 0,34$ \\
\hline & 7 & 2,19 & 2,46 & 2,44 & $2,4 \pm 0,15$ \\
\hline & 14 & 1,06 & 1,47 & 0,73 & $1,1 \pm 0,37$ \\
\hline & 21 & 0,46 & 0,2 & 0,5 & $0,4 \pm 0,16$ \\
\hline \multirow{7}{*}{$\begin{array}{l}400 \text { g i.a. } / 100 \mathrm{~L}^{-1} \\
1 \text { aplicação }\end{array}$} & -1 & $<0,05$ & $<0,05$ & $<0,05$ & $<0,05$ \\
\hline & 0 & 5,4 & 4,22 & 4,08 & $4,5 \pm 0,73$ \\
\hline & 1 & 3,83 & 3,5 & 1,55 & $2,9 \pm 1,2$ \\
\hline & 3 & 4,74 & 4,74 & 3,52 & $4,3 \pm 0,70$ \\
\hline & 7 & 2,72 & 5,6 & 2,56 & $3,6 \pm 1,7$ \\
\hline & 14 & 1,82 & 3,39 & 2,12 & $2,4 \pm 0,83$ \\
\hline & 21 & 4,65 & 3,43 & 3,79 & $3,9 \pm 0,63$ \\
\hline \multirow{7}{*}{$\begin{array}{l}200 \text { g i.a. } / 100 \mathrm{~L}^{-1} \\
4 \text { aplicações }\end{array}$} & -1 & 1,32 & 3,67 & 3,28 & $2,7 \pm 1,2$ \\
\hline & 0 & 6,13 & 7,68 & 6,97 & $6,9 \pm 0,78$ \\
\hline & 1 & 1,78 & 6,8 & 2,28 & $3,6 \pm 2,7$ \\
\hline & 3 & 8,11 & 11,96 & 9,23 & $9,8 \pm 1,9$ \\
\hline & 7 & 8,8 & 4,35 & 7,08 & $6,7 \pm 2,2$ \\
\hline & 14 & 5,95 & 3,78 & 4,5 & $4,7 \pm 1,1$ \\
\hline & 21 & 1,37 & 4,53 & 2,86 & $2,9 \pm 1,5$ \\
\hline
\end{tabular}




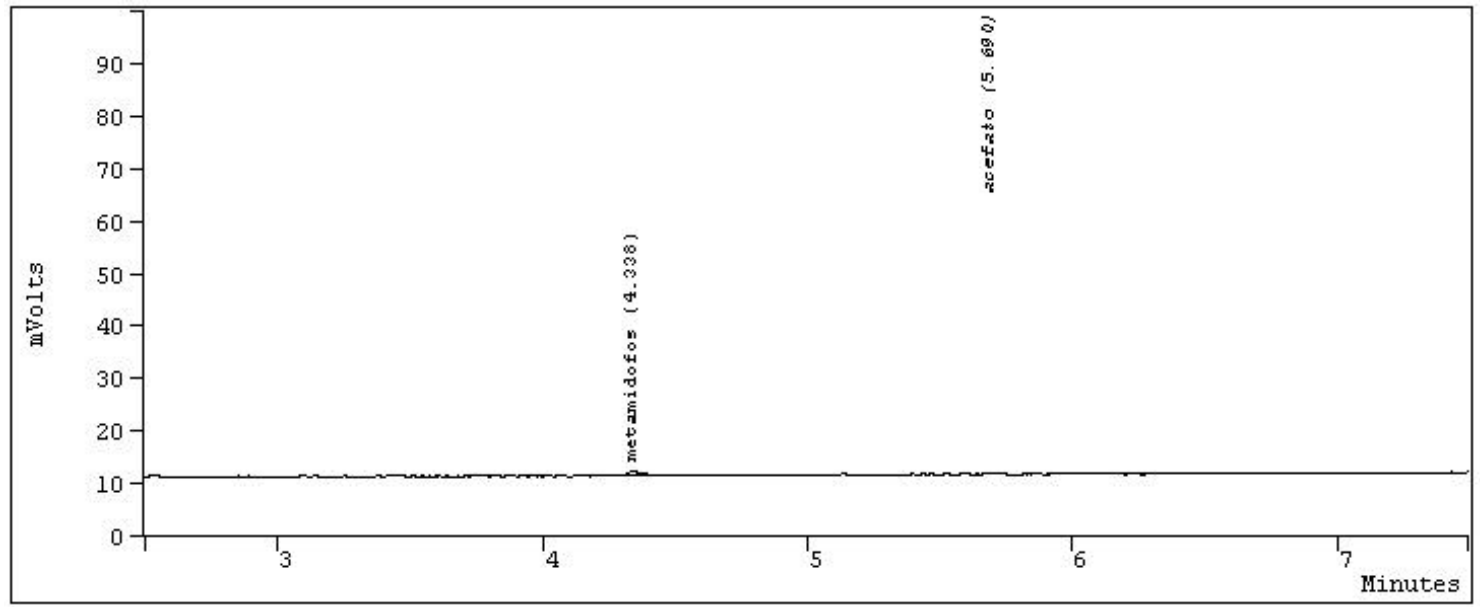

Figura 19 - Cromatograma de amostra testemunha/acefato e metamidofós, tomate campo. $2 \mu \mathrm{L}-1 \mathrm{mg}$

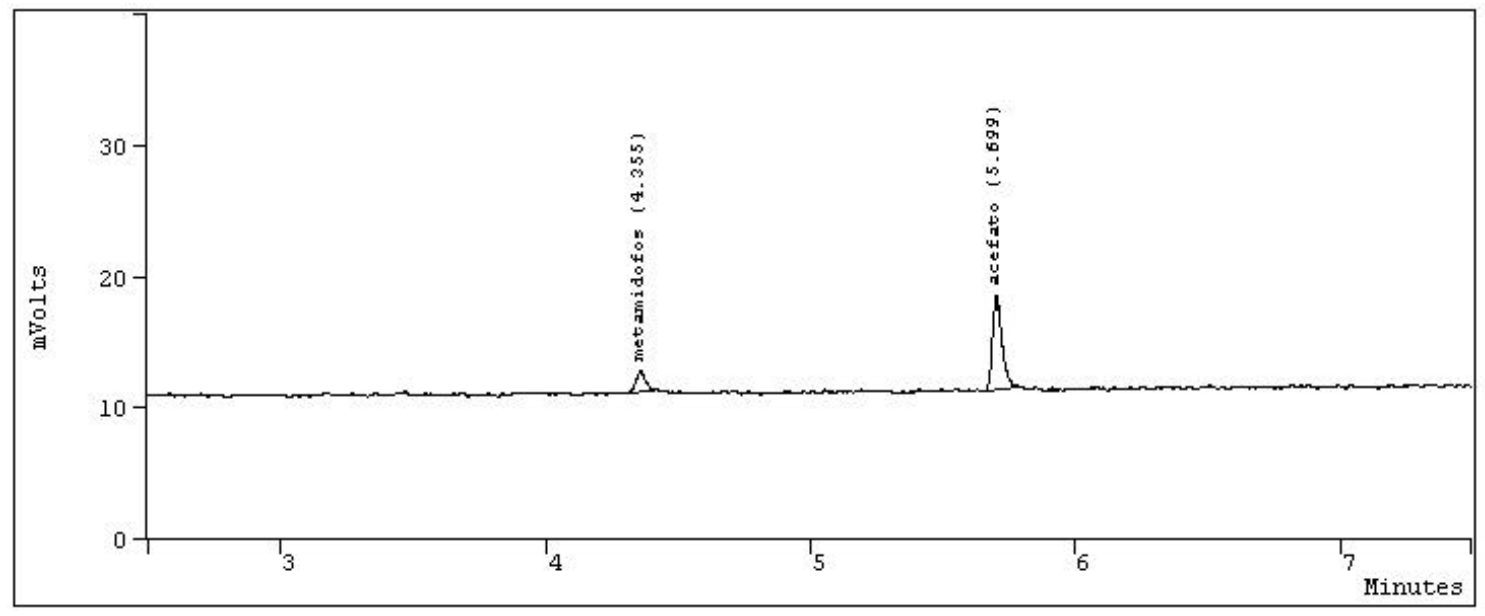

Figura 20-Cromatograma de amostra tratamento $75 \mathrm{~g}$ i.a.. $100 \mathrm{~L}^{-1}$ (4 aplicações) acefato e metamidofós, tomate campo. $2 \mu \mathrm{L}-1 \mathrm{mg}$ 


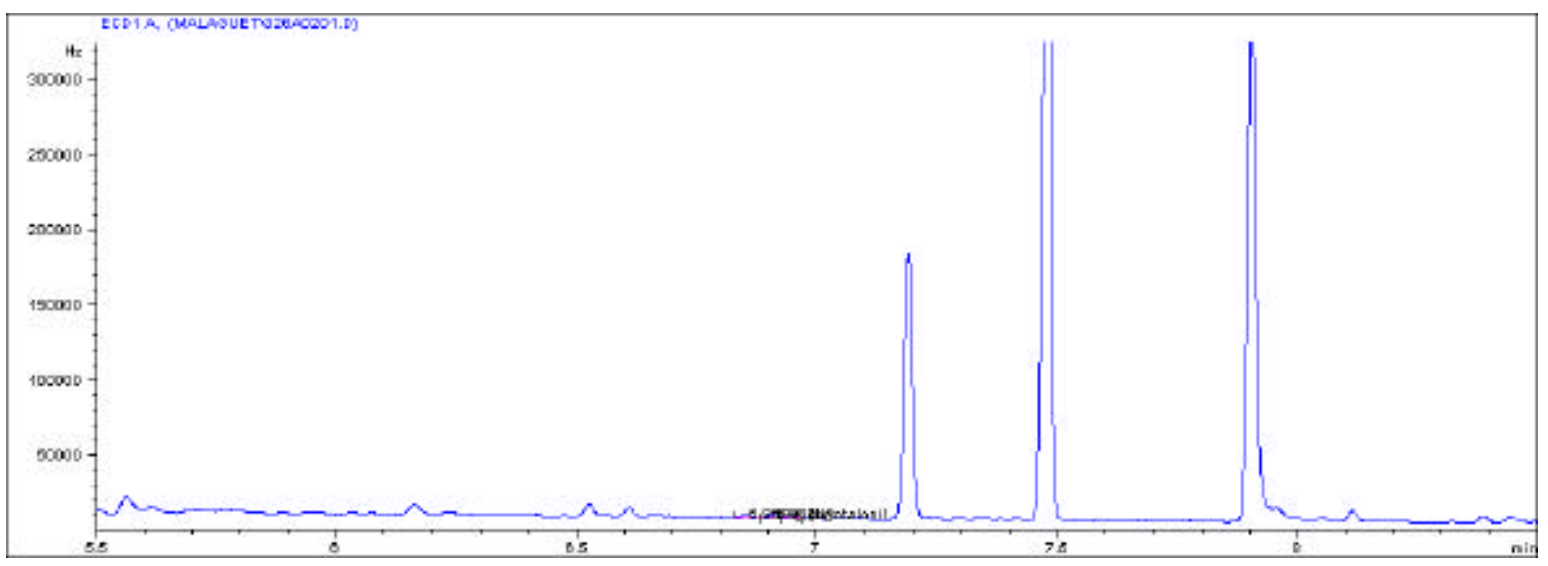

Figura 21 - Cromatograma de amostra testemunha/clorotalonil, tomate campo. 1 $\mu \mathrm{L}-0,5 \mathrm{mg}$

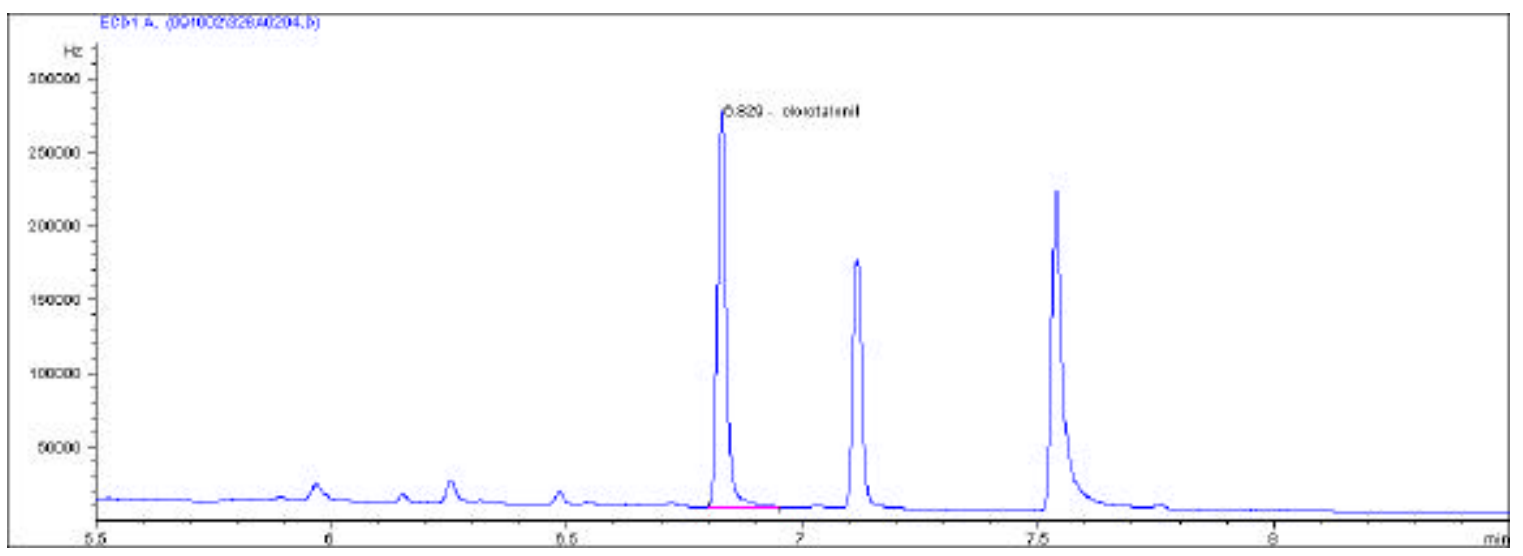

Figura 22 - Cromatograma de amostra tratamento $200 \mathrm{~g}$ i.a.. $100 \mathrm{~L}^{-1}$ (4 aplicações) clorotalonil, tomate campo. $2 \mu \mathrm{L}-0,5 \mathrm{mg}$ 


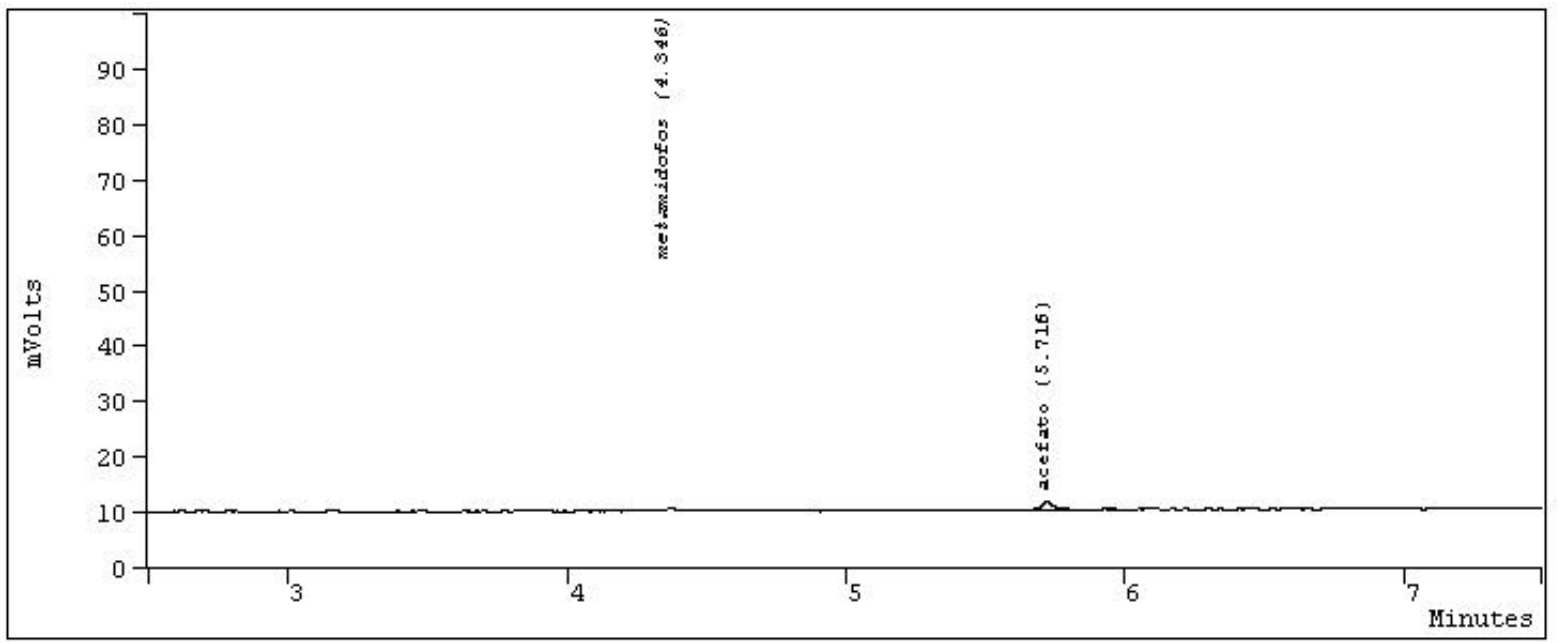

Figura 23 - Cromatograma de amostra testemunha/acefato e metamidofós, folha campo. $2 \mu \mathrm{L}-25 \mu \mathrm{g}$

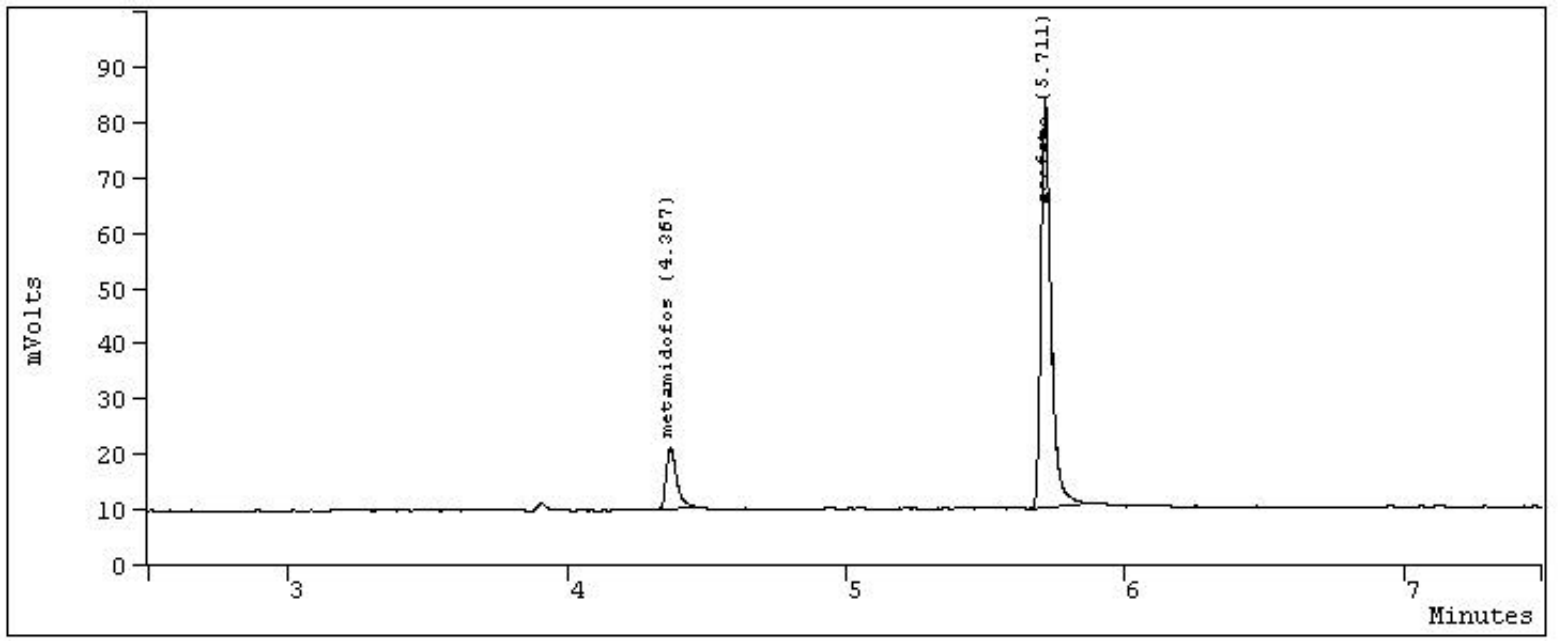

Figura 24 - Cromatograma de amostra tratamento $75 \mathrm{~g}$ i.a..100 $\mathrm{L}^{-1}$ (4 aplicações) acefato e metamidofós, folha campo. $2 \mu \mathrm{L}-25 \mu \mathrm{g}$ 


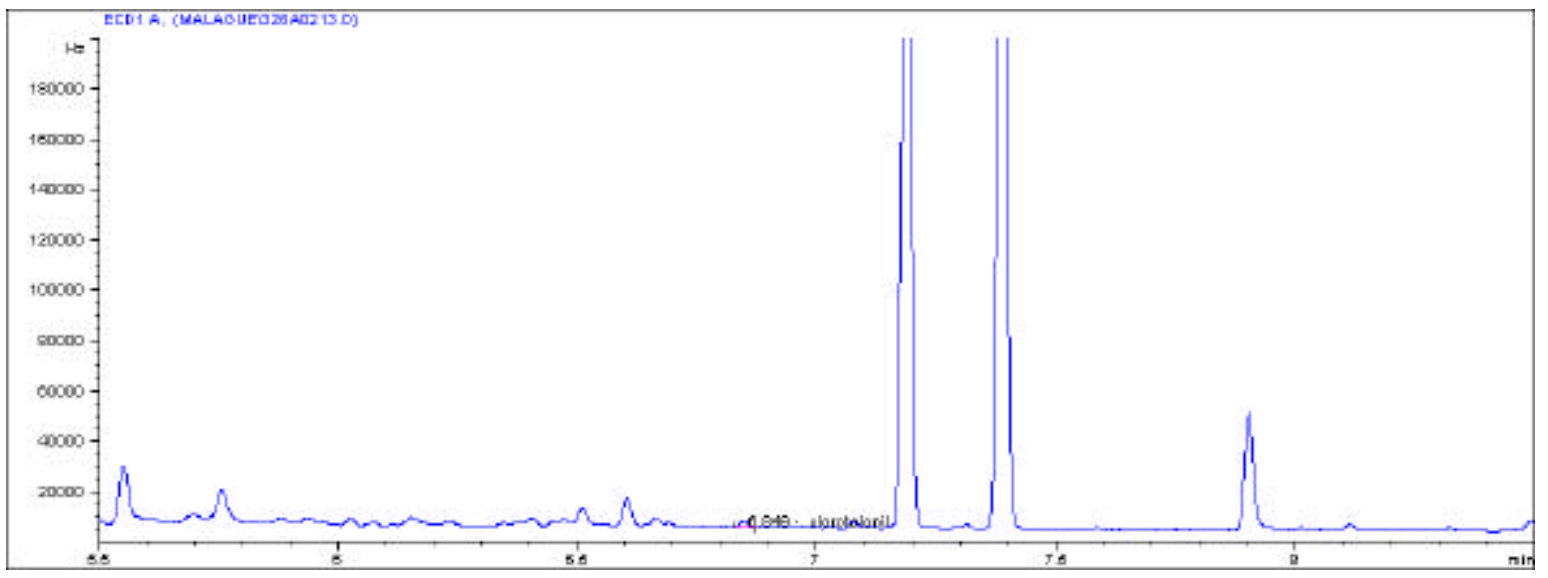

Figura 25 - Cromatograma de amostra testemunha/clorotalonil, folha campo. $2 \mu \mathrm{L}$ $-25 \mu \mathrm{g}$

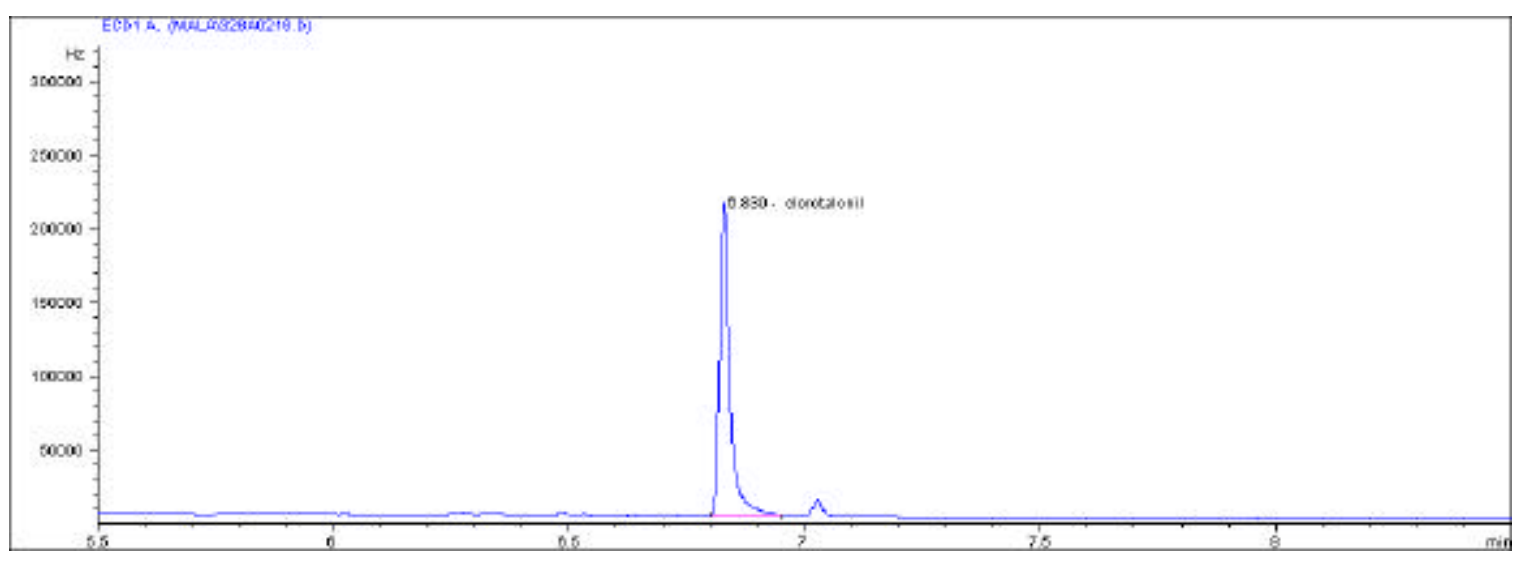

Figura 26 - Cromatograma de amostra tratamento $200 \mathrm{~g}$ i.a.. $100 \mathrm{~L}^{-1}$ (4 aplicações) clorotalonil, folha campo. $2 \mu \mathrm{L}-0,625 \mu \mathrm{g}$ 


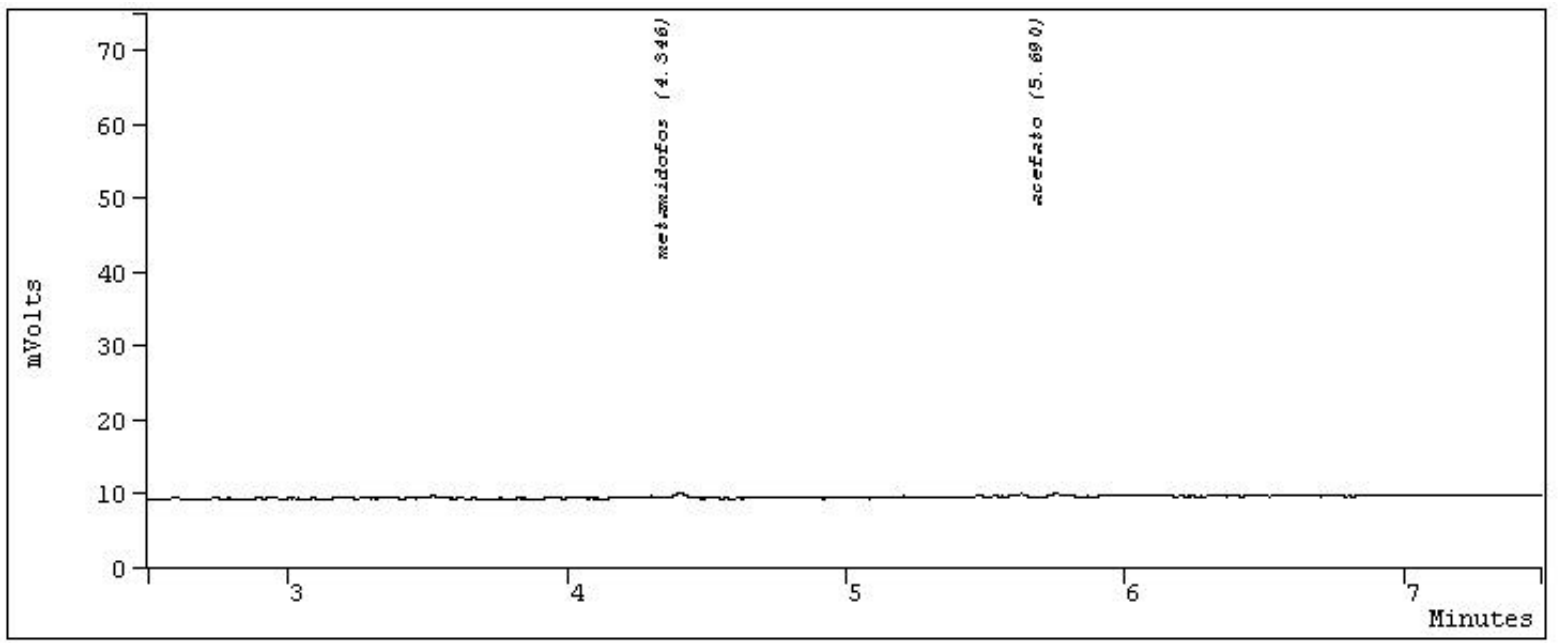

Figura 27 - Cromatograma de amostra testemunha/acefato e metamidofós, solo campo. $2 \mu \mathrm{L}-5 \mathrm{mg}$

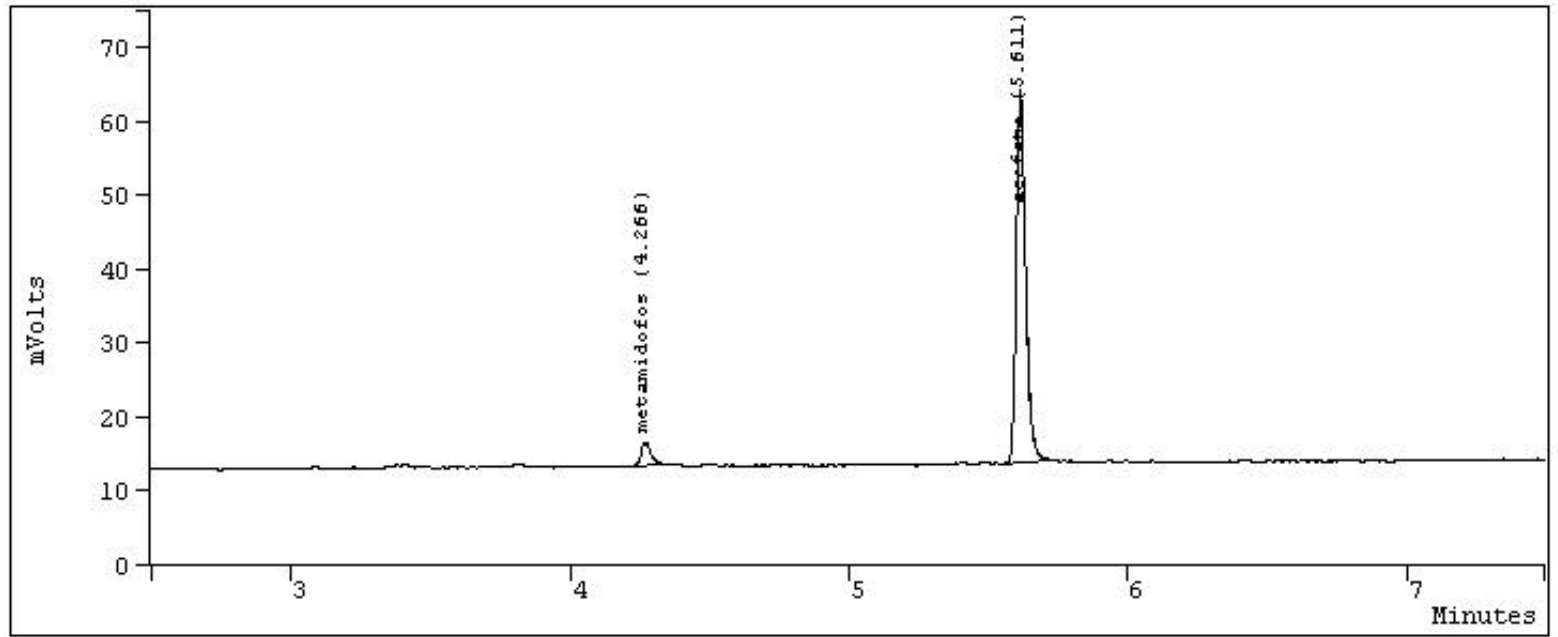

Figura 28 - Cromatograma de amostra tratamento $75 \mathrm{~g}$ i.a..100 $\mathrm{L}^{-1}$ (4 aplicações) acefato e metamidofós, solo campo. $2 \mu \mathrm{L}-5 \mathrm{mg}$ 


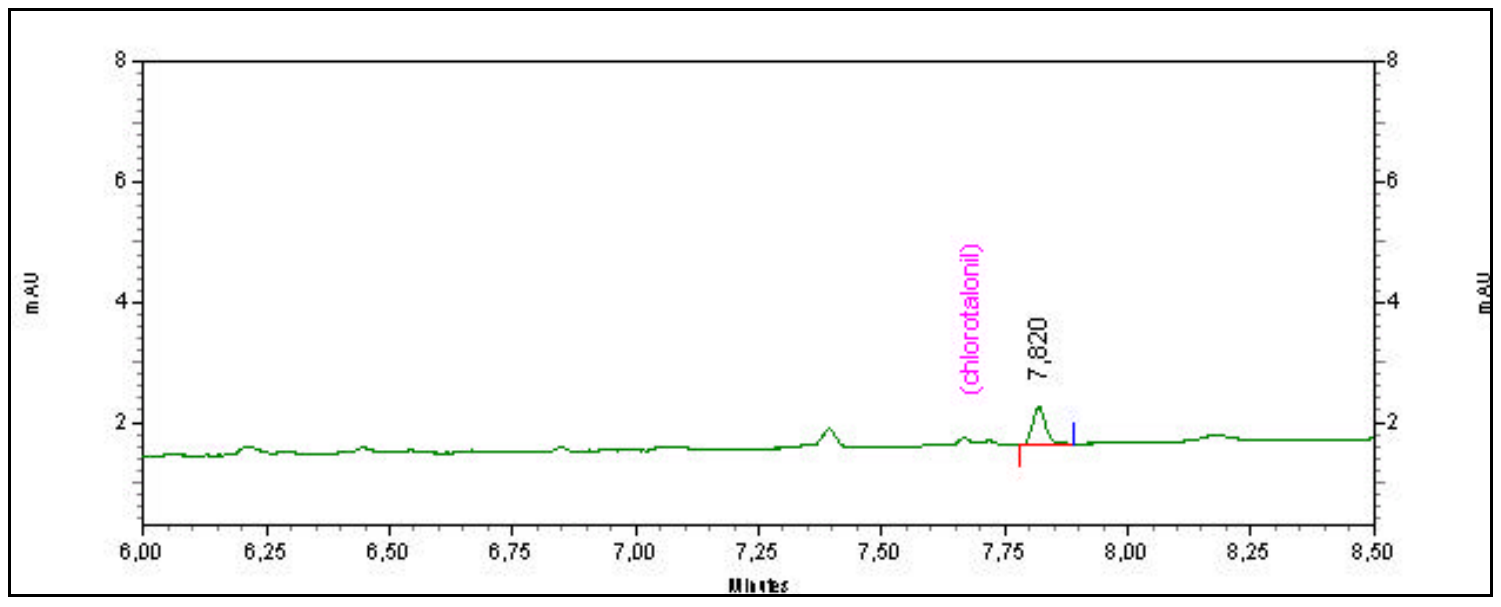

Figura 29 - Cromatograma amostra testemunha/clorotalonil, solo campo. $2 \mu \mathrm{L}-$ $2,5 \mu \mathrm{g}$

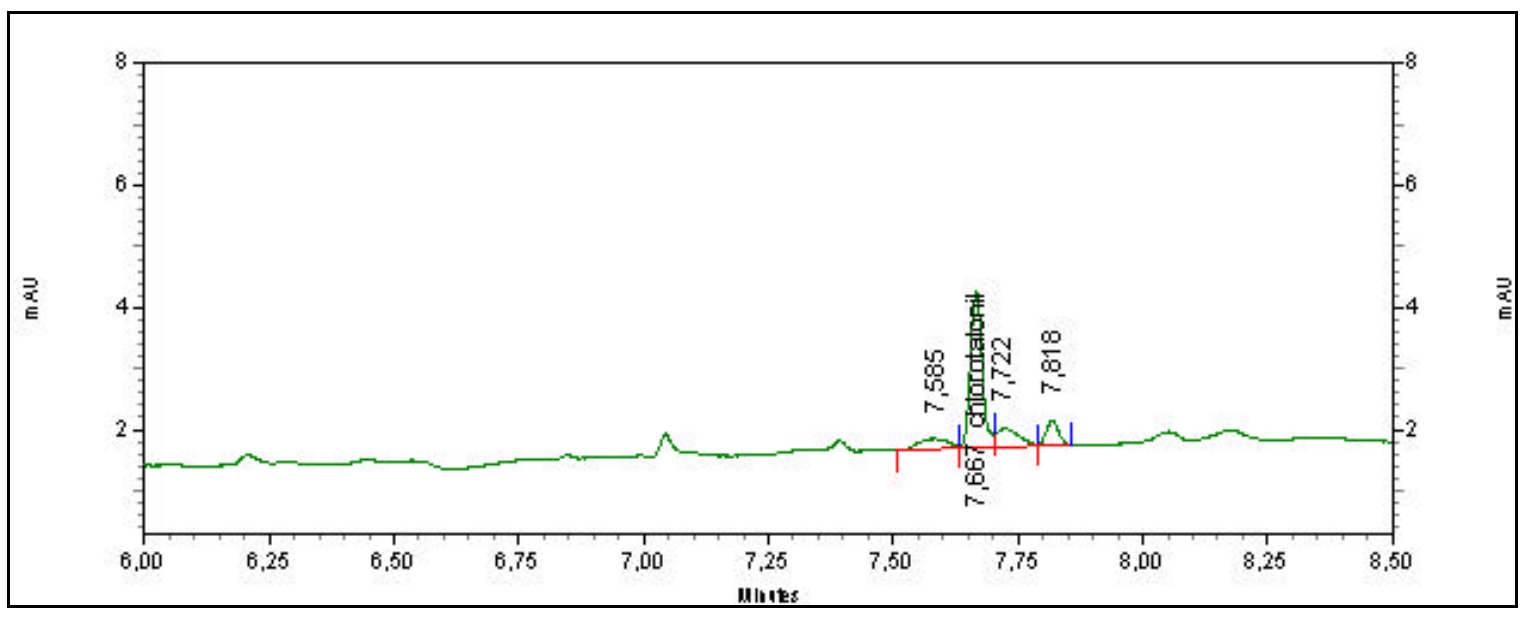

Figura 30 - Cromatograma de amostra tratamento $200 \mathrm{~g}$ i.a..100 $\mathrm{L}^{-1}$ (4 aplicações) clorotalonil, solo campo. $2 \mu \mathrm{L}-2,5 \mu \mathrm{g}$ 
No experimento de campo, nos frutos, foram observados resíduos de acefato que foram persistentes até a colheita das amostras de 14 dias, decrescendo posteriormente (Tabela 15). Verifica-se, ainda, que durante todo 0 período do estudo, os resíduos estiveram abaixo do $\operatorname{LMR}\left(<0,5 \mathrm{mg} \cdot \mathrm{kg}^{-1}\right)$, inclusive no período de carência (7 dias). Conforme pode ser observado, comparando-se os níveis da estufa (Tabela 6) com os de campo, evidencia-se que eles foram em geral semelhantes em todos os tratamentos (Figura 31), quando eram esperados resíduos maiores na estufa. Entretanto, o fato pode ser explicado pela maior relação volume/área do cultivar Caqui (estufa) em comparação com o Angela (campo) o que contribui para a "diluição" dos resíduos, associado com a amostragem insuficientemente adequada para cultura de campo determinada pelo já citado ataque da broca-pequena-dotomate.

Com respeito a metamidofós (Tabela 16), seus resíduos, no campo, foram, quase sempre inferiores ao LOQ (<0,05 mg. $\mathrm{kg}^{-1}$, ppm), sendo encontrados apenas em um único caso (70 g i.a. acefato, 4 aplicações, 3 DAT), com valor médio de $0,11 \mathrm{mg} \cdot \mathrm{kg}^{-1}$, e estiveram sempre abaixo do $\operatorname{LMR}(0,3$ mg. $\mathrm{kg}^{-1}$ ) com resultados muito semelhantes aos seus resíduos na estufa (Tabela 7). Ainda que a produção destes resíduos via metabolismo possa ser alta, ou razoável, o fato de não serem encontrados pode ser sinal de sua rápida dissipação, resultando em menor risco para os trabalhadores rurais, porquanto este é um inseticida mais tóxico do que o acefato que lhe dá origem, conforme já mencionado. Novamente, também em condições de estufa, conforme anteriormente comentado, a ocorrência de resíduos de metamidofós em frutos e especialmente folhas representa risco maior aos trabalhadores em comparação com o campo. 


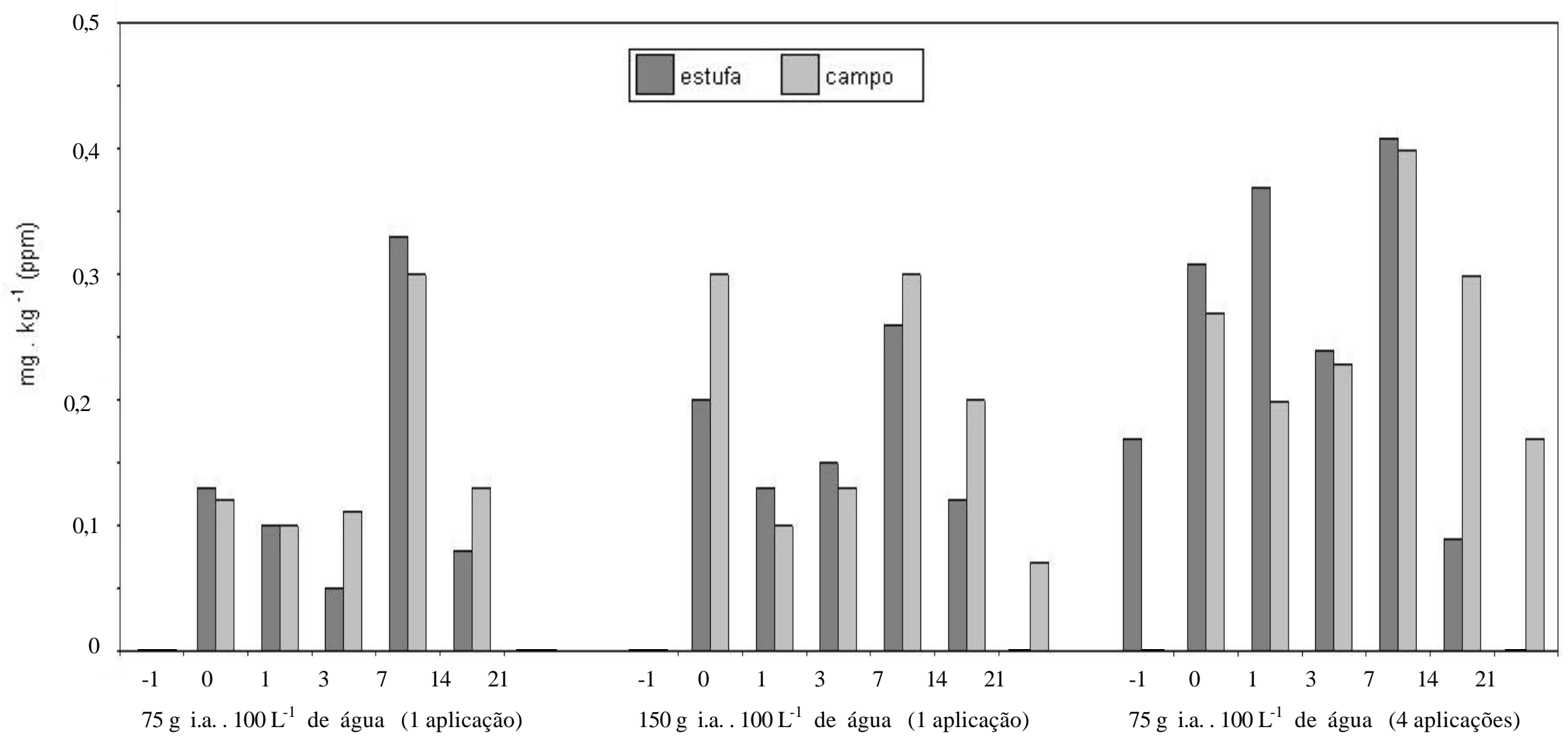

Figura 31 - Resíduos de acefato em fruto em cultura de estufa e de campo 


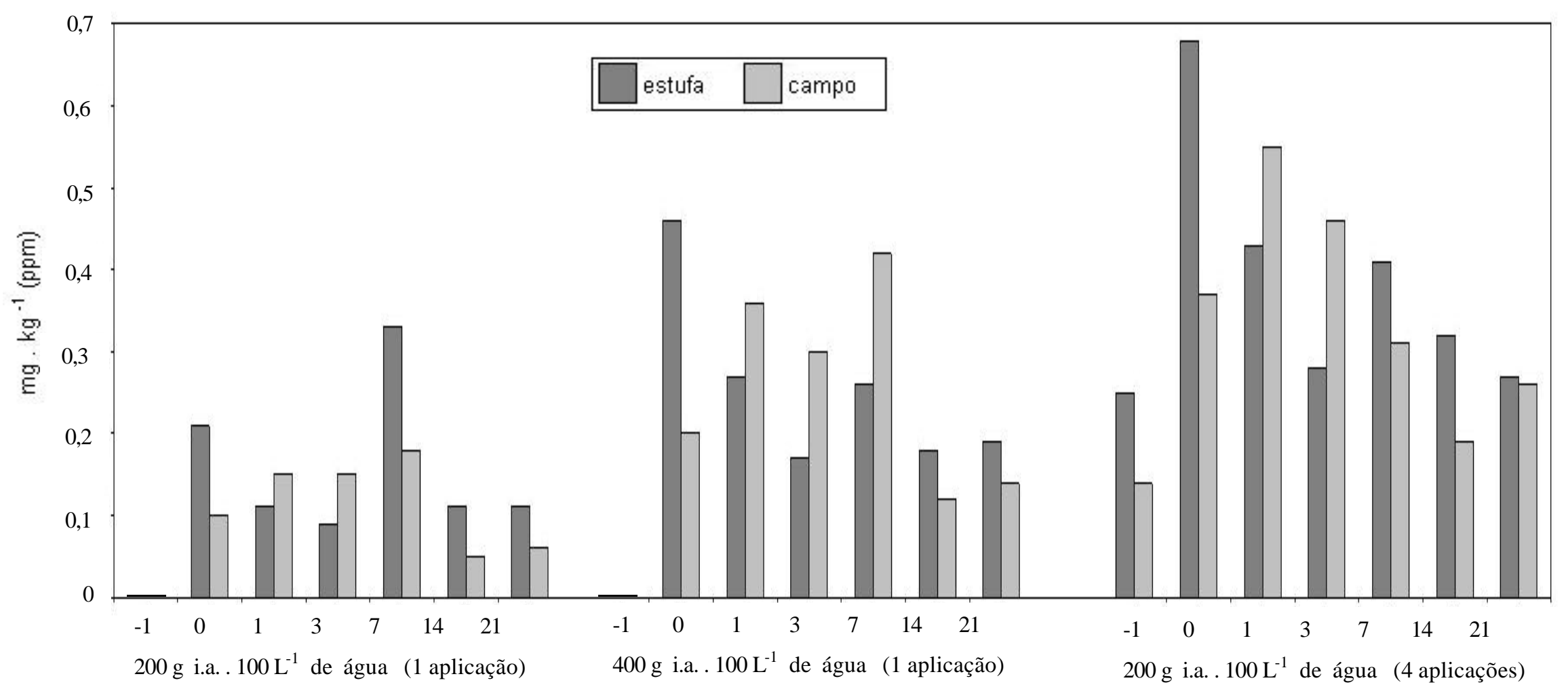

Figura 32 - Resíduos de clorotalonil em fruto em cultura de estufa e de campo 
Em relação a clorotalonil, seus resíduos nos frutos colhidos no campo foram estáveis até a amostragem de 7 dias, decrescendo após, estando, entretanto, abaixo de seu LMR ( $\left.1 \mathrm{mg} \cdot \mathrm{kg}^{-1}\right)$ no período de carência (7 dias) ou mesmo durante todo o tempo de colheita das amostras (Tabela 17). Também, como nos casos anteriores, sua degradação no campo foi semelhante à na estufa (Tabela 8 e Figura 32), sendo entretanto maiores nesta ao final do período de tomada das amostras, muito provavelmente devido a ocorrência de chuvas no experimento de campo (Tabela 2).

O exame dos dados da Tabela 18 mostra que nas folhas, para o caso do acefato, os valores encontrados indicam, no campo, que os resíduos foram degradados principalmente a partir da colheita de 3 dias. Também, seus resíduos nas folhas foram acentuadamente menores do que na estufa (Tabela 9 e Figura 33) dadas as condições de proteção contra as intempéries prevalecentes nesta.

Com respeito ao metamidofós, seus resíduos nas folhas (Tabela 19) foram maiores nas amostras de 1 dia, coincidindo com a redução significativa observada nos de acefato. Ainda, pode-se comentar que o metabolismo a partir de acefato foi mais acentuado no campo em relação à estufa (Tabela $10 \mathrm{e}$ Figura 34), e maiores nesta. Maiores níveis de metamidofós podem significar controle mais rápido de pragas no campo, comparado àestufa.

Como pode ser observado, pelos dados da Tabela 20, os resíduos de clorotalonil nas folhas foram acentuadamente menores do que nos de estufa, com ocorrência maior na amostragem realizada com 1 DAT. Interessante notar (Tabela 11 e Figura 35), ainda, que a relação entre estufa/campo foi crescente ao longo do período de colheita das amostras, aumentando de 3 vezes (zero dia) para cerca de 25 vezes (21 dias). Isso, sem dúvida, é explicado pela maior dissipação no campo em função da ocorrência de chuvas e, certamente, por incidência de radiação solar (raios ultra-violeta) (Kleier, 1994) 


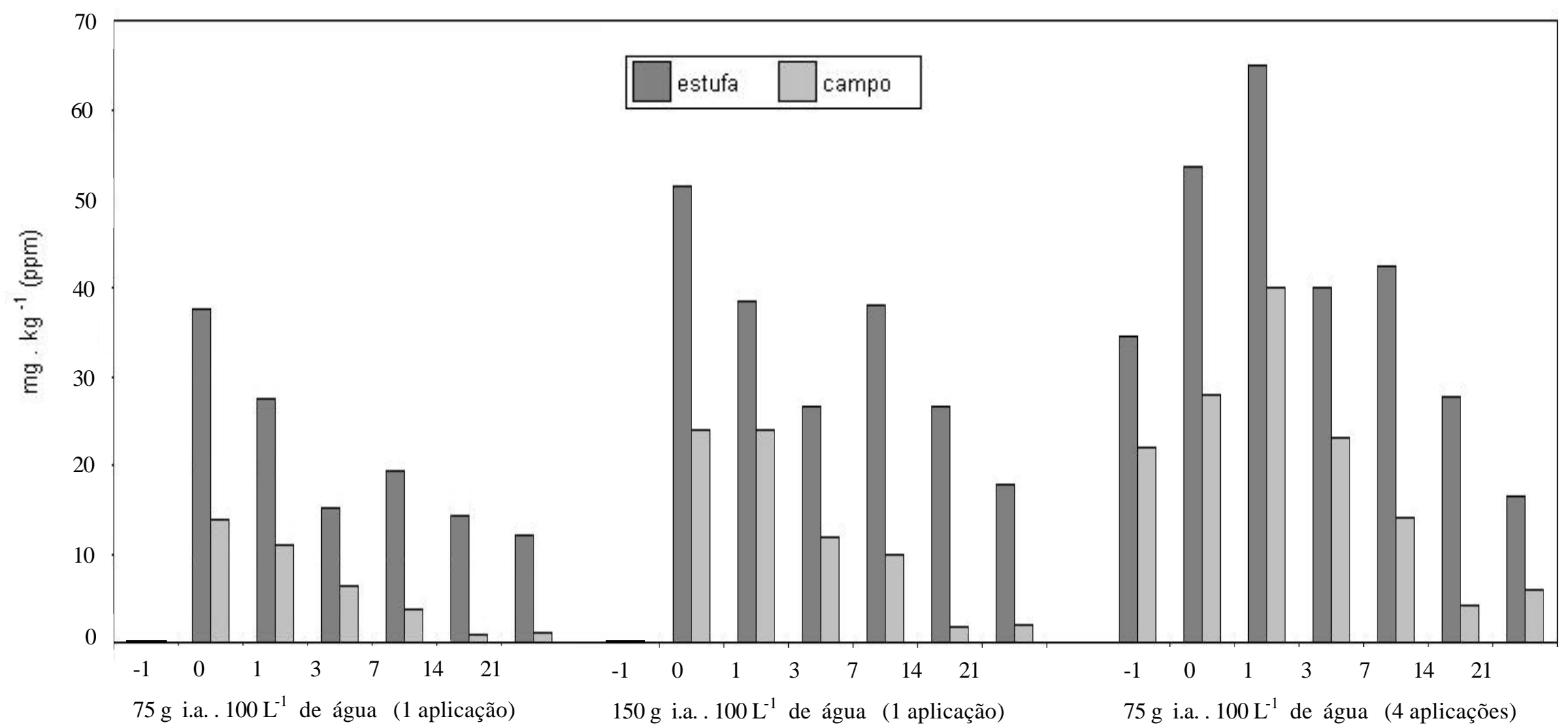

Figura 33 - Resíduos de acefato em folha em cultura de estufa e de campo 


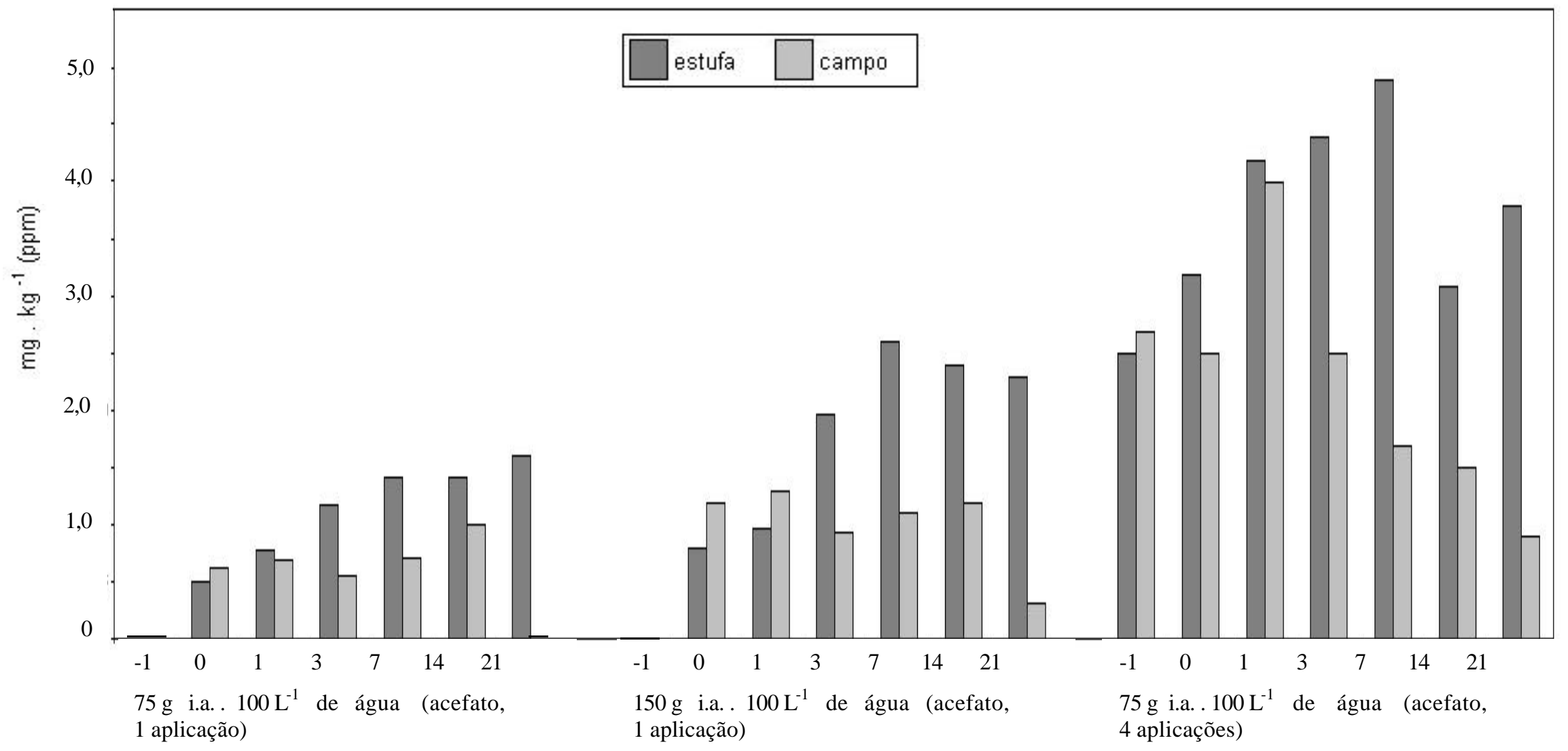

Figura 34 - Resíduos de metamidofós em folha em cultura de estufa e de campo 


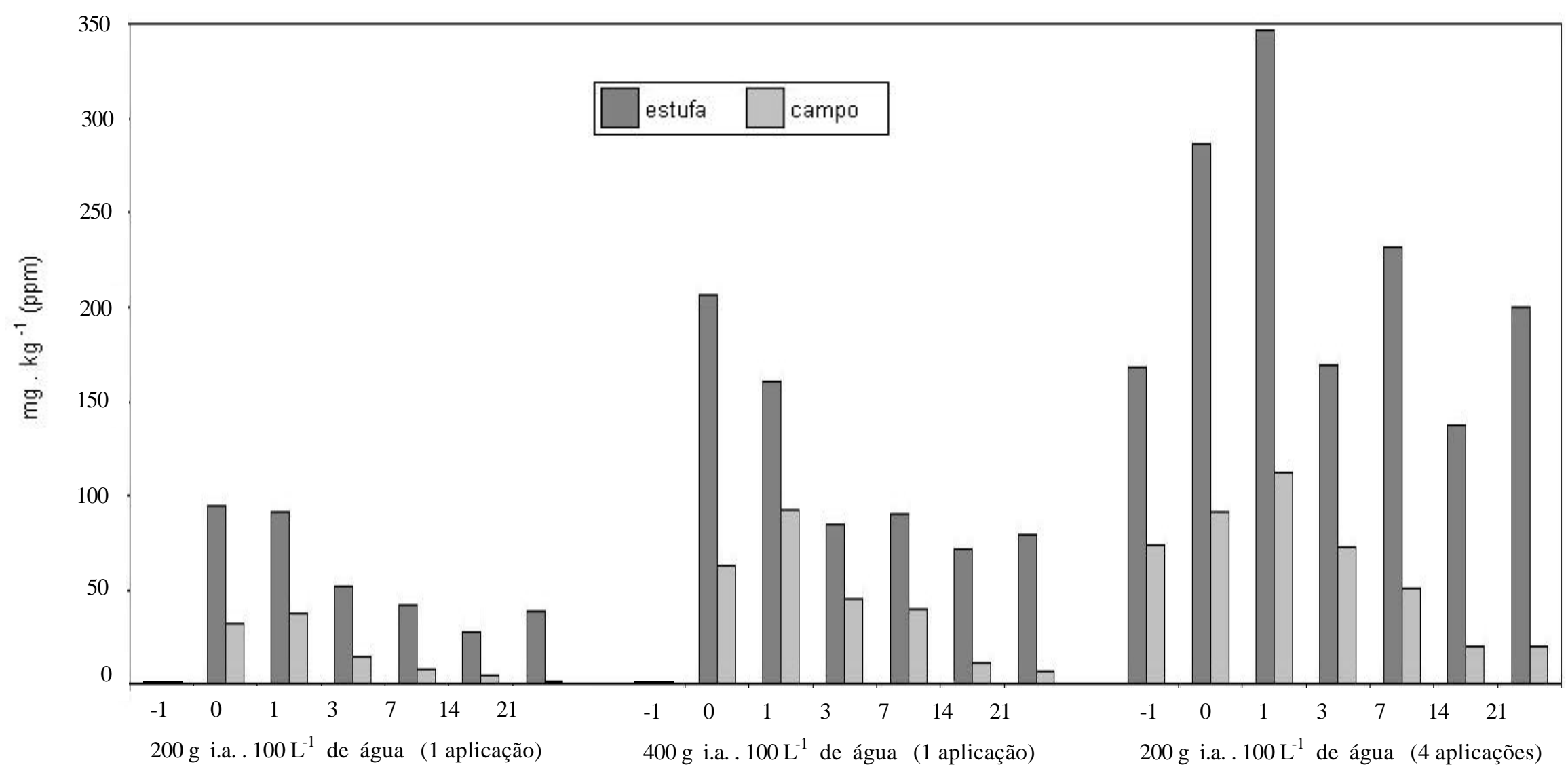

Figura 35 - Resíduos de clorotalonil em folha em cultura de estufa e de campo 
No solo (Tabela 21), a contaminação com acefato também foi menor no campo do que na estufa (Tabela 12 e Figura 36). Isso foi provavelmente devido ao transporte por capilaridade junto àsolução do solo devido a sua alta solubilidade em água. Observa-se que, já a partir de 14 DAT, os resíduos estiveram abaixo do LOQ $\left(<0,05 \mathrm{mg}^{\mathrm{kg}}{ }^{-1}\right)$; isso, com certeza, está relacionado ao fato de terem ocorrido chuvas intensas (cerca de $63 \mathrm{~mm}$ ) entre a colheita de 7 DAT e a seguinte (14 DAT).

Como no caso de solo de estufa (Tabela 13), os resíduos de metamidofós também não foram encontrados nas amostras de solo de campo, quando estiveram sempre inferiores ao LOQ ( $\left.<0,05 \mathrm{mg}^{\mathrm{kg}}{ }^{-1}, \mathrm{ppm}\right)$ (Tabela 22), conseqüência da relativa baixa produção deste metabólito a partir de acefato e também, novamente, sua solubilidade em água o que favorece sua percolação no perfil do solo, muito possivelmente, arrastados para o lençol freático.

Pela observação dos dados da Tabela 23, nota-se que os resíduos de clorotalonil no solo de campo foram, também, menores do que os de estufa (Tabela 14 e Figura 37); as maiores incidências de intempéries climáticas favoreceram, muito possivelmente, tal redução.

Como nos casos do experimento de estufa, também no de campo, o isolamento das parcelas testemunhas foi muito bem feito, uma vez que elas não apresentaram contaminação cruzada para nenhum dos 3 analitos em nenhuma matriz (fruto, folha e solo) (resíduos menores do que os respectivos LOQs). 


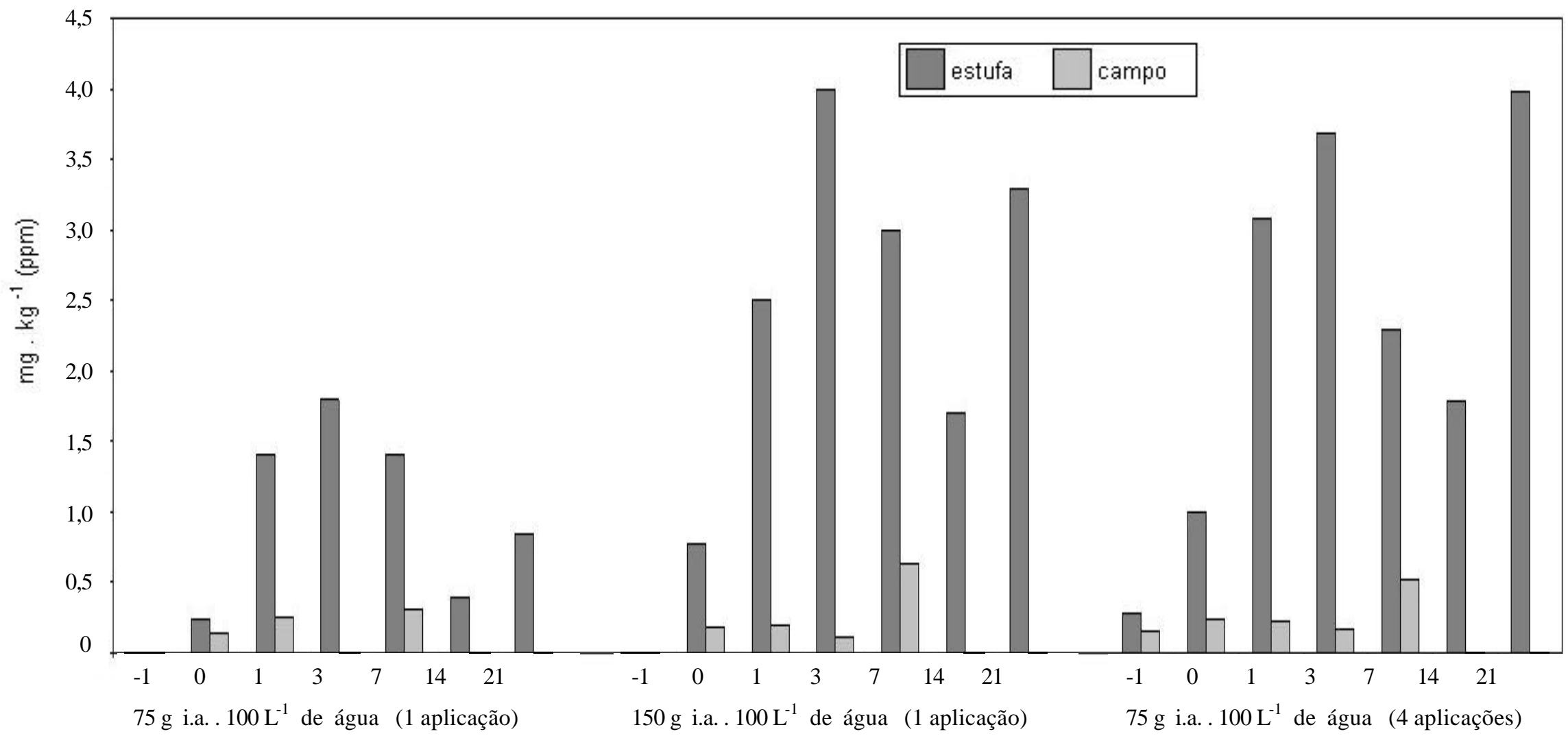

Figura 36 - Resíduos de acefato em solo de estufa e de campo cultivado com tomate 


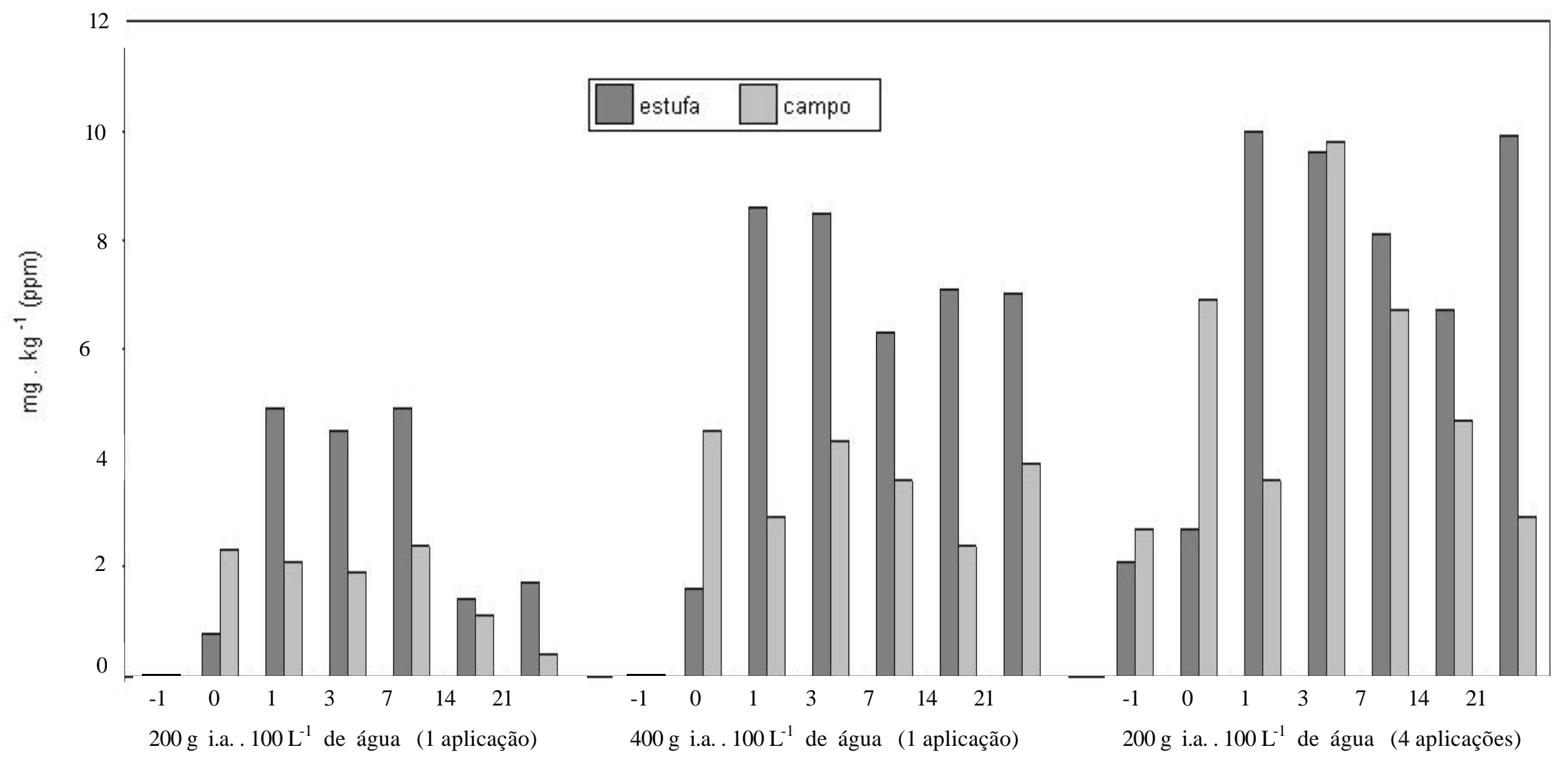

Figura 37 - Resíduos de clorotalonil em solo de estufa e de campo cultivado com tomate 
Conforme evidenciado, os resíduos de acefato, de seu metabólito metamidofós e de clorotalonil foram, em geral, maiores na folha e no solo nas condições de cultura protegida (estufa) do que em cultura de campo, estando, portanto, em geral de acordo com Cabras et al. (1985), Frank et al. (1987), Von Stryk \& Jarvis (1978), Meloni et al. (1984) e Cabras et al. (1995), que trabalhando com vários pesticidas em muitos diferentes substratos de compartimentos da produção protegida, também constataram resíduos mais altos em cultura protegida (estufa) do que em campo (plantio convencional).

Esta observação deve merecer a atenção das autoridades competentes do Ministério da Saúde, no que respeita a elaboração e/ou adequação de nova legislação para contemplar essas diferentes situações da produção agrícola, com vista à saúde dos consumidores de alimentos oferecidos à população. Igualmente, com respeito ao potencial de risco que apresentam resíduos maiores na estufa do que no campo, em substratos não comestíveis (folhas e solo), isso pode representar maior risco ocupacional; o fato deve, também, ser objeto da atenção das autoridades, uma vez que trabalhadores devem retornar æ̀ estufas para realizarem tratos culturais, tais como: amarrar plantas, colheita, mais tratamentos fitossanitários, estando, pois, mais sujeitos a entrarem em contato com tais resíduos, quando, freqüentemente, não se acham adequadamente protegidos. 


\section{CONCLUSÕES}

Nas condições experimentais, e com base nos resultados obtidos, pode-se concluir que:

- o método analítico utilizado para as análises de resíduos de acefato, metamidofós e clorotalonil em frutos e folhas de tomate e em solo é adequado e exeqüível com limites de quantificação de $0,05 \mathrm{mg} \cdot \mathrm{kg}^{-1}$ (ppm) para fruto e solo e $0,5 \mathrm{mg}^{\mathrm{kg}} \mathrm{k}^{-1}$ (ppm) para folha.

- os resíduos de acefato, metamidofós e clorotalonil, tanto nos frutos de estufa como nos de campo, sempre estiveram abaixo dos respectivos LMRs (acefato 0,5 mg. $\mathrm{kg}^{-1}$, metamidofós $0,3 \mathrm{mg} \cdot \mathrm{kg}^{-1}$ e clorotalonil 1 mg. $\mathrm{kg}^{-1}$ ) em todo o período de colheita das amostras, inclusive ao término do intervalo de segurança estabelecidos pela legislação para os três pesticidas (acefato e clorotalonil 7 dias e metamidofós 21 dias).

- os resíduos de acefato em fruto, tanto de estufa como de campo, tiveram valores e velocidade de degradação muito semelhantes, muito provavelmente porque os níveis nos de estufa foram "diluídos" pelo maior peso e volume do cultivar Caqui.

- o metabolismo de acefato a metamidofós não foi acentuado em frutos, tanto na estufa como no campo, encontrados apenas nas amostras de origem nas parcelas de múltiplas pulverizações, com níveis mais altos e 
- persistentes maiores na estufa do que no campo, embora com valores baixos.

- os resíduos de clorotalonil nos frutos foram mais altos do que os de acefato e de metamidofós, tanto na estufa como no campo, com níveis mais elevados nos de estufa.

- os resíduos de acefato nas folhas indicam que, eles são persistentes até 7 dias decorridos da última (ou única) aplicação, decrescendo após; os resíduos nas amostras de estufa foram significativamente bem superiores às de campo.

- nas folhas, a produção do metamidofós, a partir de acefato, via metabolismo, mostrou-se importante; houve maior intensidade em campo; porém eles foram maiores na estufa.

- para clorotalonil, nas folhas, seus resíduos foram mais estáveis e persistentes, se comparados com os de campo, sendo bem mais elevados quando cultivados em condições protegidas.

- no solo, os resíduos de acefato, tanto na estufa como no campo foram encontrados em níveis intermediários entre o fruto e a folha, sendo, em geral, persistentes por todo o período de tomada das amostras e, outra vez, maiores na estufa.

- o metabolismo de acefato em metamidofós no solo não foi caracterizado, tanto na estufa como no campo em todas as amostras; como pode ser suposto, produzido também em baixo grau de metabolismo, como observado para fruto e folha, no solo, estes resíduos podem estar sendo 
rapidamente lavados e lixiviados dada sua alta solubilidade em água (irrigação ou chuva).

- os resíduos de clorotalonil no solo foram, bem estáveis e persistentes tanto na estufa como no campo, sendo, também maiores na cultura protegida. 


\section{REFERÊNCIAS BIBLIOGRÁFICAS}

AGROFIT. Acephate: relatório de ingrediente ativo. (25 out.2002a)

AGROFIT. Methamidophos: relatório de ingrediente ativo (25 out.2002b)

AGROFIT. Chlorothalonil: relatório de ingrediente ativo. (25 out.2002c)

AGUILERA-del-REAL, A.; VALVERDE-GARCIA, A.; FERNANDEZALBA, A. R.; CAMACHO-FERRE, F. Behaviour of endosulfan residues in peppers, cucumbers and cherry tomatoes grown in greenhouse: evaluation of decline curves. Pesticide Science, v.51, p.194-200, 1997.

ANDERSSON, A.; PALSHEDEN, H. Multi-residue method for the analysis of pesticides in fruit and vegetables using ethyl acetate extraction, GPC clean-up and GC determination. In: NATIONAL FOOD ADMINISTRATION. Pesticide analytical methods in Sweden. Uppsala, 1998. pt.1, p. 9-41. (Rapport, 17/98).

ANDREI, E. Compêndio de defensivos agrícolas. 6. ed. São Paulo: Organização Andrei, 1999. 672 p. 
APLADA-SARLIS, P.; LIAPIS, K.S.; MILIADIS, G.E. Study of procimidone and propargite residue levels resulting from application to greenhouse tomatoes. Journal of Agricultural and Food Chemistry, v. 42, p. 1575-1577, 1994.

BRIOSCHI, D. Resíduos de clorotalonil em frutos e folhas de tomate de cultura estaqueada (Lycopersicon esculentum Mill). Piracicaba, 2001. 57 p. Dissertação (Mestrado)- Escola Superior de Agricultura "Luiz de Queiroz", Universidade de São Paulo.

CABRAS, P.; CABITZA, F.; MELONI, M.; PIRISI, F.M. Behavior of some pesticide residues on greenhouse tomatoes. 2. fungicides, acaricides, and insecticides. Journal of Agricultural and Food Chemistry, v. 33, p. 935937, 1985a.

CABRAS, P.; MELONI, M.; PIRISI, F.M.; CABITZA, F. Behavior of acylanilide and dicarboximidic residues on greenhouse tomatoes. Journal of Agricultural and Food Chemistry, v. 33, p. 86-89, 1985b.

CABRAS, P.; MELIS, M.; CABITZA, F.; CUBEDDU, M.; SPANEDDA, L. Persistence of pirimicarb in peaches and nectarines. Journal of Agricultural and Food Chemistry, v. 43, p. 2279-2282, 1995.

CABRAS, P.; SPANEDDA, L.; CABITZA, F.; CUBEDDU, M.; MARTINI, M.G.; BRANDOLINI, V. Pirimicarb and its metabolite residues in lettuce. Influence of cultural environment. Journal of Agricultural and Food Chemistry, v. 38, p. 879-882, 1990.

EVARISTO, A. ; BAPTISTA, G.C. de. Dislodgeable residues of methamidophos in staked tomatoes. Scientia Agricola, v. 59, p. 469-473, 2002. 
FRANK, R.; BRAUN, H.E.; RITCEY, G. Disappearance of captan from field and greenhouse-grown tomato fruit in relationship to time of harvest and amount of rainfall. Canadian Journal of Plant Science, v. 67, p. 355-357, 1987.

FRANK, R.; BRAUN, H.E.; RITCEY, G. STANEK, J. Pyrazophos residues from treated greehouse and growth chamber grown chrysanthemums. Canadian Journal of Plant Science, v. 69, p. 961-966, 1989.

FRANK, R.; BRAUN, H.E.; PITBLADO, R. Residues of nine insecticides and two fungicides in raw and processed tomatoes. Journal of Food Protection, v. 54, p. 41-46, 1991.

FREITAS JUNIOR, J.R.; RIGITANO, R.L.de O. Dissipação dos resíduos do inseticida metamidofós em frutos de tomateiro (Lycopersicon esculentum Mill). Ciência e Prática, v.18, p. 37-41, 1994.

GIL-GARCIA, M.D.; MARTÍNEZ VIDAL, J.L.; MARTÍNEZ GALERA, M.. Determination and degradation of methomyl in tomatoes and green beans grown in greenhouses Journal of the Association Official Agricultural Chemists, v. 80, p. 633-638, 1997.

KLEIER, D.A. Environmental effects on the photodegradation of pesticides. In: INTERNATIONAL SYMPOSIUM ORGANIZED BY THE SCI PESTICIDES GROUP IN COLLABORATION WITH THE BRITISH CROP PROTECTION COUNCIL, Canterbury, 1994. Comparing glasshouse and field pesticide performance II. proceedings. Surrey: British Crop Protection Council, 1994. p.97-109. (Monograph, 59). 
LEIDY, R.B.; SHEETS, T.J.; SORENSEN, K.A. Residues of acephate and methamidophos in greenhouse tomatoes. Journal of the American Society of Horticultural Science, v. 103, p. 392-394, 1978.

MELONI, M.; PIRISI, F.M..; CABRAS, P.; CABITZA, F. Residues of fungicides on greenhouse lettuce. Journal of Agricultural and Food Chemistry, v. 32, p. 183-185, 1984.

MÔNICO-PIFARRÉ, A.; XIRAU-VAYREDA, M. Study of carbendazin residue accumulation on grrenhouse and field-grown strawberries, after successive treatments with benomyl. Journal of the Association of Official Agricultural Chemists, v. 73, p. 553-556, 1990.

NAGAMI, H. Fungicide procymidone residue in agriculture land. Bulletin of Environmental Contamination and Toxicology, v. 56, p. 594-598, 1996.

NILSSON, U.; NYBRANT, T. Long-term studies of fungicide concentrations in greenhouses.2. fungicide concentrations in air and on leaves after different exposure times under different climate conditions. Journal of Agricultural and Food Chemistry, v. 44, p. 2878-2884, 1996.

RIPLEY, B.D.; FRANK, R.; JARVIS, W.R.; FISHER, C. Residues of ethylenebisdithiocarbamates (EBDC) and dinocap in greenhouse cucumber fruits. Canadian Journal of Plant Science, v. 65, p. 229-232, 1985.

SUHERI, H.; LATIN, R. Retention of fungicides for control of Alternaria leaf blight of muskmelon under greenhouse conditions. Plant Disease, v. 75, p. 1013-1015, 1991. 
TOMLIN, C. The pesticide manual. 10 ed. Surrey. The Royal Society of Chemistry, 1995. $1341 \mathrm{p}$.

VALVERDE-GARCIA, A.; GONZÁLES-PRADAS, E.; AGUILERA-del REAL, A. Analysis of buprofezin residues in vegetables. Application to the degradation study on eggplant grown in greenhouse. Journal of Agricultural and Food Chemistry, v. 41, p. 2319-2323, 1993a.

VALVERDE-GARCIA, A.; GONZÁLES-PRADAS, E.; AGUILERA-del REAL, A.; URENA-AMATE, M.D.; CAMACHO-FERRE, F. Determination and degradation study of chlorothalonil residues in cucumbers, peppers and cherry tomatoes. Acta Analytica Chimica, v. 276, p. 15-234, 1993b.

VON STRYK, F.G.; JARVIS, W.R. Residues of mancozeb, maneb and ethylenethiourea in fungicide-treated field and greenhouse tomatoes. Canadian Journal of Plant Science, v. 58, p. 623-628, 1978. 